Universidade de São Paulo

Escola de Engenharia de São Carlos

SILVIA GENARO MOTTI

\title{
Espectroscopia não linear de interfaces aplicada ao estudo de transistores poliméricos
}





\title{
Silvia Genaro Motti
}

\section{Espectroscopia não linear de interfaces aplicada ao estudo de transistores poliméricos}

\author{
Versão Corrigida \\ Original disponível na unidade
}

Dissertação apresentada ao Programa de Pós-Graduação em Ciência e Engenharia de Materiais da Universidade de São Paulo, para obtenção do título de Mestre em Ciências.

Área de concentração: Desenvolvimento, Caracterização e Aplicação de Materiais.

Orientador: Paulo Barbeitas Miranda 
AUTORIZO A REPRODUÇÃO E DIVULGAÇÃO TOTAL OU PARCIAL DESTE TRABALHO, POR QUALQUER MEIO CONVENCIONAL OU ELETRÔNICO, PARA FINS DE ESTUDO E PESQUISA, DESDE QUE CITADA A FONTE.

Motti, Silvia Genaro

M813e Espectroscopia não linear de interfaces aplicada ao estudo de transistores poliméricos / Silvia Genaro Motti; orientador Paulo Barbeitas Miranda. São Carlos, 2014 .

Dissertação (Mestrado) - Programa de Pós-Graduação em Ciências e Engenharia de Materiais e Área de Concentração em -- Escola de Engenharia de São Carlos da Universidade de São Paulo, 2014.

1. Eletrônica orgânica. 2. Espectroscopia não linear. 3. Polímeros conjugados. 4. Transistores por efeito de campo. 5. Interfaces sólido-sólido. 6 . Espectroscopia vibracional. I. Título. 


À minha família, por minhas raízes e educação. Aos amigos da universidade, pelo aprendizado conjunto. Aos mestres ao longo do caminho, por todo o conhecimento adquirido. 



\section{Agradecimentos}

Agradeço à CAPES, FAPESP e ao INEO pelo financiamento, ao IFSC e ao programa de pósgraduação em Ciência e Engenharia de Materiais.

Agradeço também ao Laboratório de Microeletrônica da Poli pelas wafers de silício. Ao Professor Fernando Fonseca pela importante experiência compartilhada. Ao Professor Heinz von Seggern e Lucas Fugikawa pela recepção em Darmstadt e aquisição das wafers de silício. Obrigada à Rafa pelos filmes LS, que se mostraram essenciais para os resultados. Agradeço muito ao Alexandre, que embarcou na tarefa de construir OFETs e me iniciou nas belezas e nas dores desse desafio.

Agradeço ao professor Paulo Miranda pela orientação e por possibilitar um ambiente multidisciplinar para se fazer ciência, e ao professor Roberto Faria pela oportunidade.

A todo o grupo de Polímeros, por me oferecer um ambiente tão aconchegante e ao mesmo tempo tão produtivo. Aos colegas que se tornaram amigos, pelas discussões científicas, reflexões filosóficas, e piadas esdrúxulas em volta da mesa do café. Aos técnicos e alunos mais experientes. Bruno e Débora pelo suporte químico, Níbio, Bertho e Ademir, sem os quais todos os projetos emperrariam nos problemas técnicos, Marcos e Felipe por toda a ajuda no LEO. E agradeço aos colegas do LENI, que contribuíram para as discussões científicas, compartilharam as angústias do laser e a comemoração de cada passo adiante. Agradeço também a toda a estrutura do IFSC e seus responsáveis, que possibilitaram todo esse trabalho, na oficina mecânica, oficina de óptica, manutenção e limpeza.

Agradeço a toda a minha família por ter sido a base para o meu crescimento. Em especial aos meus pais, meus primeiros orientadores, pelo valor que deram à minha educação e por todo o incentivo e confiança depositados. Também às minhas irmãs mais velhas Li e Vi, que, munidas desse mesmo alicerce, se lançaram a tantos desafios. Acompanhar vocês duas enfrentando os obstáculos da vida sem dúvida tornou as coisas mais fáceis quando chegava minha vez.

A todas as mulheres incríveis com quem dividi teto em algum momento nesses dois anos: Day, Ro, Si, Vic, Gi, Ba, Ju, Gabi, Fla... obrigada por aguentarem minhas histerias e esquisitices, por ouvirem meus problemas e alegrias, por terem sido minha casa.

E tantas outras pessoas importantes que fizeram parte da minha vida nos últimos anos e contribuíram para o meu crescimento e aprendizado. 

Se as coisas são inatingíveis... ora!

Não é motivo para não querê-las.

Que tristes os caminhos, se não fora

a presença distante das estrelas!

Mário Quintana 



\section{Resumo}

\section{MOTTI, S. G. Espectroscopia não linear de interfaces aplicada ao estudo de transisto-}

res poliméricos. 87p. Dissertação (Mestrado) - Escola de Engenharia de São Carlos, Universidade de São Paulo, São Carlos, 2014.

O uso de materiais orgânicos em dispositivos eletrônicos, além de menor custo e facilidade de processamento, permite obter flexibilidade e transparência. Entretanto, para que a aplicação comercial desses materiais seja viável, os processos que ocorrem nos dispositivos ainda precisam ser mais bem compreendidos, visando maior eficiência e tempo de vida. É de grande importância o estudo das interfaces entre o semicondutor orgânico e os contatos metálicos, onde ocorre transferência de portadores de carga, e a interface com o dielétrico em transistores orgânicos (OFETs), onde se forma o canal de condução. As interfaces de dispositivos eletrônicos poliméricos foram estudadas, utilizando-se Espectroscopia SFG (do inglês Sum Frequency Generation). Esta técnica obtém um sinal com a soma das frequências de dois feixes incidentes sobrepostos, em um processo seletivo a meios onde não há simetria de inversão, como no caso de interfaces. Com aplicação de um feixe de excitação na região visível e outro sintonizável no infravermelho médio, a espectroscopia SFG fornece um espectro vibracional da interface e permite o estudo do ordenamento e da orientação dos grupos moleculares. Foram construídos e analisados OFETs de poli-3-hexiltiofeno (P3HT) preparados sobre substrato de vidro ou silício, utilizando como isolante óxido de silício e/ou poli-metil-metacrilato (PMMA). Foram obtidos espectros in situ do canal de OFETs em operação, observando pequenas alterações na forma de linha, porém a baixa relação sinal/ruído não permitiu obter conclusões detalhadas. Foi constatada a manifestação de bandas da camada isolante de PMMA como consequência da aplicação de campo elétrico. Este fenômeno foi considerado como uma nova ferramenta para estudar a distribuição de cargas e campo elétrico no canal de transistores. Não foram detectados sinais de degradação irreversível no polímero semicondutor a curto prazo, e a mudança de comportamento elétrico foi atribuída majoritariamente a dopagem por oxigênio absorvido no material.

Palavras-chave: Eletrônica orgânica, Espectroscopia não linear, Polímeros conjugados, Transistores de efeito de campo, Interfaces sólido-sólido, Espectroscopia vibracional 



\section{Abstract}

MOTTI, S. G. Nonlinear interface spectroscopy applied to the study of polymeric transistors. 87p. Thesis (Master) - School of Engeneering of São Carlos, University of São Paulo, São Carlos, 2014.

The usage of organic materials in electronic devices allows not only low cost and ease of processing but also flexibility and transparency. However, to achieve viable commercial application, the processes involved on the devices operation must still be better comprehended, aiming for improved efficiency and life time. There is great importance in the study of the interfaces between organic semiconductors and metallic contacts, where charge transfer takes place, and between the dielectric and semiconductor layers of organic transistors (OFETs), where the conducting channel is formed. The interfaces in polymeric electronic devices were studied by SFG spectroscopy (Sum Frequency Generation). In this technique, a signal with frequency that equals the sum of those of two incident beams is generated in a process only allowed in media without inversion symmetry, such as interfaces. Using a visible excitation beam and a tunable infrared one, SFG spectroscopy yields a vibrational spectrum of the interface and provides information about the conformation and orientation of molecular groups. Poly-3-hexylthiophene (P3HT) OFETs were fabricated using glass or silicon substrates and silicon oxide and/or poly-methyl-methacrylate (PMMA) for the dielectric layer. SFG spectra were acquired in situ from the channel region of operating OFETs, observing small changes in lineshape, but low signal-to-noise ration did not allow a detailed interpretation. It was found that PMMA vibrational bands appeared when polarizing the device. This phenomenon was considered a new tool for studying the electric field and charge distribution along transistor channels. It was not noted any sign of short term irreversible degradation of the semiconducting polymer, and the change in the electrical behavior was attributed mainly to doping of the polymer by oxygen absorbed in the material.

Keywords: Organic electronics, Nonlinear spectroscopy, Conjugated polymers, Field-effect transistors, Solid-solid interfaces, Vibrational spectroscopy 



\section{Lista de Figuras}

1.1 Televisor com tela curva a base de OLEDs fabricada pela LG ${ }^{\circledR}$ e anunciada na CES (International Consumer Electronics Show) em 2013. . . . . . . . . . . . . . . . 21

1.2 Visor flexível AMOLED (Active-Matrix Organic Light Emitting Diodes) fabricado pela Samsung ${ }^{\circledR}$, com produção em larga escala anunciada em outubro de 2013. . . . 22

1.3 Esquema das estruturas típicas de alguns dispositivos orgânicos. . . . . . . . . . . . . 23

1.4 Ponto de ônibus com iluminação noturna abastecida por energia solar gerada na cobertura de painéis de OPV $\left(\right.$ Konarka $\left.{ }^{\circledR}\right)$. . . . . . . . . . . . . . . 23

1.5 Transistores orgânicos em substrato flexível, produzidos no Grupo de Polímeros Bernhard Gross $[6] \ldots \ldots \ldots \ldots \ldots \ldots \ldots \ldots$

1.6 Estrutura química do P3HT regiorregular. . . . . . . . . . . . . . 25

1.7 Processo de degradação do P3HT iniciado com a oxidação dos anéis tiofeno. . . . . . 26

1.8 Processo de degradação do P3HT iniciado com a oxidação das cadeias laterais. . . . 27

2.1 Diagrama de níveis de energia em um polímero conjugado. . . . . . . . . . . . 31

2.2 Esquema básico de um transistor de efeito de campo. . . . . . . . . . . . . . . . . 33

2.3 Medidas elétricas típicas de um OFET. Valores de corrente e potencial estão em módulo. No caso de dispositivos tipo p, os valores de $I_{D}, V_{D}$ e $V_{G}$ são negativos. . . 34

2.4 Gráfico semi-log de uma medida de transferência (utilizando o módulo dos valores de

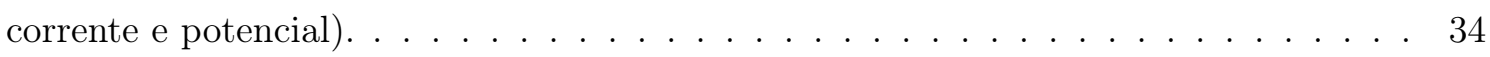

2.5 Canal do OFET no regime linear e no ponto de pinch-off. . . . . . . . . . . . . 34

2.6 Feixes envolvidos no experimento SFG em relação às coordenadas do laboratório. A polarização dos dois feixes incidentes e do sinal soma podem ser ou paralela (p) ou perpendicular $(\mathrm{s})$ ao eixo de incidência (tracejado) . . . . . . . . . . . . . 37 
2.7 Transições de energia envolvidas na geração de sinal SFG.

2.8 Referenciais para a transformação de coordenadas moleculares para coordenadas do laboratório descrita na Equação 2.9. Os ângulos $\theta, \phi$ e $\psi$ descrevem a orientação molecular. . . . . . . . . . . . . . . . . . . . 39

2.9 Geração de Segundo Harmônico em uma interface. . . . . . . . . . . . . . . . . . . 41

3.1 Possíveis arquiteturas para a construção de transistores. . . . . . . . . . . . . . . . 43

3.2 Tipos de OFETs preparados. . . . . . . . . . . . . . . . . . 44

3.3 Estrutura química do PMMA (poli-metil-metacrilato) . . . . . . . . . . . . . . 44

3.4 Preparação dos filmes Langmuir-Schaefer. . . . . . . . . . . . . . . . . . . . 45

3.5 Estrutura de construção dos OFETs vidro/PMMA/P3HT: (a) máscara de evaporação do eletrodo de porta, (b) máscara de evaporação dos eletrodos de dreno e fonte e (c) aspecto do dispositivo final. . . . . . . . . . . . . . . . . 46

3.6 OFETs construídos em substrato de silício, (a) máscara de evaporação dos eletrodos dreno e fonte e (b) aspecto final dos dispositivos. . . . . . . . . . . . . . 47

3.7 Aparato experimental para medidas de espectroscopia não-linear. . . . . . . . . . . . 50

3.8 Diagrama da estação de medida para espectroscopia SFG. . . . . . . . . . . . . . . . 51

3.9 Alguns desenhos do projeto da câmara para amostras, desenhado no SolidWorks ${ }^{\circledR}$. Dimensões em milímetros. . . . . . . . . . . . . . . . . . . 53

3.10 Câmara com suporte para amostras projetada para realização de medidas elétricas e espectroscópicas.

4.1 Espectro de absorção óptica do P3HT. . . . . . . . . . . . . . . . . . 56

4.2 Espectros de absorção óptica de filmes de P3HT com espessuras variadas. . . . . . . 57

4.3 Espectro FTIR do P3HT. . . . . . . . . . . . . . . . . . . . . . 58

4.4 Espectros SFG de filme de P3HT sobre PMMA/vidro em três conjuntos de polarização. 60

4.5 Espectros SFG de filme de P3HT sobre $\mathrm{SiO}_{2} / \mathrm{Si}$ com tratamento térmico, em três conjuntos de polarização. . . . . . . . . . . . . . . . . 6 61

4.6 Espectros SFG de filme de P3HT sobre $\mathrm{SiO}_{2} / \mathrm{Si}$ sem tratamento térmico, em três conjuntos de polarização. . . . . . . . . . . . . . . . . . . . 62 
4.7 Momento de dipolo referente ao modo de estiramento simétrico $\mathrm{C}=\mathrm{C}$ em cada monômero do P3HT regioregular. . . . . . . . . . . . . . . . . . . . 62

4.8 Organização das cadeias de P3HT em lamelas, com dipolo resultante aproximadamente perpendicular aos anéis.

4.9 Espectros SFG de filmes de P3HT sobre $\mathrm{SiO}_{2} / \mathrm{Si}$ depositados pelos métodos de spincasting e Langmuir-Schaefer, em polarização ppp. . . . . . . . . . . . . . . . . . . . 64

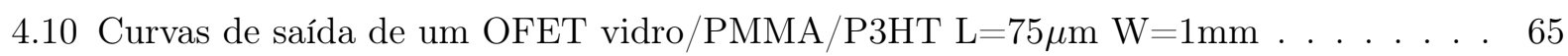

4.11 Curvas de saída de um OFET vidro/PMMA/P3HT L=125 $\mu \mathrm{m} \mathrm{W}=1,66 \mathrm{~mm} \ldots$. . . . 65

4.12 Curvas de saída de um OFET vidro/PMMA/P3HT L=150 $\mu \mathrm{m} \mathrm{W}=2 \mathrm{~mm} \ldots \ldots 5$

4.13 Curvas de saída de um OFET vidro/PMMA/P3HT L=175 $\mu \mathrm{m} \mathrm{W}=2,33 \mathrm{~mm} \ldots$. . . . 65

4.14 Curvas de saída de um OFET vidro/PMMA/P3HT L=200 $\mu \mathrm{m} \mathrm{W}=2,66 \mathrm{~mm} \ldots$. . . . 65

4.15 Curvas de transferência normalizadas conforme $\mathrm{W} / \mathrm{L} \ldots \ldots$. . . . . . . . . 65

4.16 Medidas de intensidade SHG em um canal de OFET vidro/PMMA/P3HT em pola-

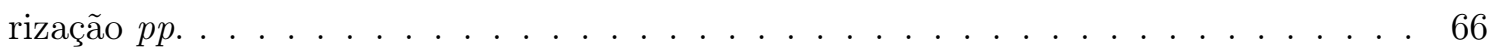

4.17 Curvas de saída de alguns OFETs $\mathrm{Si} / \mathrm{SiO}_{2} / \mathrm{P} 3 \mathrm{HT}$ de dimensões $\mathrm{L}=80 \mu \mathrm{m}$ e W $=2$

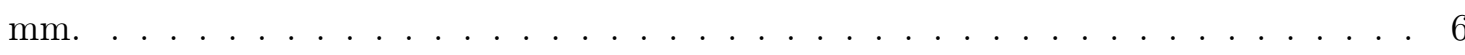

4.18 (a) Curvas de saída de um OFET Si/SiO $/$ P3HT-LS com 300 nm de espessura de óxido e dimensões $\mathrm{L}=100 \mu \mathrm{m}$ e $\mathrm{W}=2 \mathrm{~mm}$. (b) Curvas de transferência (com $V_{D}$ $=-10 \mathrm{~V}$ ) em escala linear e escala semi-logarítmica. . . . . . . . . . . .

4.19 Espectros SFG obtidos no canal do OFET Si/SiO $/$ P3HT-LS referente às curvas da

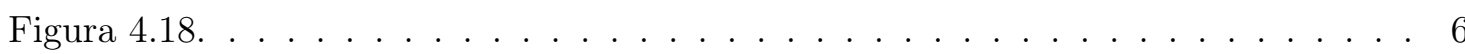

4.20 Curvas de saída de alguns OFETs $\mathrm{Si} / \mathrm{SiO}_{2} / \mathrm{PMMA} / \mathrm{P} 3 \mathrm{HT}$ com L $=100 \mu \mathrm{m}$ e W $=$

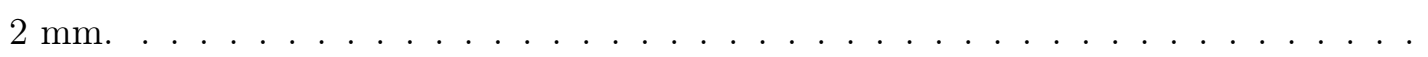

4.21 (a) Curva de saída de um OFET Si/SiO $/$ PMMA/P3HT-LS (de dimensões L = 100 $\mu \mathrm{m}$ e $\mathrm{W}=2 \mathrm{~mm}$ ) utilizado no estudo SFG. (b) Curvas de transferência (com $V_{D}=$ $-30 \mathrm{~V}$ ) em escala linear e escala semi-logarítmica. . . . . . . . . . . . . . .

4.22 Espectros SFG em polarização ppp obtidos do canal do OFET Si/SiO $2 / \mathrm{PMMA} / \mathrm{P} 3 \mathrm{HT}$ LS referente às curvas da Figura 4.21. 
4.23 Manifestação da banda em $1240 \mathrm{~cm}^{-1}$ no OFET Si/SiO $/$ PMMA/P3HT conforme aplicação de $V_{G}$ (dados sem normalização com referência de ZnS, espectros obtidos com polarização $p p p)$

4.24 (a) Curva de saída de um OFET Si/SiO $/$ PMMA/P3HT (de dimensões L $=100 \mu \mathrm{m}$ e $\mathrm{W}=2 \mathrm{~mm}$ ) utilizado no estudo SFG. (b) Curvas de transferência (com $V_{D}=-40$ V) em escala linear e escala semi-logarítmica. . . . . . . . . . . . . . . . . 73

4.25 Manifestação da banda em $1720 \mathrm{~cm}^{-1}$ no OFET Si $/ \mathrm{SiO}_{2} / \mathrm{PMMA} / \mathrm{P} 3 \mathrm{HT}$ conforme aplicação de $V_{G}$ (dados normalizados, espectros obtidos com polarização $\left.p p p\right)$ ) . . . . 74

4.26 Manifestação da banda em $1720 \mathrm{~cm}^{-1}$ no OFET Si/SiO $/$ PMMA/P3HT conforme aplicação de $V_{G}$ e $V_{D}$ (dados normalizados, espectros obtidos com polarização $\left.p p p\right)$ ) . 75

4.27 Manifestação das bandas em (a) $1240 \mathrm{~cm}^{-1}$ e (b) $1720 \mathrm{~cm}^{-1} \mathrm{em} \mathrm{OFETs} \mathrm{Si} / \mathrm{SiO}_{2} / \mathrm{PMMA} / \mathrm{P} 3 \mathrm{HT}$ conforme aplicação de valores positivos e negativos de $V_{G}$. Espectros obtidos com

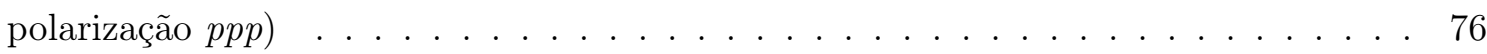

4.28 Curvas de saída de um OFET Si/SiO $/$ P3HT-LS (a) antes e (b) depois de cinco horas em operação e exposição a atmosfera e luz. . . . . . . . . . . . . . . . . . . . . . 77

4.29 Espectros SFG do P3HT no canal do OFET no OFET Si/SiO $2 / P M M A / P 3 H T$ cujas curvas elétricas são apresentadas na Figura 4.28, antes e depois do tempo de operação exposto a luz e oxigênio. . . . . . . . . . . . . . . . . . . . . 78

4.30 Curvas de saída do OFET Si/SiO $/$ P3HT da Figura 4.28 (a) após 12 horas em vácuo e (b) após 30h em vácuo. . . . . . . . . . . . . . . . . . . . . . . . . 79 


\section{Sumário}

1 Introdução $\quad 21$

1.1 Eletrônica orgânica . . . . . . . . . . . . . . . . . . . . . . . 21

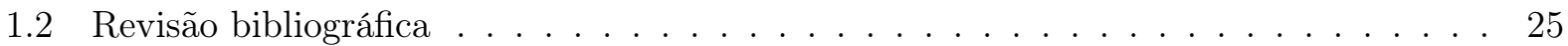

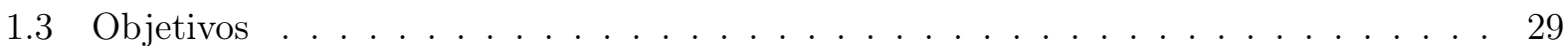

2 Fundamentos Teóricos $\quad 31$

2.1 Transistores de Efeito de Campo Orgânicos . . . . . . . . . . . . . . . . 31

2.2 Espectroscopia não-linear de interfaces . . . . . . . . . . . . . . . . . . 36

3 Materiais e métodos 43

3.1 Preparação e caracterização dos OFETs . . . . . . . . . . . . . . . . . . 43

3.2 Espectroscopia SHG e SFG . . . . . . . . . . . . . . . . . . . . . . . . 49

4 Resultados e discussão $\quad 55$

4.1 Caracterizações preliminares . . . . . . . . . . . . . . . . . . 55

4.2 OFETs vidro/PMMA $/ \mathrm{P} 3 \mathrm{HT} \ldots \ldots \ldots \ldots \ldots \ldots \ldots \ldots$

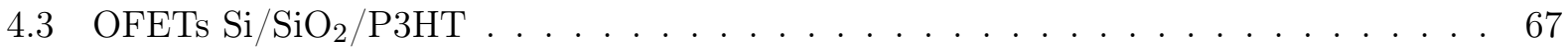

4.4 OFETs $\mathrm{Si} / \mathrm{SiO}_{2} / \mathrm{PMMA} / \mathrm{P} 3 \mathrm{HT} \ldots \ldots \ldots \ldots \ldots \ldots \ldots$

4.5 Degradação . . . . . . . . . . . . . . . . . . . . 76

$\begin{array}{llr}5 & \text { Conclusões } & 81\end{array}$

$\begin{array}{ll}\text { Referências } & 83\end{array}$ 



\section{Introdução}

\subsection{Eletrônica orgânica}

Polímeros são macromoléculas orgânicas formadas por unidades menores e repetitivas chamadas meros. Por muito tempo o grande interesse na produção e desenvolvimento de polímeros foram suas propriedades mecânicas e alta resistividade. A partir da década de 70, com a descoberta das propriedades condutoras do poliacetileno [1, 2], o interesse científico e tecnológico em polímeros conjugados vem crescendo. A eletrônica orgânica visa à construção de dispositivos a base de materiais semicondutores orgânicos e promete uma revolução tecnológica [3].

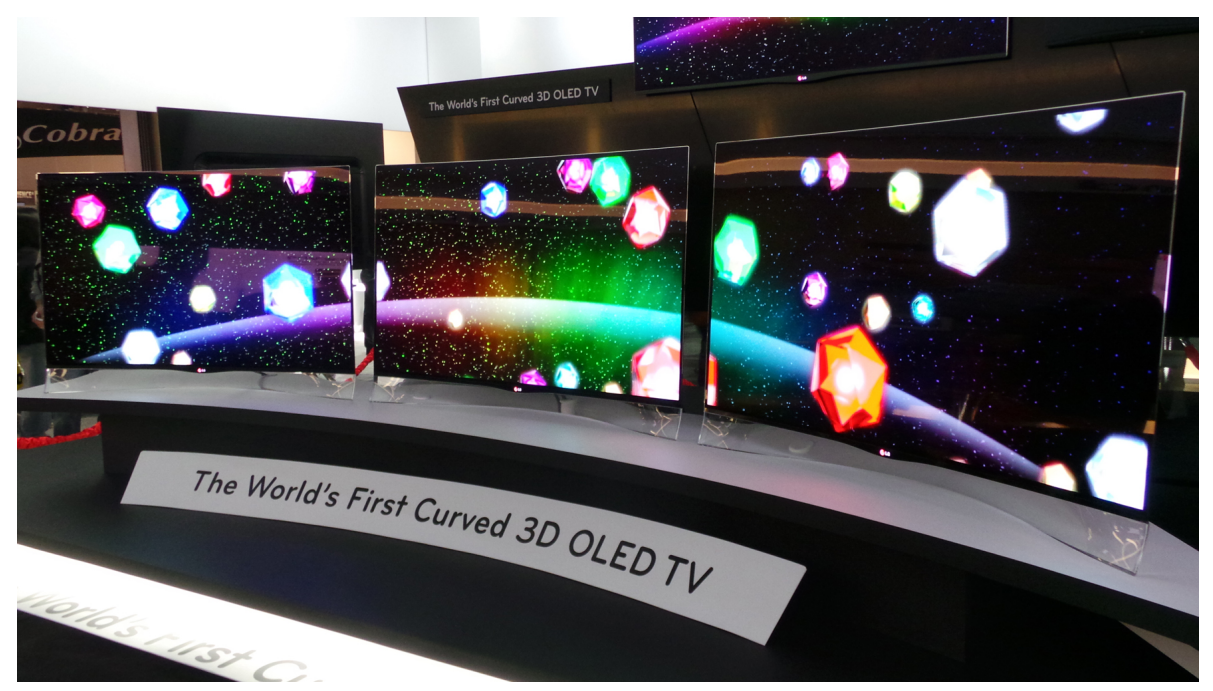

Figura 1.1: Televisor com tela curva a base de OLEDs fabricada pela LG ${ }^{\circledR}$ e anunciada na CES (International Consumer Electronics Show) em 2013.

Uma das vantagens do uso de materiais orgânicos em dispositivos eletrônicos é a possibilidade de aplicação de estruturas químicas variadas e misturas de compostos, obtendo diferentes características. Também permitem a produção de componentes com outras interessantes propriedades de materiais orgânicos, como flexibilidade [4] e transparência, além de possibilitar a fabricação de 
dispositivos utilizando condições menos drásticas e mais econômicas (em relação a temperatura e pressão, por exemplo) do que no caso de materiais inorgânicos. Atualmente os dispositivos eletrônicos vêm se inserindo cada vez mais nos objetos e atividades do cotidiano, e isso torna fundamental a produção de dispositivos com baixo custo e de fácil aplicação em diversos tipos de substratos.

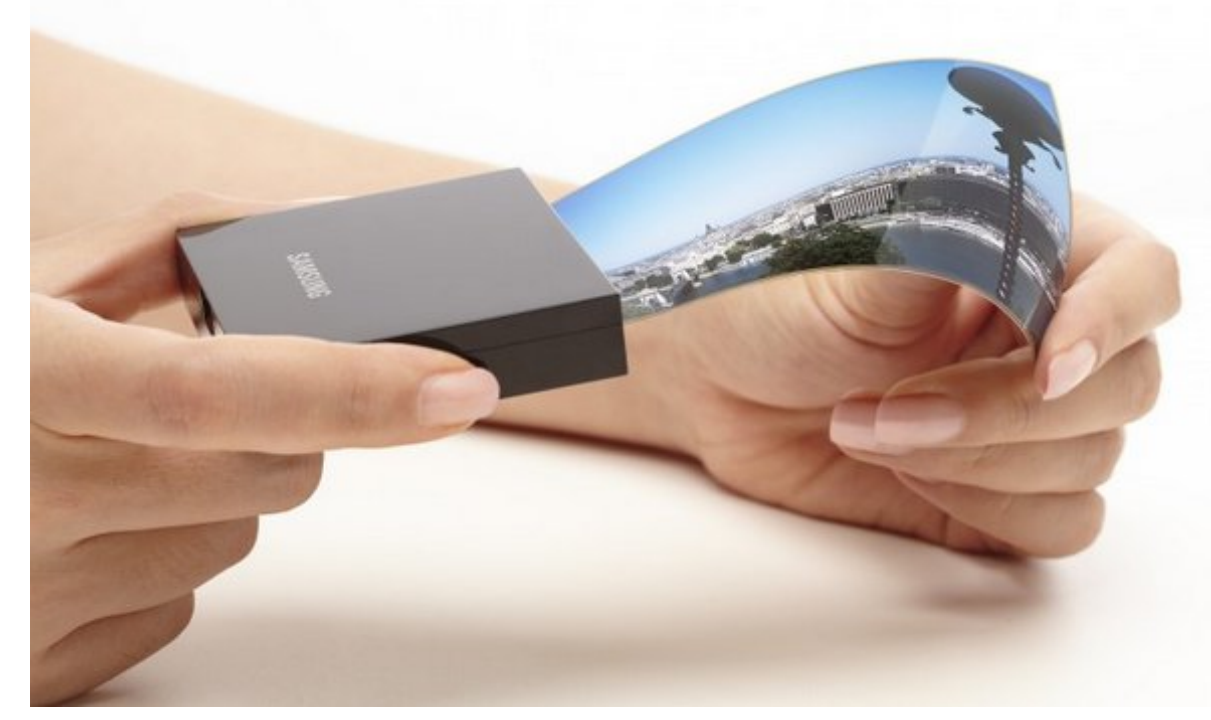

Figura 1.2: Visor flexível AMOLED (Active-Matrix Organic Light Emitting Diodes) fabricado pela Samsung ${ }^{\circledR}$, com produção em larga escala anunciada em outubro de 2013.

A variabilidade de estrutura química de materiais orgânicos é particularmente interessante para aplicação em dispositivos emissores de luz (OLEDs, Organic Light Emitting Diodes, Figuras 1.1 e 1.2) pois possibilita maior controle das cores emitidas. A estrutura comum de OLEDs, como mostra a Figura 1.3, tipicamente consiste em um material emissor de luz entre uma camada de um material transportador de elétrons em contato com um catodo e uma camada de material transportador de buracos (cargas positivas) em contato com um anodo. As camadas são depositadas sobre substratos transparentes para permitir a emissão da luz, e frequentemente utiliza-se óxido de índio-estanho (ITO) como anodo devido a sua transparência.

Uma das aplicações que mais vem sendo estudadas é em dispositivos fotovoltaicos orgânicos (OPVs, Organic Photovoltaics, Figura 1.4) para obtenção de energia solar. OPVs são construídos com uma camada fotossensível com uma mistura de um material receptor e um doador de elétrons. Essa camada é depositada entre um catodo e um anodo, com uma camada para transporte de buracos e elétrons entre os eletrodos e a camada ativa (Figura 1.3). Entre as vantagens das células 
OLED

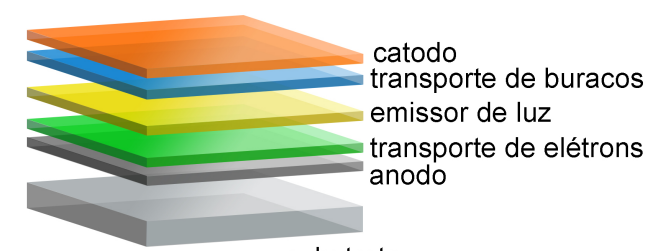

substrato

\section{OPV}

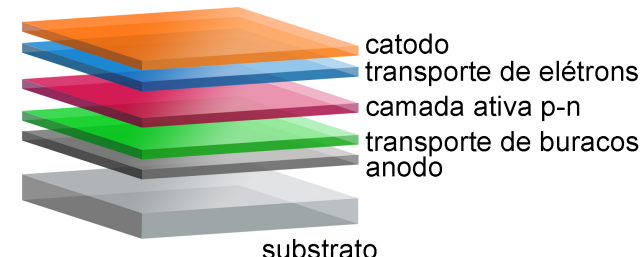

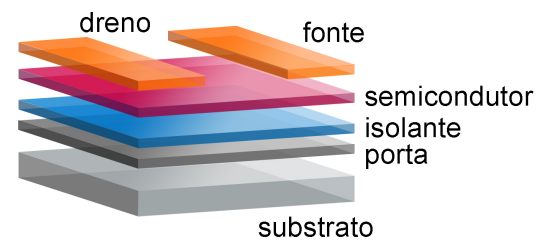

Figura 1.3: Esquema das estruturas típicas de alguns dispositivos orgânicos.

solares orgânicas em relação àquelas a base de materiais inorgânicos está a possibilidade de integrar esses dispositivos em tecidos e objetos de uso cotidiano.

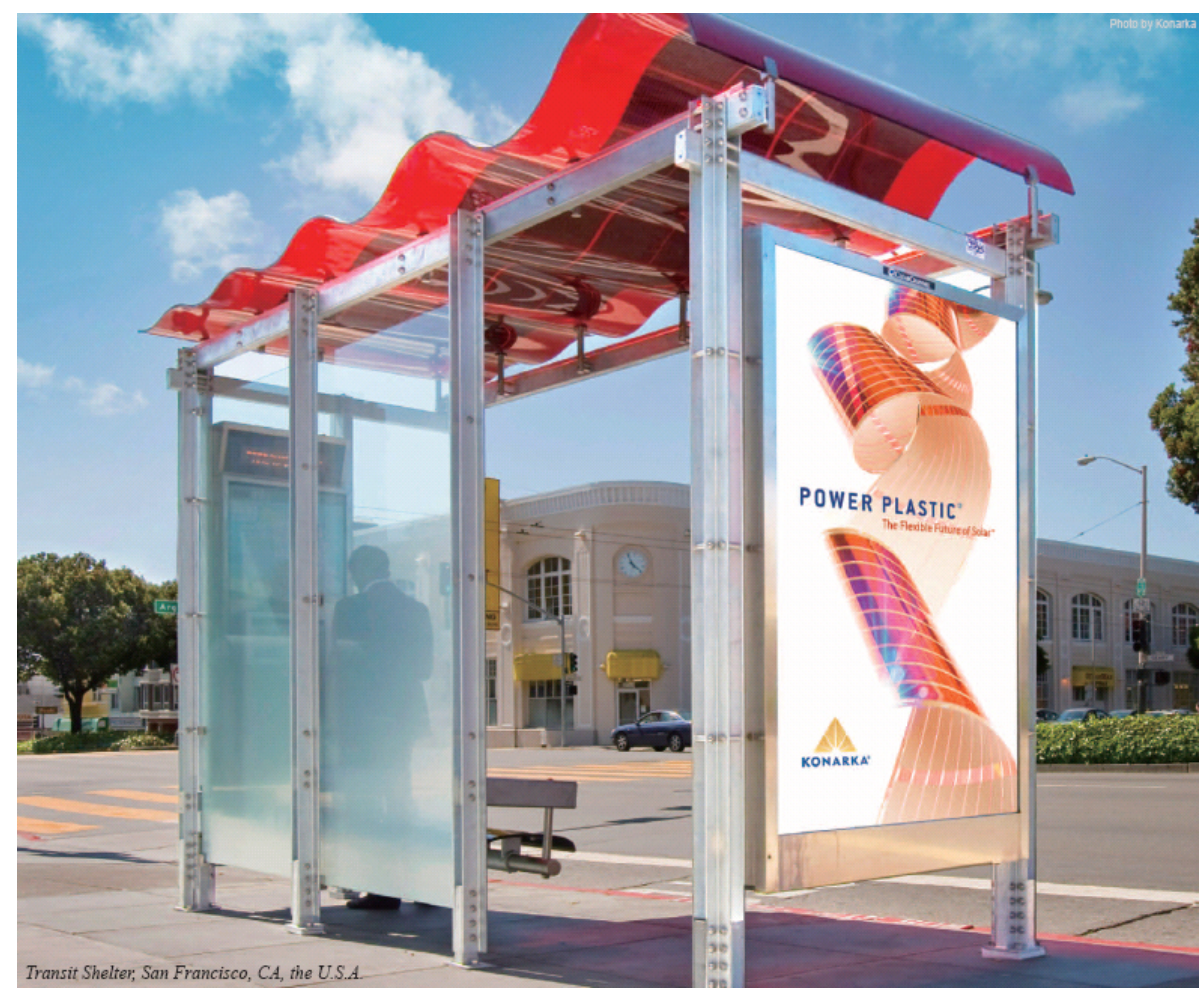

Figura 1.4: Ponto de ônibus com iluminação noturna abastecida por energia solar gerada na cobertura de painéis de OPV (Konarka $\left.{ }^{\circledR}\right)$.

Outra aplicação de grande interesse é na obtenção de OFETs (Organic Field-Effect Transistors) [5]. Os transistores inorgânicos foram desenvolvidos na década de 50, substituindo as válvulas e 
sendo então responsáveis pelos grandes avanços da eletrônica nas décadas seguintes. São dispositivos fundamentais em circuitos, atuando como amplificadores ou chaveadores de corrente. Possuem três terminais, chamados dreno, fonte e porta. O eletrodo de porta modula a passagem de corrente entre dreno e fonte através de um material semicondutor, que é isolado do eletrodo de porta por uma camada de dielétrico, como ilustrado na Figura 1.3

OFETs são direcionados a aplicações diferentes dos transistores inorgânicos. Os valores de mobilidade de carga são baixos em semicondutores orgânicos, resultando em dispositivos mais lentos e inviabilizando a substituição de materiais inorgânicos em processadores, por exemplo. O interesse no uso de OFETs está na aplicação em artigos de uso cotidiano nos quais não é fundamental uma alta velocidade de chaveamento. O desenvolvimento de transistores orgânicos possibilita a fabricação de etiquetas RFID Radio Frequency Identification, memórias, displays e diversos circuitos em material orgânico para aplicação em objetos de uso comum, com a vantagem das excelentes propriedades mecânicas desses materiais (Figura 1.5) e potencialmente a um custo muito mais baixo que o dos transistores inorgânicos.

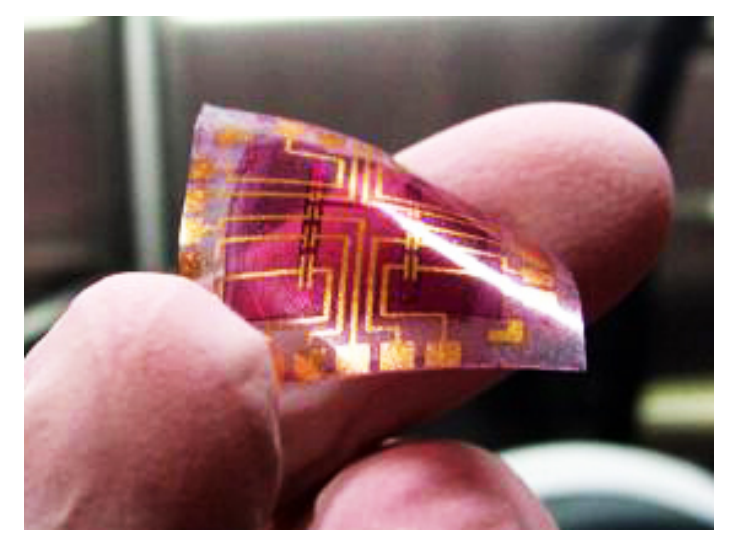

Figura 1.5: Transistores orgânicos em substrato flexível, produzidos no Grupo de Polímeros Bernhard Gross [6].

Por outro lado, a utilização e produção comercial de dispositivos eletrônicos orgânicos enfrentam barreiras, como o reduzido tempo de vida em funcionamento e a eficiência que ainda vem sendo melhorada [7]. É preciso entender mais detalhadamente os processos envolvidos no funcionamento dos dispositivos visando maior eficiência e possibilitando o desenvolvimento racional de novos materiais para vencer as barreiras que atualmente limitam seu desempenho. Também se deve estudar o processo de degradação do material e os fatores que influenciam a perda de performance elétrica. 


\subsection{Revisão bibliográfica}

O P3HT (poli-3-hexiltiofeno) (Figura 1.6) se destaca como material orgânico semicondutor tipo p, não só pelas propriedades elétricas, mas também por ser de fácil processamento e apresentar boa estabilidade [8]. Os valores de mobilidade de carga para o P3HT em transistores de efeito de campo chegam a $0,2 \mathrm{~cm}^{2} /$ V.s [9] (valores típicos para o silício em temperatura ambiente são de $1400 \mathrm{~cm}^{2} /$ V.s para elétrons e $450 \mathrm{~cm}^{2} /$ V.s para buracos). Em sua forma regiorregular (rr-P3HT), forma lamelas cristalinas com configuração head-to-tail que favorecem a mobilidade de portadores ao longo da cadeia conjugada [10]. Essas características do P3HT o faz um polímero largamente utilizado nos estudos e na produção de OFETs e OPVs. No caso de OPVs, um aspecto fundamental para a aplicação de P3HT como material ativo é seu amplo espectro de absorção de luz visível.

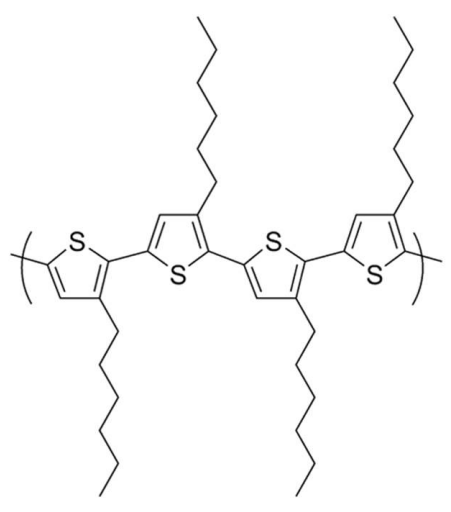

Figura 1.6: Estrutura química do P3HT regiorregular.

Outro fator de essencial importância para a fabricação de transistores orgânicos é a camada isolante do dispositivo. O PMMA (poli-metil-metacrilato) possui constante dielétrica próxima à do óxido de silício e tem sido amplamente utilizado como dielétrico em OFETs, apresentando diversas vantagens em comparação com isolantes inorgânicos [11]. Este polímero apresenta fácil processamento, ótimas propriedades mecânicas e alta estabilidade.

O P3HT, por outro lado, apesar de apresentar melhor estabilidade química em relação à maior parte dos demais polímeros conjugados, tem ainda certa sensibilidade às condições ambientes, característica desse tipo de material. Isto representa um fator limitante para o tempo de vida dos dispositivos.

O grande número de trabalhos na literatura abordando a estabilidade do P3HT, seus processos 
químicos de degradação e os fatores ambientais que os influenciam, tornaram este polímero um modelo típico para estudos de degradação em dispositivos orgânicos. A degradação do P3HT é atribuída a dois mecanismos distintos de fotooxidação [12]. Estudos do polímero em solução indicam a oxidação promovida por oxigênio singlete, que é produzido por transferência de energia entre o estado excitado triplete do P3HT e o oxigênio no estado fundamental, e reage com as unidades tienil por meio de um mecanismo de adição de Diels-Alder. O endoperóxido instável formado nesta reação se decompõe em sulfinas ou compostos carbonílicos, conforme mostra a Figura 1.7. [13, 14].

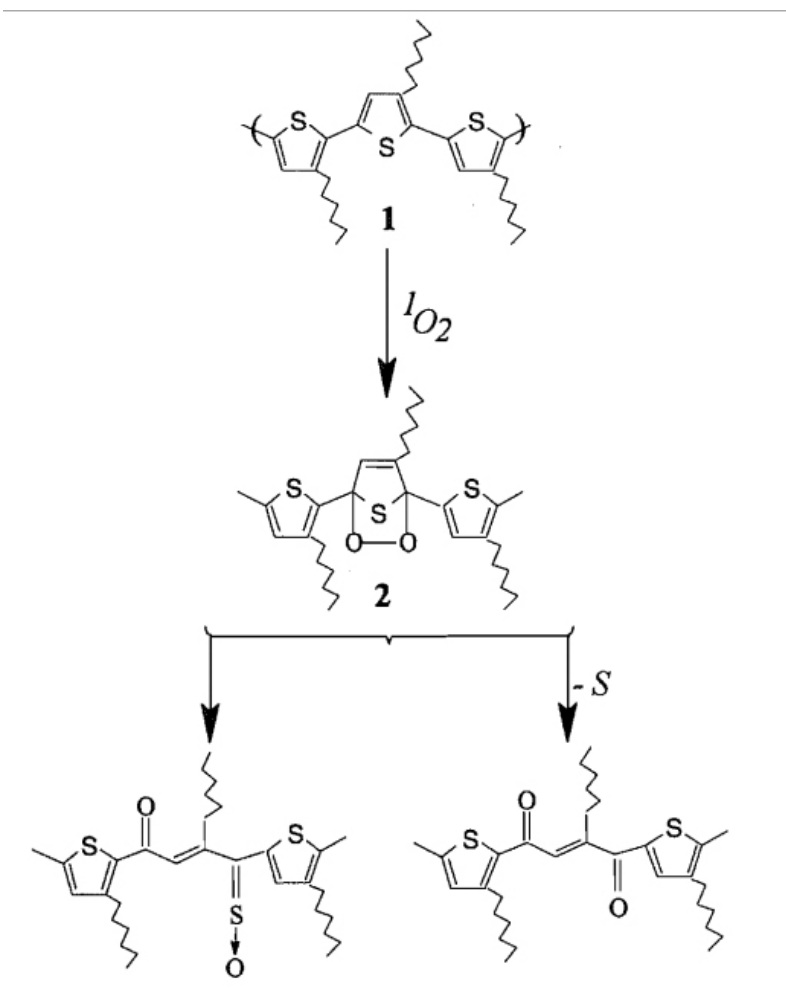

Figura 1.7: Processo de degradação do P3HT iniciado com a oxidação dos anéis tiofeno.

Por outro lado, estudos mostram que o processo de degradação do P3HT em estado sólido não segue o mesmo mecanismo. A segunda rota de oxidação é promovida por oxigênio triplete, por meio de um mecanismo radicalar que inicia com a oxidação das cadeias laterais (Figura 1.8) [15, 16]. No mecanismo proposto ocorre a abstração de um hidrogênio do carbono alfa da cadeia alquílica e formação de peróxido. Pode ocorrer ligações cruzadas entre os radicais formados e também formação de produtos voláteis [17].

O estudos desses processos em dispositivos funcionais é essencial para o desenvolvimento de novos materiais e a produção de dispositivos com maior estabilidade. Entretanto, em OFETs a 


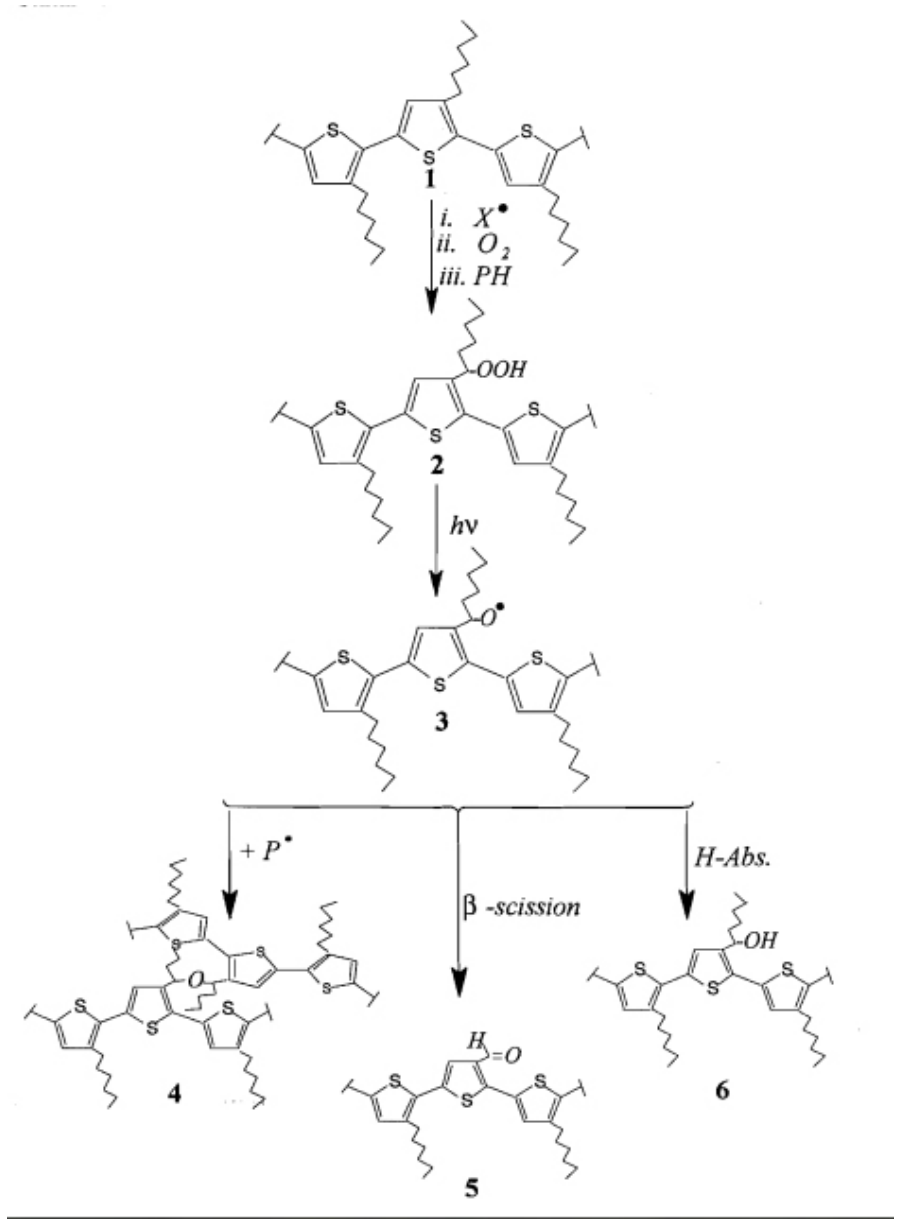

Figura 1.8: Processo de degradação do P3HT iniciado com a oxidação das cadeias laterais.

camada ativa é confinada a poucos nanometros da interface entre o semicondutor e o dielétrico, de forma que torna-se essencial investigar os processos de degradação nessa interface ativa, e não apenas no volume do material, onde a degradação pode ter um papel secundário em relação à performence do dispositivo. As técnicas que permitem obter informações da interface ativa das amostras são portanto ferramentas importantes para identificar os mecanismos de degradação que afetam o tempo de vida dos dispositivos.

Os fenômenos de interface são fundamentais para o funcionamento de dispositivos eletrônicos orgânicos, como a injeção de portadores de carga na interface do semicondutor orgânico com os eletrodos (geralmente metálicos), a formação e recombinação de portadores de carga oposta em dispositivos emissores de luz ou células fotovoltaicas, e a formação do canal de condução na interface entre o semicondutor e o isolante em transistores. Estes processos são críticos para a performance e estabilidade dos dispositivos. Estudos teóricos apontam tanto a formação de ligações químicas 
[18] quanto apenas fenômenos de dopagem [19] nas interfaces dos polímeros conjugados com os eletrodos metálicos. Experimentalmente, a investigação destas interfaces em geral apresenta algumas dificuldades e limitações. As técnicas frequentemente aplicadas no estudo de superfícies não são capazes de examinar seletivamente interfaces na parte interna da amostra, que são as regiões de interesse no caso de dispositivos eletrônicos. Medidas de espectroscopia fotoelétrica, como XPS (X-Ray Photoelectron Spectroscopy) e UPS (UV Photoelectron Spectroscopy) foram utilizadas no estudo das interfaces de metal com polímero condutor e apontam evidencias de dopagem ou formação de ligações covalentes [20, 21]. Também foram encontrados indícios de formação de ligações covalentes em estudos utilizando FTIR (Fourier Transform Infrared Spectroscopy) [22] e SERS (Surface Enhanced Raman Scattering) [23]. No caso de SERS, XPS e UPS, os fotoelétrons provém da camada externa da amostra (dezenas de angstrons), de modo que para obter um sinal confiável da interface polímero-substrato (metal ou dielétrico), isso exige a preparação de amostras com filmes muito finos. Além disso, as técnicas de espectroscopia fotoelétrica utilizam feixes de energias muito altas que danificam as amostras orgânicas. No caso de SERS, é necessário utilizar substratos metálicos rugosos, que não necessariamente correspondem aos utilizados em dispositivos reais. Já em FTIR, a técnica não discrimina os sinais provenientes do volume e das interfaces, e portanto também exige a utilização de filmes poliméricos muito finos nas amostras.

Uma opção para o estudo de interfaces são as técnicas espectroscópicas com base em efeitos ópticos não-lineares de segunda ordem [24]. Estes fenômenos, por exemplo, geração de segundo harmônico e geração de soma de frequências, são limitados por simetria e ocorrem apenas em cristais não centrossimétricos. No caso contrário, os efeitos de segunda ordem ocorrem unicamente em interfaces, onde ocorre quebra da simetria de inversão [25].

Assim, a utilização de espectroscopia SFG (Sum-Frequency Generation) e SHG (Second Harmonic Generation) permite então investigar a interface entre o semicondutor e o isolante em transistores orgânicos de efeito de campo (OFETs), realizando medidas em dispositivos funcionais de forma não destrutiva.

Por exemplo, a modulação do sinal SHG em OFETs em funcionamento reflete a acumulação e condução de portadores de carga [26, 27]. Manaka et al. [28, 29] realizou medidas SHG resolvido no tempo para estudar a dinâmica da distribuição de campo elétrico no canal de OFETs de acordo com a injeção e movimento de portadores de carga. 
Ye et al. [30, 31] utilizou espectroscopia SFG para investigar OFETs em operação e correlacionar a performance elétrica com aspectos dos espectros vibracionais obtidos na região correspondente às vibrações das cadeias laterais. Espectroscopia SFG também foi utilizada por Anglin et al. para estudar OFETs de P3HT em operação. Foi observado um aumento do sinal não ressonante do polímero no canal conforme aplicação de potencial de porta [32], e foi feito um estudo de orientação das cadeias conjugadas em substratos com diferentes modificações, relacionando a mobilidade de portadores e performance elétrica com a orientação das cadeias [33]. Em outro estudo foram observados efeitos de campo elétrico, transições polarônicas e/ou perturbações estruturais nos espectros SFG obtidos de OFETs de PTAA (poli-triarilamina), que se correlacionam com o comportamento do dispositivo em operação [34]. Walter et al. [35] também utilizou espectroscopia SFG para estudar o efeito da funcionalização da superfície do dielétrico com surfactantes na organização das moléculas semicondutoras na interface ativa de OFETs e relacionar com a performance dos dispositivos. A distribuição de campo elétrico em canais de OFETs foi observada por espectromicroscopia SFG por Nakai et al. [36], observando a modulação do sinal conforme injeção e acumulação de portadores carga. Embora esses estudos tenham contribuído enormemente para o entendimento da relação entre organização molecular na interface e o desempenho de OFETs, o potencial da espectroscopia SFG de obter espectros vibracionais da interface, e potencialmente identificar alterações na estrutura molecular induzidas por dopagem ou degradação, não foi ainda completamente explorado.

\subsection{Objetivos}

Considerando a importância de se aprimorar a estabilidade e tempo de vida dos dispositivos construídos com material orgânico, este trabalho teve por objetivo estudar os processos de degradação que levam à perda de eficiência. Os transistores de efeito de campo orgânicos foram objeto de estudo, utilizando P3HT como material semicondutor. Como descrito anteriormente, o P3HT é um polímero estudado em um volume considerável de trabalhos anteriores, que tratam de seus processos de degradação, tendo sido demonstrado nos últimos anos tratar-se de um material de aplicação favorável na construção de transistores e outros dispositivos, incluindo células solares orgânicas.

A interface semicondutor/isolante em OFETs é crucial para o funcionamento do dispositivo, sendo que a região ativa não é maior do que algumas unidades de nanômetro. Dada a relevância dessa interface para os estudos físicos e químicos, as técnicas de Espectroscopia não-linear de interfaces 
são de grande interesse no trabalho proposto, e serão usadas como ferramenta para acompanhar o funcionamento e a degradação dos OFETs neste trabalho, atentando às diferenças entre os processos que ocorrem na interface em relação ao que se observa no volume do filme polimérico. 


\section{Fundamentos Teóricos}

\subsection{Transistores de Efeito de Campo Orgânicos}

\section{Condução em materiais orgânicos}

A condutividade elétrica em polímeros, oligômeros e certas moléculas orgânicas é proporcionada pela estrutura conjugada das cadeias carbônicas. Em materiais isolantes as cadeias são formadas por átomos de carbono com hibridização $\mathrm{sp}^{3}$ formando ligações $\sigma$, podendo apresentar ligações duplas em pontos localizados da estrutura. Cadeias conjugadas, ou seja, que alternam ligações simples e duplas, são formadas por carbonos $\mathrm{sp}^{2}$, que apresentam geometria plana e permitem a deslocalização dos orbitais $\pi$ adjacentes ao longo da estrutura. A sobreposição de orbitais ao longo de um segmento da cadeia forma uma estrutura eletrônica de bandas, entre as quais há um intervalo de níveis de energia proibidos, ou band gap (Figura 2.1).

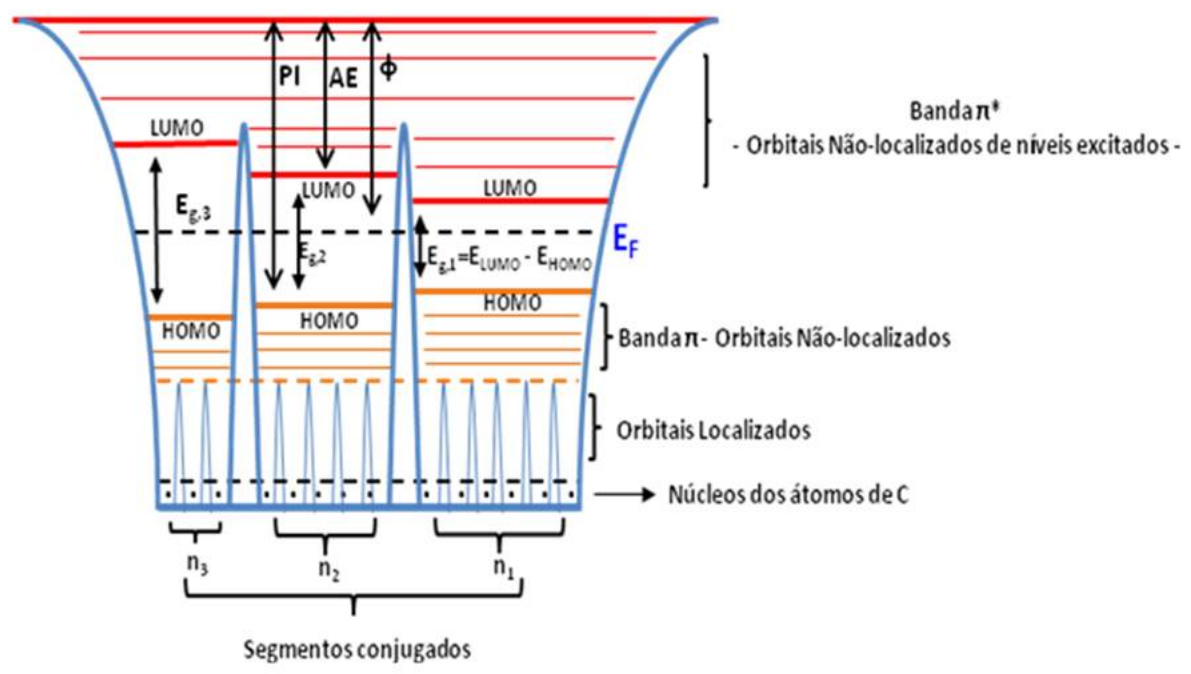

Figura 2.1: Diagrama de níveis de energia em um polímero conjugado. 
No caso caso de segmentos orgânicos conjugados, a banda conhecida como banda de valência em semicondutores é conhecida como HOMO (Highest Occupied Molecular Orbital), e é formada por orbitais ligantes $\pi$. A banda chamada de condução nos semicondutores inorgânicos é chamada de LUMO (Lowest Occupied Molecular Orbital), e é formada por orbitais anti-ligantes $\pi^{*}$. A formação de portadores de carga se dá quando um elétron absorve um fóton e efetua a transição $\pi$ - $\pi^{*}$ que envolve uma energia mínima correspondente ao gap, produzindo então um par elétron-buraco. Este par pode estar ligado por interação Coulombiana, formando um éxciton, ou dissociar-se produzindo um par de portadores de carga livres. Outra maneira de se produzir portadores de carga é via injeção de elétrons na banda $\pi^{*}$ ou remoção de elétrons da banda $\pi$, via transferência de carga para outros materiais (por exemplo, eletrodos metálicos), resultando então em elétrons ou buracos livres, respectivamente.

O transporte desses portadores em materiais amorfos é tratado pelo modelo de hopping [37], no qual os portadores saltam entre segmentos conjugados de comprimento variável, separados por barreiras energéticas devido a defeitos conformacionais. Esses saltos occorrem por um processo de tunelamento assistido por fônons entre estados próximos ao nível de Fermi. A interação de portadores de carga com fônons (modos de vibração da rede) resulta na formação de polarons, cujos níveis eletrônicos estão localizados no band-gap do semicondutor, próximos aos HOMO e LUMO [38]. Assim, a mobilidade dos portadores de carga nos materiais orgânicos em geral depende fortemente da temperatura e do grau de ordenamento das cadeias conjugadas.

\section{OFETs}

Transistores são dispositivos que atuam como moduladores de corrente, sendo portanto os mais importantes componentes de diversos circuitos elétricos. Possuem três terminais, que são denominados dreno, fonte e porta, também frequentemente identificados pelos nomes em inglês, drain, source e gate, respectivamente.

A corrente atravessa o canal de condução formado pelo semicondutor entre os eletrodos de dreno e fonte. O semicondutor é isolado do eletrodo de porta por uma camada de dielétrico, através do qual se forma um campo elétrico gerado pelo potencial aplicado entre os terminais fonte e porta (indicado por $V_{G}$ ). O campo elétrico formado leva à dopagem do semicondutor e acúmulo de portadores de carga na interface ativa, de forma análoga a um capacitor. A intensidade de corrente 
no canal depende não apenas do potencial aplicado entre dreno e fonte (indicado por $V_{D}$ ) mas principalmente do campo elétrico transversal ao canal, gerado pelo potencial aplicado ao eletrodo de porta [39].

A Figura 2.2 apresenta os elementos básicos de um transistor de efeito de campo. A construção do dispositivo apresentada na figura é chamada de arquitetura bottom-gate top-contacts. Outras arquiteturas serão descritas no capítulo 3 .

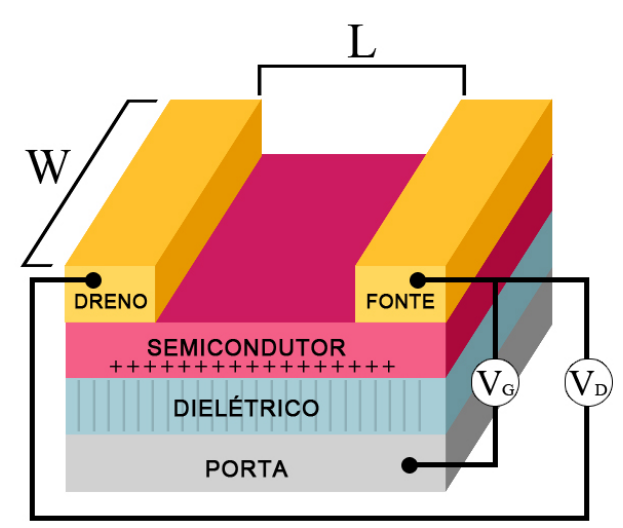

Figura 2.2: Esquema básico de um transistor de efeito de campo.

Diferentemente dos transistores inorgânicos que operam em modo de inversão (o canal é formado na interface semicondutor-dielétrico, acima do limiar de operação, por cargas opostas à dopagem do semicondutor), os OFETs operam em modo de acumulação, onde uma camada de carga com o mesmo sinal da dopagem é formada na interface entre o semicondutor e o dielétrico acumulando portadores em função da polarização do eletrodo de porta.

Pode-se caracterizar o dispositivo com dois tipos de medida, que estão representados na Figura 2.3. As curvas de saída são obtidas medindo a corrente que atravessa o canal em função de $V_{D}$ para vários valores fixos de $V_{G}$. As curvas de transferência, por outro lado, são curvas de $I_{D}$ em função de $V_{G}$ para valores fixos de $V_{D}$. Para baixos valores de potencial de dreno o canal se comporta como um resistor, e a corrente aumenta proporcionalmente ao aumento de $V_{D}$. É possível observar nas curvas de saída que a corrente satura após um determinado potencial.

É chamado de pinch-off, ou ponto de estrangulamento, o ponto a partir do qual a corrente do canal começa a saturar. Isso ocorre pelo aumento de resistência quando a diferença de potencial deixa de ser uniforme ao longo da extensão do canal entre dreno e fonte e o canal afunila (Figura $2.5)$. 


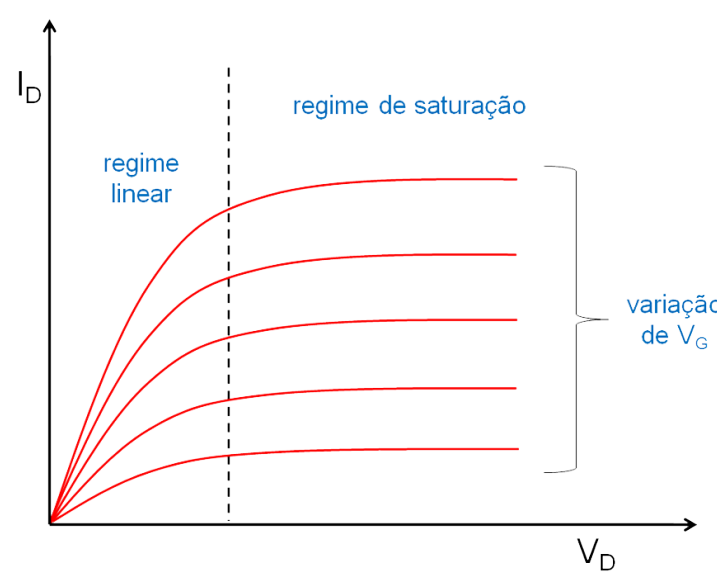

(a) Curvas de saída

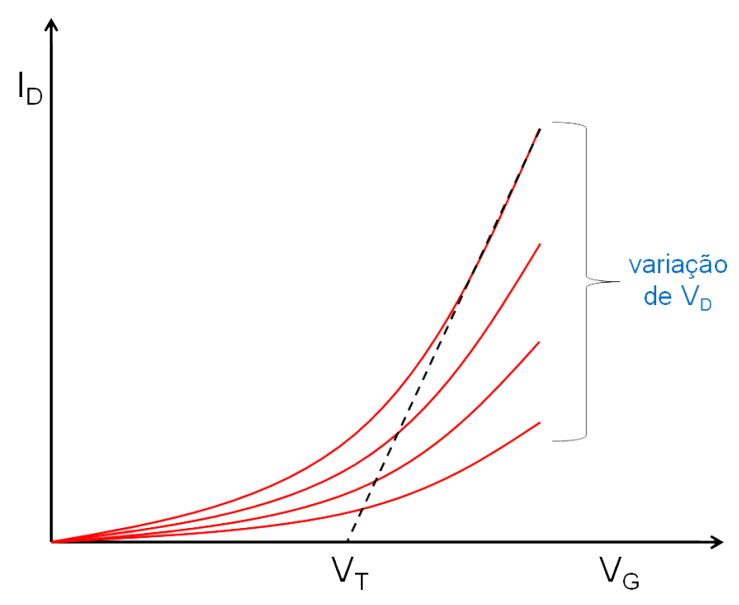

(b) Curvas de transferência

Figura 2.3: Medidas elétricas típicas de um OFET. Valores de corrente e potencial estão em módulo. No caso de dispositivos tipo p, os valores de $I_{D}, V_{D}$ e $V_{G}$ são negativos.

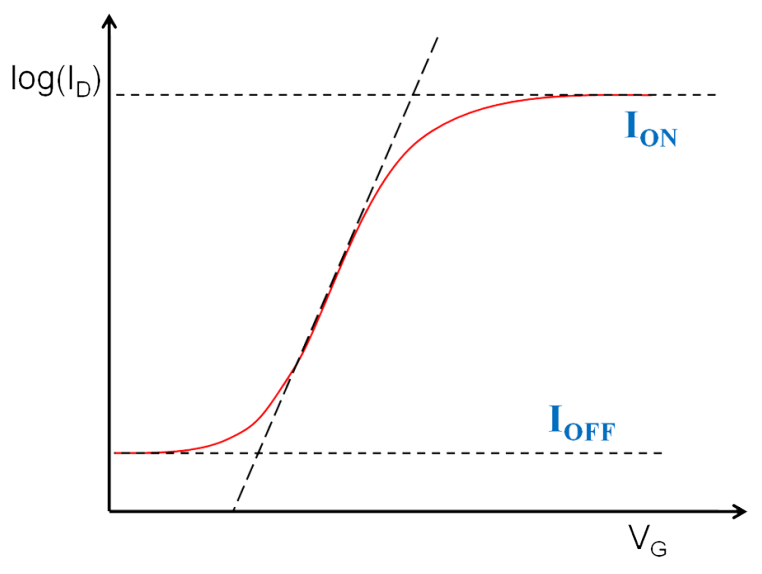

Figura 2.4: Gráfico semi-log de uma medida de transferência (utilizando o módulo dos valores de corrente e potencial).
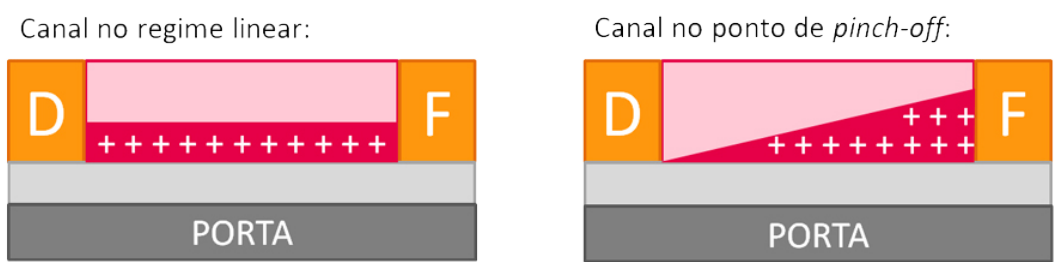

Figura 2.5: Canal do OFET no regime linear e no ponto de pinch-off.

O potencial de limiar $V_{T}$ obtido a partir das curvas de transferência (Figura 2.3b), no caso de FETs orgânicos, pode ser interpretado como o potencial necessário para igualar a densidade de carga da interface ao volume. Esse valor é utilizado como parâmetro de ajuste nas equações, sendo 
subtraído de $V_{G}$ para obter um potencial de porta efetivo.

O gráfico semi-log das curvas de transferência (Figura 2.4) permite extrair outros parâmetros interessantes para a caracterização do OFET, uma vez que exibe de forma clara a transição para o estado ligado do dispositivo com aplicação do potencial de porta. Calcula-se a razão ON/OFF do dispositivo dividindo a corrente de canal do dispositivo ligado pelo valor de corrente no estado desligado.

A corrente $I_{D}$ que passa pelo canal pode ser expressa pela equação 2.1 , onde $\mathrm{C}$ é a capacitância do canal através do isolante em relação à porta, $\mu_{F E T}$ é a mobilidade de efeito de campo dos portadores de carga, $V_{T}$ é o potencial de limiar e $V_{D}$ e $V_{G}$ são os potenciais aplicados entre dreno e fonte e porta e fonte, respectivamente.

$$
I_{D}=\mu_{F E T} C \frac{W}{L}\left\{\left(V_{G}-V_{T}\right) V_{D}-\frac{V_{D}^{2}}{2}\right\}
$$

Esta equação é obtida a partir do modelo de aproximação de canal gradual, proposto por Shockley [40], no qual assume-se que o campo elétrico gerado pela diferença de potencial entre os contatos dreno e fonte é paralelo à interface semicondutor-isolante e é uniforme em toda a extensão do canal. Considera-se também que a mobilidade de efeito de campo $\mu_{F E T}$ é constante e qualquer corrente de fuga, influência dos contatos ou resistência parasítica são ignoradas.

A região de regime linear é definida onde $-V_{D} \ll-\left(V_{G}-V_{T}\right)$ e a região de saturação onde $-V_{D} \geq-\left(V_{G}-V_{T}\right)$. Utilizando esses dois limites é possível obter as equações 2.2 e 2.3 , que permitem calcular a mobilidade de carga nos dispositivos a partir das curvas de saída.

$$
\begin{gathered}
I_{D l i n}=\mu_{F E T} C \frac{W}{L}\left(V_{G}-V_{T}\right) V_{D} \\
I_{\text {Dsat }}=\mu C \frac{W}{2 L}\left(V_{G}-V_{T}\right)^{2}
\end{gathered}
$$

Horowitz et al. [41] propôs o modelo Multi Trapping and Releasing (armadilhamento e desarmadilhamento de cargas), descrevendo a mobilidade efetiva dos portadores de carga em materiais orgânicos policristalinos e sua dependência com a temperatura. Neste modelo o transporte de cargas é ativado termicamente e seu comportamento é descrito em função das densidades de cargas livres e armadilhadas em estados localizados. O comportamento de OFETs pode ser descrito mais detalhadamente em função da temperatura e do potencial de porta pelo modelo de Vissenberg-Matters 
[42]. Este modelo é baseado na teoria de percolação para a condutividade e na teoria de saltos de alcance variável (na qual se tem saltos de longa distância e baixa energia de ativação ou saltos de alta energia de ativação entre sítios próximos) a partir de uma distribuição gaussiana de estados.

Estes modelos não serão descritos aqui com detalhe, posto que não é o objetivo central deste trabalho fazer uma análise acurada do comportamento elétrico dos OFETs.

\subsection{Espectroscopia não-linear de interfaces}

Óptica não-linear é um campo de estudo que envolve a alteração das propriedades ópticas de um sistema em consequência da interação do material com radiação de alta intensidade, em geral proveniente de uma fonte laser [43]. A radiação incidente em um material induz a polarização do meio, que é representada por

$$
\vec{P}=\overleftrightarrow{\chi} \cdot \vec{E}
$$

onde E é o campo elétrico incidente e $\chi$ é a susceptibilidade elétrica linear do meio. A incidência de radiação de alta intensidade em um material induz uma resposta que desvia do comportamento linear [25].

Nesse caso, a polarização pode ser representada por uma série de Taylor conforme a Equação 2.5 .

$$
\vec{P}=\overleftrightarrow{\chi}^{(1)} \cdot \vec{E}+\overleftrightarrow{\chi}^{(2)} \cdot \vec{E}^{2}+\overleftrightarrow{\chi}^{(3)} \cdot \vec{E}^{3}+\ldots
$$

O termo de segunda ordem da polarização não-linear é responsável pelos processos de geração de Segundo Harmônico (SHG, Second Harmonic Generation), Soma de Frequências (SFG, SumFrequency Generation), Diferença de Frequências (DFG, Difference-Frequency Generation) e Retificação Óptica (OR, Optical Rectification). O termo de terceira ordem está relacionado com processos como efeito Kerr e EFISHG (Electric-Field-Induced Second-Harmonic Generation, ou seja, geração de Segundo Harmônico na presença de um campo DC).

A susceptibilidade de segunda ordem $\overleftrightarrow{\chi}^{(2)}$ é um tensor de posto 3 e na condição de um meio com simetria de inversão deve ser nulo para obedecer as condições da Equação 2.6. 


$$
\overleftrightarrow{\chi}_{i j k}^{(2)}=\overleftrightarrow{\chi}_{-i-j-k}^{(2)}=-\overleftrightarrow{\chi}_{i j k}^{(2)}
$$

Portanto, as técnicas espectroscópicas baseadas em processos de segunda ordem são geralmente seletivas a interfaces, onde há quebra de simetria.

\section{Espectroscopia SFG}

O sinal SFG é gerado a partir da sobreposição temporal e espacial de dois feixes de frequências distintas. A frequência do sinal obtido é a soma das frequências incidentes (Figura 2.6). Tipicamente utiliza-se um feixe monocromático visível e um feixe sintonizável no infravermelho médio (Figura 2.7). Descreveremos aqui os pontos essenciais da técnica necessários para o entendimento e interpretação dos resultados. Maiores detalhes podem ser obtidos nas referências [25], [43] e [44].

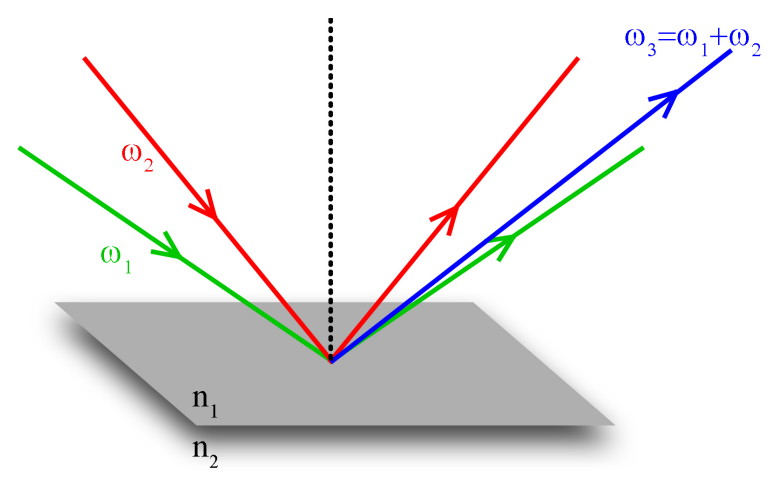

Figura 2.6: Feixes envolvidos no experimento SFG em relação às coordenadas do laboratório. A polarização dos dois feixes incidentes e do sinal soma podem ser ou paralela (p) ou perpendicular (s) ao eixo de incidência (tracejado).

A intensidade do sinal (Equação 2.7) depende da intensidade dos dois feixes incidentes e do quadrado da susceptibilidade de segunda ordem efetiva $\chi_{e f f}^{(2)}$. O termo $\chi_{e f f}^{(2)}$ possui duas componentes, como mostra a Equação 2.8, sendo uma delas uma parte não-ressonante, ou seja, constante quando a frequência do feixe infravermelho é sintonizada.

$$
\begin{gathered}
I_{S F G} \propto\left|\chi_{e f f}^{(2)}\right|^{2} \cdot I_{V I S} \cdot I_{I R} \\
\chi_{e f f}^{(2)}=\chi_{N R}^{(2)}+\chi_{R}^{(2)}
\end{gathered}
$$




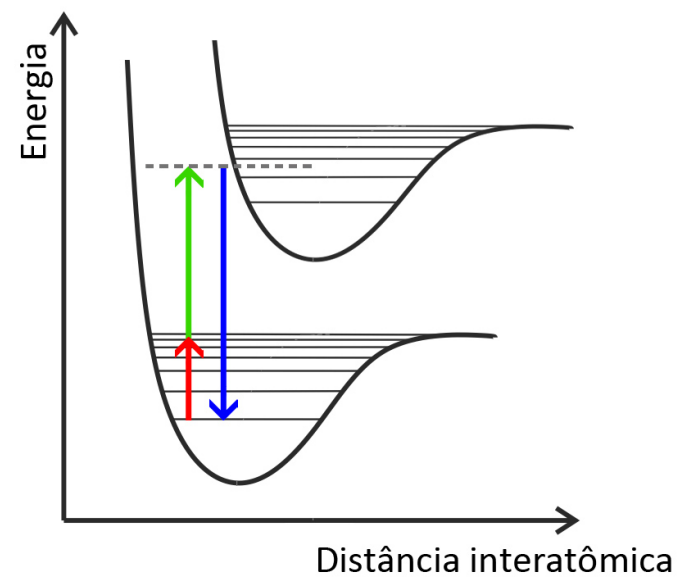

Figura 2.7: Transições de energia envolvidas na geração de sinal SFG.

A componente ressonante varia com a frequência do feixe infravermelho conforme os modos vibracionais dos grupos moleculares presentes na interface de interesse são excitados. $\chi_{R}^{(2)}$ é na verdade média sobre a distribuição de orientações moleculares de uma transformação de coordenadas do tensor de polarizabilidade molecular de segunda ordem do referencial molecular para o referencial do laboratório (Equação 2.9):

$$
\overleftrightarrow{\chi}_{R, i j k}^{(2)}=N \sum<(\hat{i} \cdot \hat{l})(\hat{j} \cdot \hat{m})(\hat{k} \cdot \hat{n})>\alpha_{l m n}^{(2)}
$$

onde ijk são as coordenadas do laboratório e $l m n$ são as coordenadas moleculares. O símbolo $<>$ representa a média sobre a distribuição de orientações moleculares. Nota-se que para uma orientação aleatória, $\overleftrightarrow{\chi}_{R, i j k}^{(2)}=0$. Fica portanto demonstrada a sensibilidade da espectroscopia SFG ao ordenamento molecular na interface. A Figura 2.8 ilustra a transformação de coordenadas, onde $x y z$ podem ser qualquer das coordenadas do laboratório $i j k$, e $a b c$ podem ser qualquer das coordenadas moleculares $l m n$.

A polarizabilidade de segunda ordem $\alpha^{(2)}$ é uma propriedade microscópica característica de cada molécula na interface, de onde se origina a dependência com os modos vibracionais, como mostra a Equação 2.10 .

$$
\alpha_{l m n}^{(2)}=\sum_{q} \frac{1}{2 \omega_{q}\left(\omega_{q}-\omega_{l} r-i \Gamma_{q}\right)} \frac{\partial \mu_{n}}{\partial Q} \frac{\partial \alpha_{l m}^{(1)}}{\partial Q}
$$




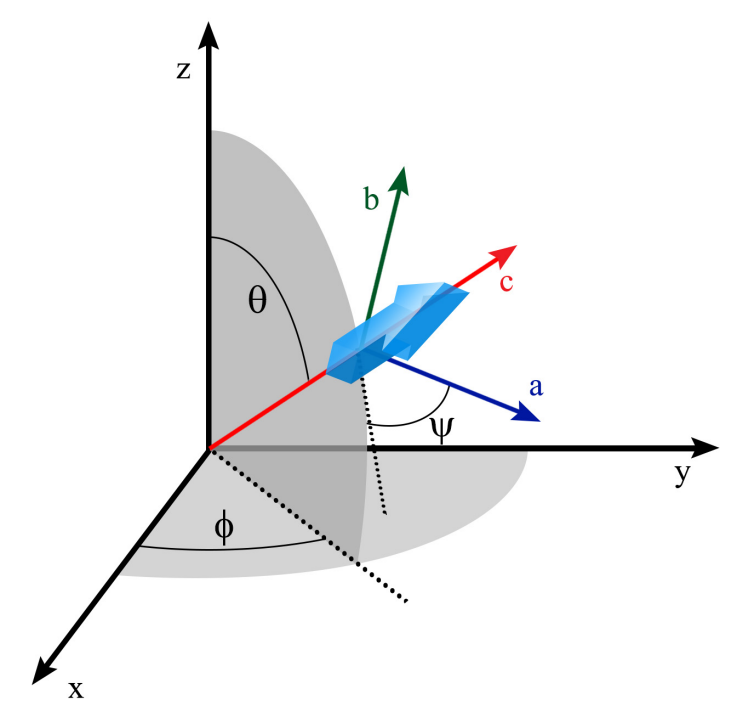

Figura 2.8: Referenciais para a transformação de coordenadas moleculares para coordenadas do laboratório descrita na Equação 2.9. Os ângulos $\theta, \phi$ e $\psi$ descrevem a orientação molecular.

$$
\begin{gathered}
\frac{\partial \mu_{n}}{\partial Q}=\left(\frac{\hbar}{2 \omega_{q}}\right)^{-\frac{1}{2}}\left\langle g\left|\mu_{n}\right| q\right\rangle \\
\frac{\partial \alpha_{l m}^{(1)}}{\partial Q}=\left(\frac{\hbar}{2 \omega_{q}}\right)^{-\frac{1}{2}} \sum_{n}\left(\frac{\left\langle g\left|\mu_{l}\right| n\right\rangle\left\langle n\left|\mu_{m}\right| q\right\rangle}{\omega_{s}-\omega_{n g}+i \Gamma_{n g}}-\frac{\left\langle n\left|\mu_{l}\right| q\right\rangle\left\langle g\left|\mu_{m}\right| n\right\rangle}{\omega_{s}-\omega_{q n}+i \Gamma_{q n}}\right)
\end{gathered}
$$

Observa-se a partir destas equações que o sinal SFG é dependente tanto de $\frac{\partial \mu_{n}}{\partial Q}$ (a variação da componente $n$ do dipolo em função da coordenada normal $Q$ ) quanto de $\frac{\partial \alpha_{l, m}^{(1)}}{\partial Q}$ (a variação das componentes $l$ e $m$ da polarizabilidade em função da coordenada normal $Q$ ). Isso significa que as regras de seleção para atividade SFG exige que determinado modo vibracional seja ativo tanto na espectroscopia infravermelho quanto em Raman.

A partir da Equação 2.10 é possível obter uma equação para a dependência de $\chi^{(2)}$ com a frequência do infravermelho, que permite ajustar os espectros SFG para uma análise quantitativa. O sinal SFG, obtido em função da frequência do infravermelho incidente, normalizado pelas energias do visível e infravermelho de excitação é equivalente a um $\chi$ efetivo $\chi_{S}^{(2)}\left(\omega_{I R}\right)$, dado pela Equação 2.13, utilizada para ajustar os espectros e obter as amplitudes $A_{q}$, frequências de ressonância $\omega_{q}$ e largura $\Gamma_{q}$ dos modos vibracionais, além da contribuição não-ressonante $\chi_{N R}^{(2)}$, que em geral tem amplitude e fase. 


$$
\left|\chi_{S}^{(2)}\left(\omega_{I R}\right)\right|^{2}=\left|\chi_{R}^{(2)}+\chi_{N R}^{(2)}\right|^{2}=\left|\sum_{q} \frac{A_{q}}{\omega_{I} R-\omega_{q}+i \Gamma_{q}}+\chi_{N R}^{(2)}\right|^{2}
$$

Conforme a polarização dos feixes incidentes e do sinal detectado, pode-se ainda obter informações sobre a orientação média dos grupos moleculares referentes aos modos vibracionais observados nos espectros SFG. Em uma interface isotrópica no plano, de simetria $C_{\infty}$, as 27 componentes do tensor susceptibilidade de segunda ordem são reduzidas para quatro componentes independentes:

$$
\begin{gathered}
\chi_{z x x}^{(2)}=\chi_{z y y}^{(2)} ; \\
\chi_{x z x}^{(2)}=\chi_{y z y}^{(2)} ; \\
\chi_{x x z}^{(2)}=\chi_{y y z}^{(2)} ; \\
\chi_{z z z}^{(2)}
\end{gathered}
$$

Essas componentes podem ser estudadas separadamente utilizando os conjuntos de polarizações apresentados na tabela 2.1, onde a primeira letra se refere à polarização do sinal SFG, a segunda à polarização do feixe visível e a terceira ao feixe infravermelho. A contribuição relativa dessas componentes depende da orientação molecular média, além de fatores experimentais como índice de refração e ângulo de incidência dos feixes.

\begin{tabular}{ll}
\hline conjunto de polarizações & componentes de $\chi_{e f f}^{(2)}$ \\
\hline $\mathrm{pss}$ & $\chi_{z x x}^{(2)}=\chi_{z y y}^{(2)}$ \\
$\operatorname{sps}$ & $\chi_{x z x}^{(2)}=\chi_{y z y}^{(2)} ;$ \\
$\operatorname{ssp}$ & $\chi_{x x z}^{(2)}=\chi_{y y z}^{(2)} ;$ \\
$\operatorname{ppp}$ & $\chi_{z z z}^{(2)}, \chi_{z x x}^{(2)}, \chi_{z y y}^{(2)}, \chi_{x z x}^{(2)}, \chi_{y z y}^{(2)}, \chi_{x x z}^{(2)}, \chi_{y y z}^{(2)}$ \\
\hline
\end{tabular}

Tabela 2.1: Componentes de $\chi_{e f f}^{(2)}$ que contribuem para o sinal SFG em cada conjunto de polarizações [44].

\section{Geração de Segundo Harmônico}

Um caso especial de soma de frequências é a combinação de dois fótons de mesma energia. Nesse caso a radiação resultante é o segundo harmônico da radiação incidente. A geração do segundo harmônico de um feixe incidente em uma interface (Figura 2.9) tem uma dependência direta com a susceptibilidade de segunda ordem, de forma análoga ao descrito anteriormente. Utilizando 
uma frequência fixa e detectando as variações no sinal gerado em função de algum parâmetro experimental, pode-se relacionar a intensidade SHG, por exemplo, com maior ou menor ordenamento molecular na interface, ou presença de cargas.

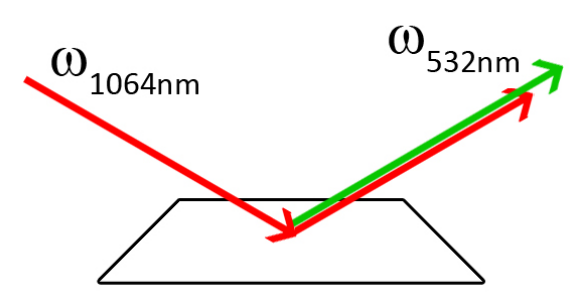

Figura 2.9: Geração de Segundo Harmônico em uma interface.

A presença de um campo elétrico constante também contribui para a geração de segundo harmônico em um efeito chamado EFISHG (Electric-Field-Induced Second-Harmonic Genaration), conforme a Equação 2.14. Neste caso o sinal também é gerado no volume de um material centrossimétrico por um processo de terceira ordem, e o termo de susceptibilidade pode ser tratado como um $\chi^{(2)}$ de segunda ordem efetivo.

$$
I_{S H G} \propto I_{I R}^{2} \cdot\left|\chi^{(2)}+\chi^{(3)} \cdot E_{D C}\right|^{2}
$$

A variação de polarização do feixe incidente e do sinal detectado também permite separar componentes da susceptibilidade e do campo elétrico constante. No caso de dispositivos eletrônicos, a análise adequada do sinal SHG permite estudar a distribuição de campo elétrico e de cargas no material [26]. 


\section{Materiais e métodos}

Neste Capítulo serão descritos os procedimentos adotados para a preparação de amostras e realização de medidas.

Ao longo do trabalho, diversos obstáculos tiveram que ser contornados, levando a modificações e adaptações tanto na fabricação de dispositivos quanto na aquisição de dados espectroscópicos. Os métodos especificados a seguir são aqueles envolvidos no desenvolvimento dos resultados que serão apresentados na sequência.

\subsection{Preparação e caracterização dos OFETs}

Tipicamente existem quatro arquiteturas possíveis para a fabricação de transistores de efeito de campo, que são ilustradas na Figura 3.1. Embora ao longo deste trabalho tenham sido construídos dispositivos em arquiteturas diferentes para fins de comparação, os resultados que serão apresentados são de dispositivos construídos na arquitetura bottom-gate top-contacts, ou seja, com o eletrodo de porta na parte inferior, recoberto pelo dielétrico, e os eletrodos de dreno e fonte na superfície externa do semicondutor.

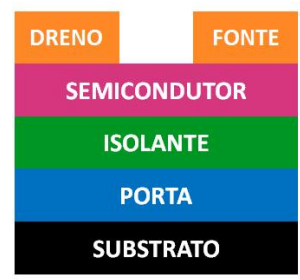

bottom-gate

top-contacts

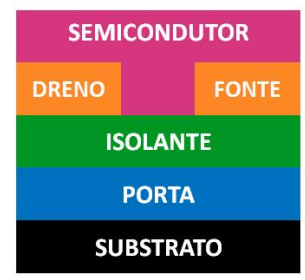

bottom-gate

bottom-contacts

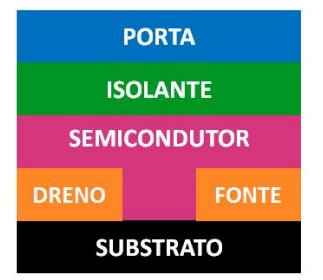

top-gate bottom-contacts

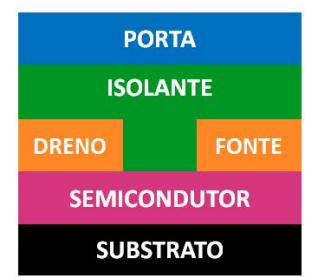

top-gate top-contacts

Figura 3.1: Possíveis arquiteturas para a construção de transistores.

Os OFETs nos quais a camada de semicondutor é encapsulada no interior da amostra (nos tipos 
top-gate) apresentam usualmente maior tempo de vida em razão do menor contato do polímero semicondutor com oxigênio. Procurou-se estudar dispositivos com o semicondutor exposto, para melhor observar os efeitos de degradação e também pela maior facilidade de processamento e de aquisição das medidas espectroscópicas. A arquitetura bottom-gate top-contacts se mostrou mais adequada em relação à bottom-gate bottom-contacts para a realização dos experimentos em razão da alta intensificação do sinal SFG do polímero conjugado depositado sobre os filmes metálicos. O sinal intenso proveniente do polímero sobre os eletrodos nas amostras bottom-gate bottom-contacts mascara o sinal da região do canal do dispositivo, portanto esse tipo de construção foi descartado.

Ao longo do trabalho foram preparados três tipos de OFETs, utilizando diferentes materiais (Figura 3.2). Essas diferentes metodologias se mostraram necessárias ao longo do desenvolvimento do trabalho conforme a identificação de dificuldades técnicas.

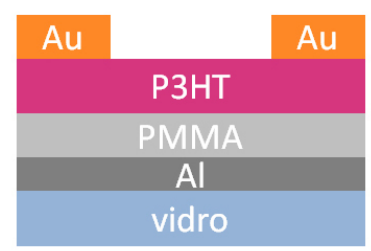

(a)

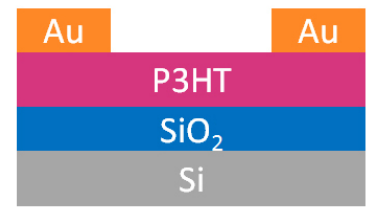

(b)

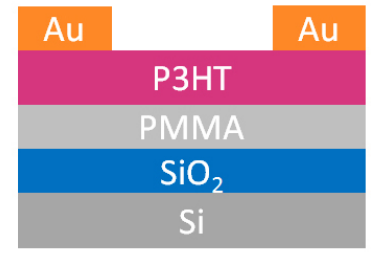

(c)

Figura 3.2: Tipos de OFETs preparados.

O primeiro tipo de OFET, com eletrodo de porta de alumínio sobre substrato de vidro e PMMA (Figura 3.3) como isolante (Figura 3.2a), foi preparado de acordo com procedimentos estabelecidos e aprimorados em trabalhos anteriores, porém seu uso como amostra para espectroscopia SFG se mostrou impraticável devido ao grande dano causado pelos feixes laser nos exemplares analisados. Em seguida foram utilizados substratos de silício dopado recobertos com óxido isolante (Figura $3.2 \mathrm{~b}$ ), que demonstrou baixa performance elétrica devido a alta corrente de fuga. Para obter melhor desempenho elétrico nos dispositivos, foi produzido o terceiro tipo de amostras, aplicando uma camada de PMMA como isolante elétrico adicional (Figura 3.2c).

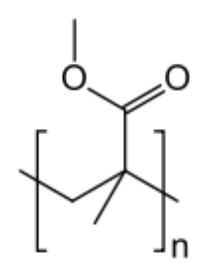

Figura 3.3: Estrutura química do PMMA (poli-metil-metacrilato). 
Em todas as amostras preparadas o polímero semicondutor utilizado foi o P3HT (poli-3-hexiltiofeno) comercial (Sigma-Aldrich), grau eletrônico, pureza 99,99\%, massa molecular média $\mathrm{M}_{n}$ entre 15 e $45 \mathrm{kDa}$ e 95\% regiorregular. Nas amostras contendo camada de PMMA (poli-metil-metacrilato) foi utilizado o polímero comercial (Sigma-Aldrich) de massa molecular média 120 kDa, pureza 99

Todos os filmes depositados por spin-casting foram preparados em glove-box, sob atmosfera de $\mathrm{N}_{2}$, assim como todos os tratamentos térmicos e a deposição de filmes metálicos. Algumas amostras foram fabricadas com filmes Langmuir-Schaefer. Neste método, uma solução do polímero é espalhada na cuba de Langmuir sobre uma subfase líquida. A monocamada é mantida a uma determinada pressão e uma face do substrato é colocada em contato com a superfície, transferindo a camada ordenada de polímero (Figura 3.4). Estes filmes foram preparados em uma cuba KSV 5000 em sala limpa classe 10000 com temperatura interna constante de $22^{\circ} \mathrm{C}$.

(a)

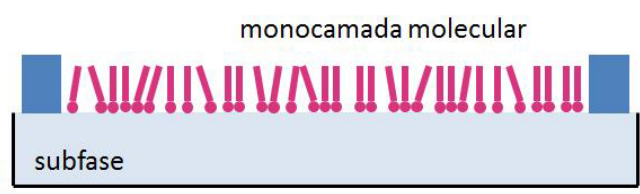

(c)

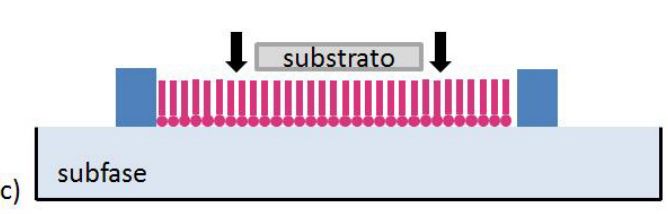

(b)

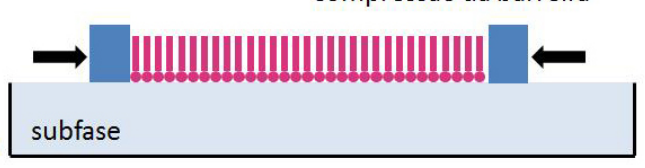

Figura 3.4: Preparação dos filmes Langmuir-Schaefer.

A espessura dos filmes foi determinada utilizando um perfilômetro Veeco Dektak 150.

Foram utilizados dois tipos de substrato de silício para a construção de dispositivos, com 90 $\mathrm{nm}$ ou $300 \mathrm{~nm}$ de espessura do recobrimento de $\mathrm{SiO}_{2}$. As lâminas com $90 \mathrm{~nm}$ de óxido (produzido por oxidação seca) tinham espessura $525 \mu \mathrm{m}$, dopagem tipo p, resistividade $10 \mathrm{ohm} \mathrm{cm}$ e foram adquiridas da Microchemicals Gmbh. As demais lâminas eram de espessura $375 \mu \mathrm{m}$, dopagem tipo p, resistividade $0,01 \mathrm{ohm} \mathrm{cm}$ e a camada de $300 \mathrm{~nm}$ de óxido foi preparada por oxidação seca no Laboratório de Microeletrônica da Escola Politécnica da USP. 


\section{OFETs vidro/PMMA/P3HT}

O primeiro tipo de dispositivo foi preparado em substrato de vidro com PMMA como dielétrico, e os eletrodos de dreno e fonte (em ouro) e de porta (em alumínio) foram depositados por evaporação. As máscaras utilizadas para a evaporação dos filmes metálicos são apresentadas na Figura 3.5. Como é possível observar, cada amostra contém 9 OFETs, com diferentes dimensões, que são apresentadas na Tabela 3.1.

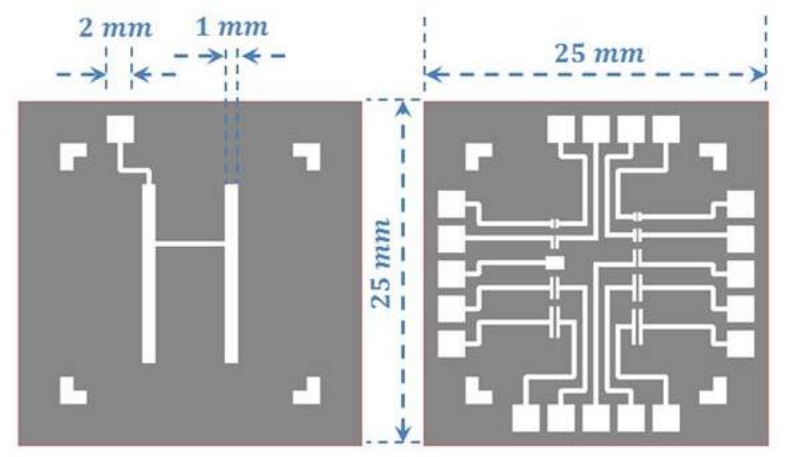

(a) (b)

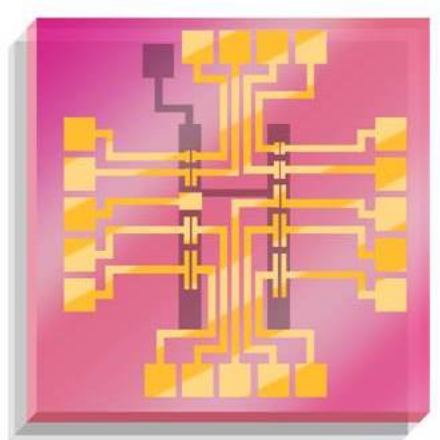

(c)

Figura 3.5: Estrutura de construção dos OFETs vidro/PMMA/P3HT: (a) máscara de evaporação do eletrodo de porta, (b) máscara de evaporação dos eletrodos de dreno e fonte e (c) aspecto do dispositivo final.

\begin{tabular}{lll}
\hline OFET & $\mathbf{W}(\mathbf{m m})$ & $\mathbf{L}(\mu \mathbf{m})$ \\
\hline T1 & 0,66 & 50 \\
T2 & 0,66 & 50 \\
T3 & 1 & 75 \\
T4 & 1 & 75 \\
T5 & 1,33 & 100 \\
T6 & 1,66 & 125 \\
T7 & 2 & 150 \\
T8 & 2,33 & 175 \\
T9 & 2,66 & 200 \\
\hline
\end{tabular}

Tabela 3.1: Dimensões dos dispositivos vidro/PMMA/P3HT, onde W é o comprimento e L é a largura do canal.

O dispositivo foi preparado inicialmente depositando alumínio como eletrodo de porta por evaporação térmica a vácuo (70 $\mathrm{nm}$ a uma taxa de $1 \AA / \mathrm{s})$ sobre lâminas de vidro. A limpeza das lâminas foi feita primeiramente de forma mecânica, com uma esponja, água e sabão. As lâminas foram colocadas em seguida em um banho em fervura de água e detergente Merck Extran ${ }^{\circledR}$. Após 
alguns minutos as lâminas foram enxaguadas em água Milli- ${ }^{\circledR}$. Por fim, as lâminas foram limpas em acetona e em seguida em isopropanol em fervura.

O dielétrico foi obtido depositando PMMA em MEK (metil-etil cetona) (40 mg/mL) por spincasting sobre o alumínio (800 rpm, 60 segundos). Os filmes de PMMA foram submetidos a tratamento térmico a $100^{\circ} \mathrm{C}$ por 15 minutos. Em seguida foi depositado a camada semicondutora utilizando P3HT em tetralina $(15 \mathrm{mg} / \mathrm{mL}$ ) também por spin-casting (o processo teve a velocidade gradualmente acelerada em três passos; passo 1: $400 \mathrm{rpm}, 120$ segundos; passo 2: $2000 \mathrm{rpm}, 150$ segundos; passo 3: 7000 rpm, 20 segundos). Após a formação dos filmes as amostras passaram por tratamento térmico a $120^{\circ} \mathrm{C}$ por 15 minutos. Os contatos de dreno e fonte foram obtidos depositando ouro por evaporação térmica (50 nm a uma taxa de $1 \AA / \mathrm{s}$ ) sobre o filme de P3HT.

\section{OFETs $\mathrm{Si} / \mathrm{SiO}_{2} / \mathrm{P} 3 \mathrm{HT}$}

Neste tipo de dispositivo, os substratos de silício dopado atuam como contato de porta e os eletrodos de dreno e fonte são depositados por evaporação. A máscara utilizada para a evaporação dos contatos de ouro resulta em 6 OFETs por amostra (Figura 3.6), com diferentes larguras de canal, que são especificadas na Tabela 3.2.

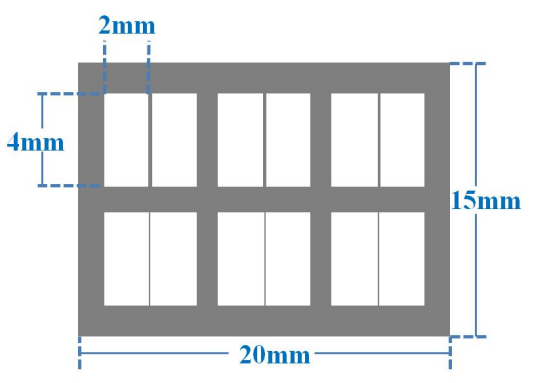

(a)

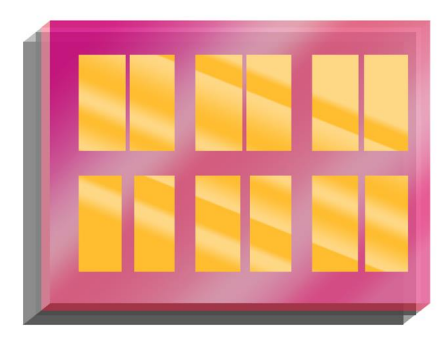

(b)

Figura 3.6: OFETs construídos em substrato de silício, (a) máscara de evaporação dos eletrodos dreno e fonte e (b) aspecto final dos dispositivos.

Os substratos foram limpos com solução Nochromix ${ }^{\circledR}$ (solução $9 \mathrm{~g} / \mathrm{L}$ de persulfato de amônio em ácido sulfúrico) e enxaguados em água Milli- $\mathrm{Q}^{\circledR}$. O óxido na superfície inferior dos substratos foi removido com solução BOE (Buffered Oxide Etch, HF concentrado tamponado em $\mathrm{NH}_{4} \mathrm{~F}$ na proporção 1:6) [45], e foi evaporado alumínio sobre a superfície livre do silício condutor para garantir um bom contato do terminal de porta.

Para a fabricação dos dispositivos, os substratos preparados foram limpos por plasma utilizando 


\begin{tabular}{lll}
\hline OFET & $\mathbf{W}(\mathbf{m m})$ & $\mathbf{L}(\mu \mathbf{m})$ \\
\hline $\mathrm{T} 1$ & 2 & 30 \\
$\mathrm{~T} 2$ & 2 & 40 \\
$\mathrm{~T} 3$ & 2 & 50 \\
$\mathrm{~T} 4$ & 2 & 60 \\
$\mathrm{~T} 5$ & 2 & 80 \\
$\mathrm{~T} 6$ & 2 & 100 \\
\hline
\end{tabular}

Tabela 3.2: Dimensões dos dispositivos construídos sobre substrato de silício, onde W é o comprimento e L é a largura do canal.

um sistema Plasma Etch Systems PE-25-JW, mantendo vazão de oxigênio para pressão de 250 mbar na câmara, por 10 minutos a uma potência de 40\%. Sobre a superfície de óxido de cada amostra foi depositada a camada de P3HT, e para isso foram utilizados dois procedimentos diferentes. Em parte das amostras o P3HT foi depositado via spin-casting a partir de uma solução em clorofórmio (15 mg/mL) com rotação $1000 \mathrm{rpm}$ por 60 segundos, e nas demais amostras foi depositado o filme Langmuir-Schaefer (P3HT-LS) espalhando uma solução em clorofórmio $(0,1 \mathrm{mg} / \mathrm{mL})$ na cuba e acumulando seis camadas sobre os substratos, mantendo pressão na superfície de $30 \mathrm{mN} / \mathrm{m}$. Os filmes preparados por spin-casting passaram por tratamento térmico a $120^{\circ} \mathrm{C}$ por 15 minutos. Os eletrodos de ouro como dreno e fonte foram depositados sobre o filme polimérico por evaporação a vácuo (50 nm a uma taxa de $1 \AA / \mathrm{s}$ ).

\section{OFETs $\mathrm{Si} / \mathrm{SiO}_{2} / \mathrm{PMMA} / \mathrm{P} 3 \mathrm{HT}$}

Os substratos foram preparados da mesma forma que os dispositivos $\mathrm{Si} / \mathrm{SiO}_{2} / \mathrm{P} 3 \mathrm{HT}$, removendo o óxido na face inferior e evaporando contatos de alumínio sobre o silício livre. Após a preparação e limpeza dos substratos, foi depositado um filme de PMMA sobre o $\mathrm{SiO}_{2}$ para reforçar a resistência do dielétrico e diminuir a corrente de fuga. Os filmes de PMMA foram preparados por spin-casting (800 rpm, 60 segundos) a partir de uma solução $30 \mathrm{mg} / \mathrm{mL}$ em MEK (metil-etil cetona). Os filmes foram submetidos a tratamento térmico por 10 minutos a $100^{\circ} \mathrm{C}$. Em seguida depositou-se o filme de P3HT. Também foram utilizados dois procedimentos diferentes para a preparação dos filmes de P3HT sobre PMMA. Os filmes via spin-casting foram depositados a partir de uma solução em tetralina de concentração $8 \mathrm{mg} / \mathrm{mL}$, com a rotação do processo gradualmente aumentada (passo 1: $800 \mathrm{rpm}, 60$ segundos; passo 2: $2000 \mathrm{rpm}, 150$ segundos; passo 3: $7000 \mathrm{rpm}, 20$ segundos) e os filmes Langmuir-Schaefer (P3HT-LS) foram preparados depositando seis camadas sobre os 
substratos, mantendo presão na superfície de $30 \mathrm{mN} / \mathrm{m}$ a partir de uma solução em clorofórmio (0,1 mg/mL) espalhada na cuba. Nas amostras com filmes de P3HT depositados por spin-casting foi realizado tratamento térmico a $120^{\circ} \mathrm{C}$ por 15 minutos. Sobre os filmes foram depositados os eletrodos de ouro por evaporação a vácuo (50 nm a uma taxa de $1 \AA / \mathrm{s}$ ).

\section{Caracterização elétrica}

As medidas elétricas dos dispositivos vidro/PMMA/P3HT foram realizadas utilizando um eletrômetro Keithley ${ }^{\circledR} 238$ como fonte e sistema de medida entre os eletrodos dreno e fonte, e um Keithley ${ }^{\circledR} 237$ entre fonte e porta.

Os demais dispositivos foram submetidos a medidas elétricas utilizando um sistema de caracterização de semicondutores Keithley ${ }^{\circledR}$ modelo 4200-SCS.

\section{Espectroscopia de absorção óptica}

Os espectros de absorção óptica foram obtidos utilizando um espectrofotômetro Hitachi U-2900. Foram feitas varreduras de 300 a $700 \mathrm{~nm}$ a uma velocidade de $400 \mathrm{~nm}$ por minuto, com abertura de 1,5 nm na fenda do monocromador. Os filmes de P3HT foram depositados sobre filmes de PMMA sobre substratos de vidro e as medidas foram feitas em transmissão, utilizando o espectro de uma amostra de filme de PMMA sobre vidro como linha de base.

\section{Espectroscopia Infravermelho por Transformada de Fourrier (FTIR)}

As medidas espectroscópicas vibracionais no infravermelho foram obtidas em um aparelho Thermo Nicolet Nexus 470 FTIR. Foram feitas 132 aquisições para cada espectro, abrangendo toda a faixa do infravermelho médio com resolução de $4 \mathrm{~cm}^{-1}$.

Os espectros foram obtidos de filme de P3HT depositado a partir de solução em clorofórmio seco sobre uma janela de $\mathrm{NaCl}$, utilizando a mesma região e orientação da qual se obteve a medida de linha de base previamente.

\subsection{Espectroscopia SHG e SFG}

As medidas SHG e SFG foram realizadas no LENI - Laboratório de Espectroscopia Não-linear de Interfaces do Instituto de Física de São Carlos da USP. O aparato experimental está esquematizado 
na Figura 3.7. Um laser Nd:YAG ( $\operatorname{com} \lambda=1064 \mathrm{~nm})$ gera pulsos de aproximadamente 30 ps por mode-locking ativo e passivo, com taxa de repetição de $20 \mathrm{~Hz}$. O feixe pulsado pode ser direcionado para a realização de medidas SFG ou SHG.

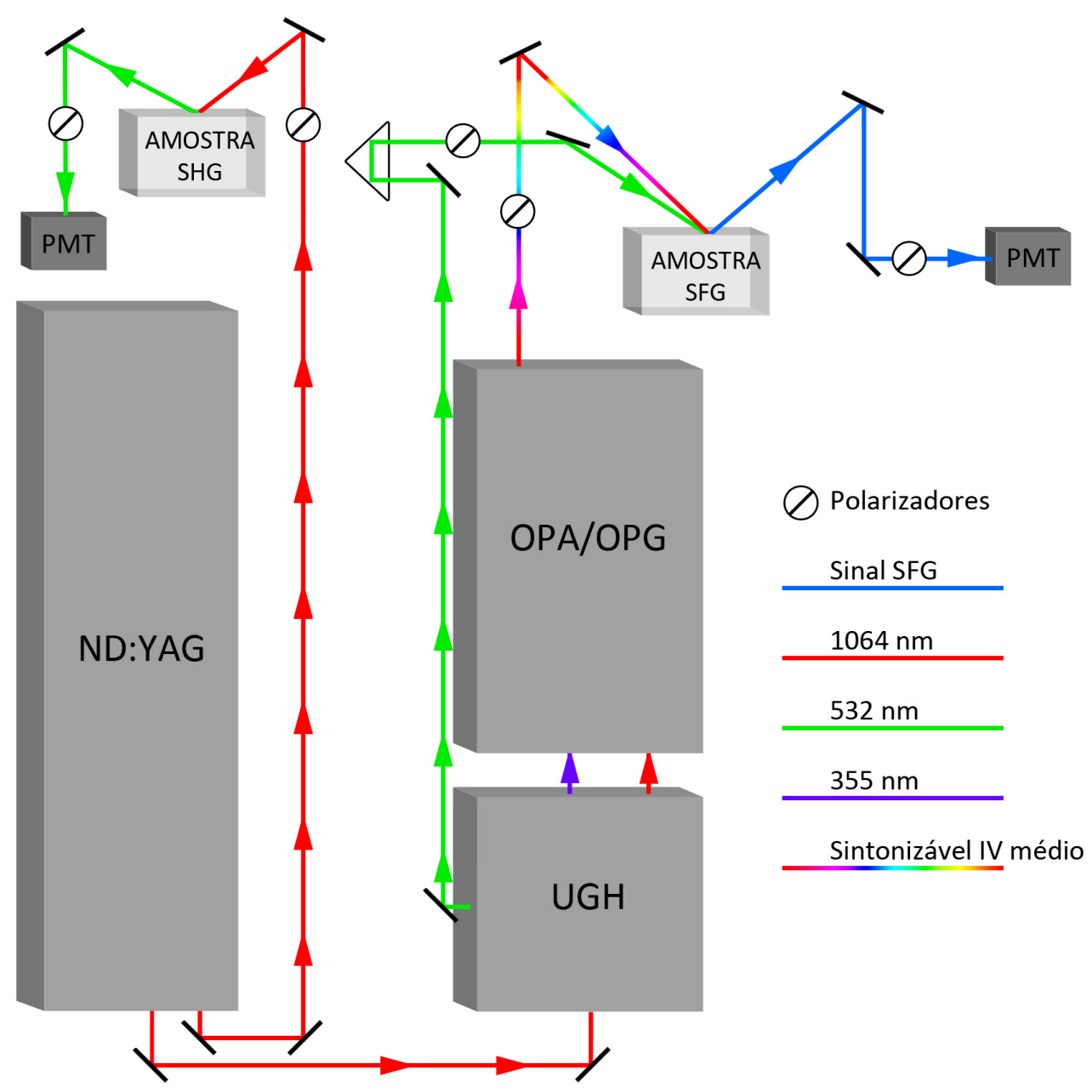

Figura 3.7: Aparato experimental para medidas de espectroscopia não-linear.

Para a realização de medidas SHG detecta-se o sinal com comprimento de onda de $532 \mathrm{~nm}$ emitido pela amostra ao incidir o feixe fundamental de $1064 \mathrm{~nm}$. Pode-se ajustar a polarização do feixe de excitação e também do sinal gerado, que podem ser $s$ (perpendicular ao plano de incidência) ou $p$ (paralelo). O ângulo de incidência do feixe infravermelho é de cerca de $60^{\circ}$ em relação ao eixo normal. Para a espectroscopia SFG, obtém-se o feixe sintonizável no infravermelho médio por meio de vários processos em cristais não-lineares. A partir do feixe proveniente do laser, uma unidade geradora de harmônicos produz um feixe com a frequência original no infravermelho próximo (1064 nm) e seu terceiro harmônico (355 nm). Estes feixes são combinados em seguida 
por geração/amplificação paramétrica óptica (OPG/OPA) e geração por diferença de frequências (DFG), que permitem obter um feixe de saída que pode ser variado desde a região do visível até $10 \mu \mathrm{m}$. Este feixe incide sobre a amostra juntamente com uma parte do feixe visível (532 nm) gerado na UGH (unidade geradora de harmônicos), com sobreposição espacial e temporal (ajustada por uma linha de atraso). Ambos os feixes podem ter a polarização ajustada para $s$ (perpendicular ao plano de incidência) ou $p$ (paralela ao plano de incidência), assim como o sinal gerado, cuja frequência é a soma das frequências dos feixes incidentes. Os ângulos de incidência são de $65^{\circ}$ para o visível e $55^{\circ}$ para o infravermelho. A detecção é feita por fotomultiplicadoras após filtros espectrais para eliminar o feixe visível espalhado pela amostra, e um monocromador sintonizado para detectar o sinal SFG.

Cada espectro é obtido traçando a média de 100 aquisições por ponto a uma variação de 3 $\mathrm{cm}^{-1}$ da frequência do infravermelho. As medidas de intensidade em cada ponto são normalizadas dividindo os valores pelas respectivas energias dos feixes incidentes e o espectro obtido é então normalizado pela medida em uma amostra de referência, neutralizando efeitos de alinhamento e sobreposição dos feixes. Nos experimentos abordados neste trabalho foi utilizado um filme de sulfeto de zinco como amostra de referência, que apresenta $\chi^{(2)}$ não ressonante conhecido.

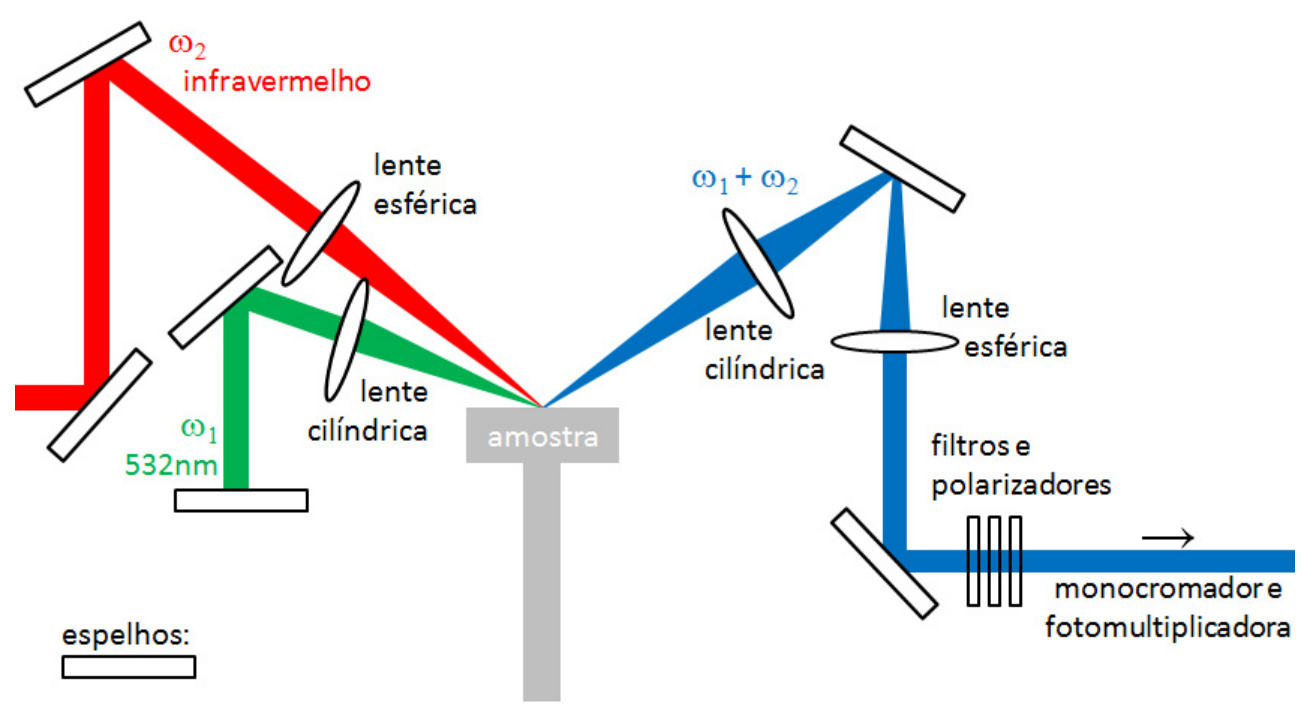

Figura 3.8: Diagrama da estação de medida para espectroscopia SFG.

Para as medidas espectroscópicas em transistores a estação de medida (Figura 3.8) foi modificada para incluir uma lente cilíndrica ( com distância focal $\mathrm{f}=15 \mathrm{~cm}$ ) que focaliza horizontalmente o feixe 
visível, fazendo com que incida exatamente sobre o canal do dispositivo sem atingir uma grande área dos eletrodos de ouro. Dessa forma o sinal detectado é otimizado, reduzindo o sinal não-ressonante intenso proveniente do metal e concentrando a energia do feixe na região de interesse. Uma vez que o canal do transistor é estreito (da ordem de dezenas de micrômetros), o sinal gerado sofre difração, e para contornar este problema e direcionar o sinal para o detector, utilizou-se outra lente cilíndrica $(\mathrm{f}=15 \mathrm{~cm})$ e uma lente esférica $(\mathrm{f}=35 \mathrm{~cm})$ no caminho óptico entre a amostra e a fotomultiplicadora.

As energias dos feixes utilizados nos experimentos foram atenuadas de forma que permitissem obter uma boa relação sinal/ruído sem causar danos nas amostras. Os experimentos SHG foram realizados com cerca de $30 \mu \mathrm{J}$ para feixe de excitação de $1064 \mathrm{~nm}$. Os experimentos SFG tiveram o limiar de dano avaliado a cada alteração do aparato, mas valores típicos de energia utilizados foram de $8 \mu \mathrm{J}$ para o visível (532 nm) e $150 \mu \mathrm{J}$ para o infravermelho médio.

As medidas foram realizadas em um porta amostra específico, que foi planejado de acordo com as necessidades do projeto e confeccionado na oficina mecânica do Instituto de Física de São Carlos. A Figura 3.9 ilustra alguns dos desenhos que constituem o projeto do porta-amostra. A versão final deste é apresentada na Figura 3.10.

O porta amostras foi projetado de forma com que fosse possível conectar os contatos elétricos, incluindo uma base de cobre para contato de porta, dentro de uma câmara fechada em atmosfera inerte ou vácuo. Para não bloquear o caminho óptico dos feixes de prova para as medidas espectroscópicas, o aparato permite que as amostras sejam posicionadas próximas à tampa, que possui uma janela de fluoreto de cálcio, que é transparente aos comprimentos de onda utilizados nos experimentos. 


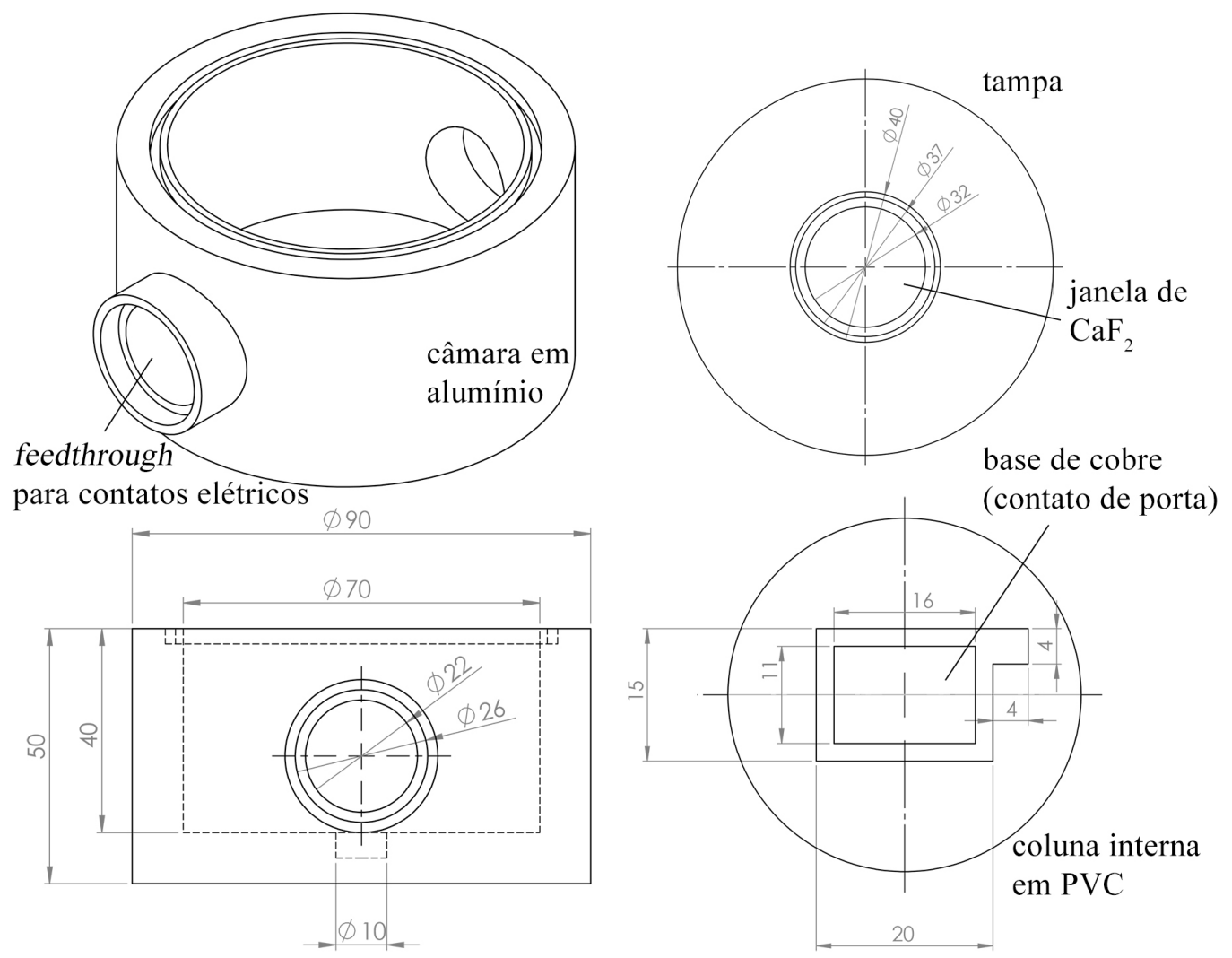

Figura 3.9: Alguns desenhos do projeto da câmara para amostras, desenhado no SolidWorks ${ }^{\circledR}$. Dimensões em milímetros.

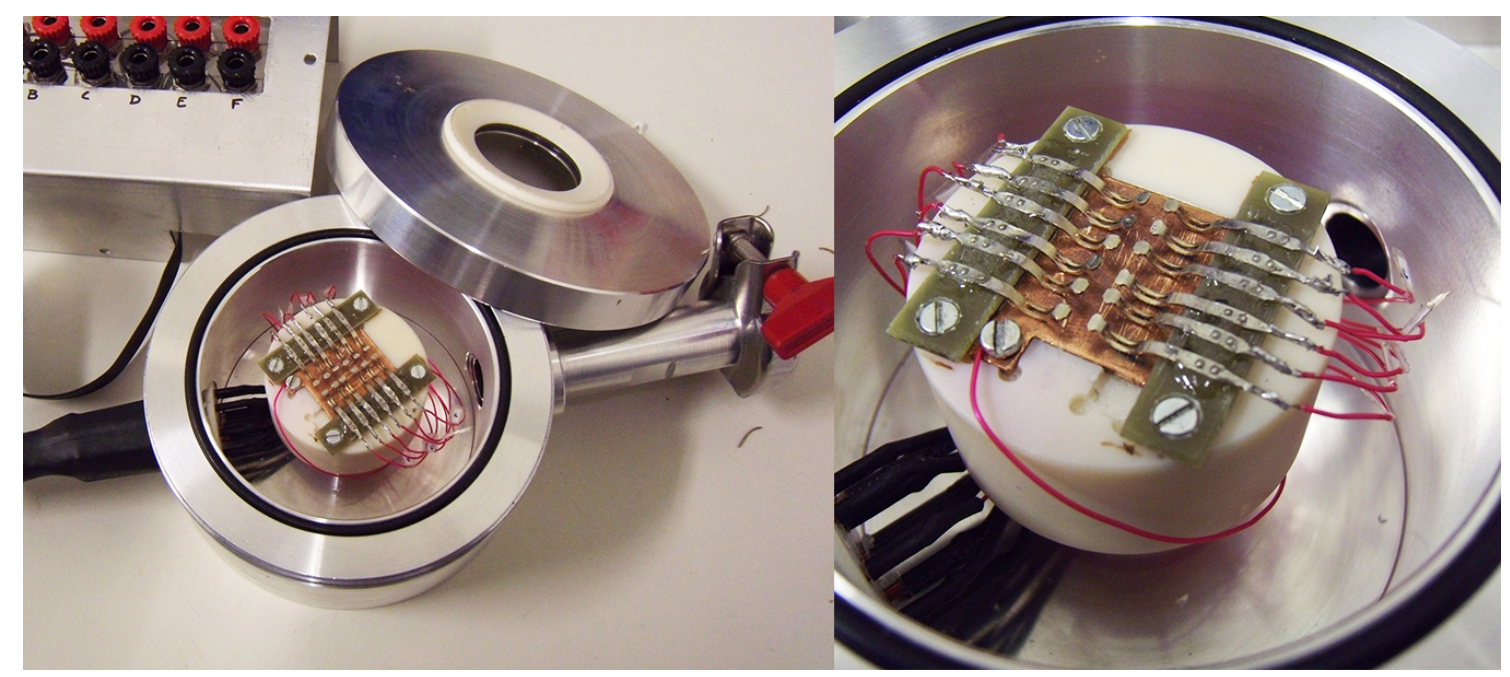

Figura 3.10: Câmara com suporte para amostras projetada para realização de medidas elétricas e espectroscópicas. 


\section{Resultados e discussão}

Este Capítulo apresentará os resultados obtidos conforme o desenvolvimento da metodologia experimental e a otimização dos processos e aparatos utilizados. Primeiramente serão apresentados dados importantes obtidos a fim de caracterizar os materiais utilizados. Em seguida serão discutidos os espectros SFG de filmes de P3HT sobre os substratos utilizados na fabricação dos dispositivos.

Os resultados dos estudos em OFETs serão divididos conforme sua construção, sendo apresentados primeiramente os dispositivos vidro/PMMA/P3HT, e em seguida os dispositivos $\mathrm{Si} / \mathrm{SiO}_{2} / \mathrm{P} 3 \mathrm{HT}$. Uma vez que os OFETs em substrato de silício apresentaram alta corrente de fuga, foram preparados também amostras com filme de PMMA sobre a camada de óxido, que serão discutidos em seguida.

Por fim, serão apresentadas algumas análises realizadas relativas à degradação e perda de performance elétrica dos dispositivos.

\subsection{Caracterizações preliminares}

\section{Espectroscopia de absorção óptica}

Foram obtidos espectros de absorção óptica de filme de P3HT preparados por spin-casting. A Figura 4.1 apresenta a curva de absorção do P3HT.

O ombro observado em cerca de $620 \mathrm{~nm}$ pode ser atribuído à banda característica da absorção do complexo formado pelo polímero em contato com oxigênio [46].

Tanto o comprimento de onda do feixe visível de excitação do aparato de espectroscopia SFG $(532 \mathrm{~nm})$ quanto a faixa de frequências do sinal soma gerado (na região do azul, em torno de 500 nm) estão na banda de absorção do polímero. A primeira consequência deste fato é a suscetibilidade do P3HT à degradação pela incidência do feixe visível. É de grande importância avaliar o limiar de dano do experimento SFG e determinar a atenuação do feixe de excitação em $532 \mathrm{~nm}$ que permita 


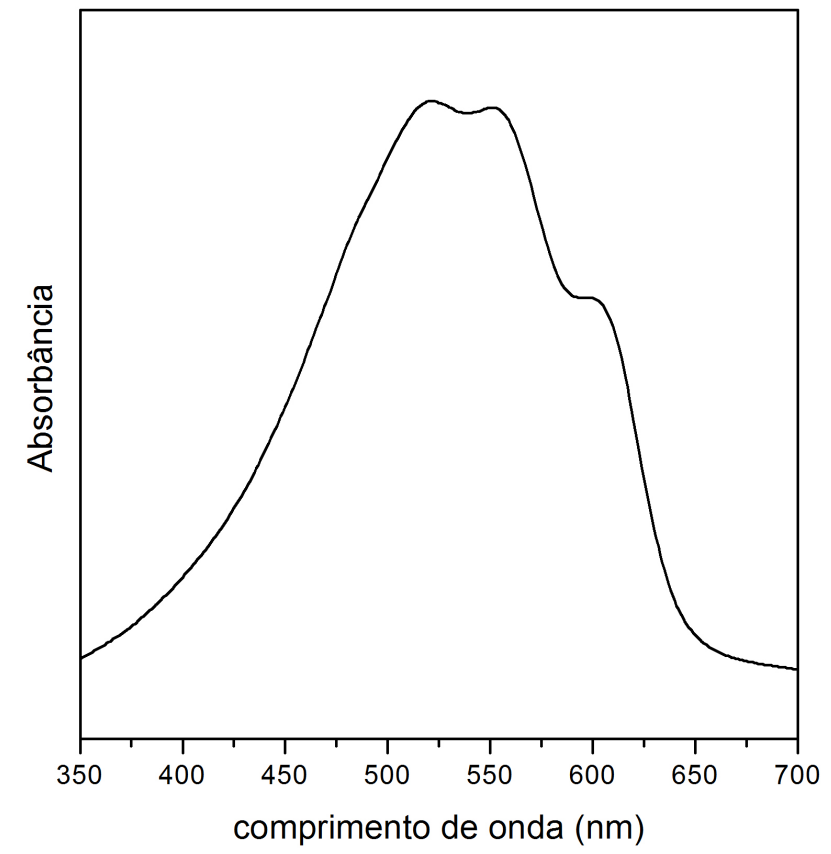

Figura 4.1: Espectro de absorção óptica do P3HT.

obter um bom sinal sem danificar as amostras. Por outro lado, a ressonância dos feixes de excitação e do sinal SFG também implica em um aumento considerável no sinal SFG gerado.

No sistema abordado neste projeto, o espectro de absorção óptica do P3HT apresenta ainda um outro contratempo, que é a supressão do sinal soma gerado na interface inferior (P3HT-dielétrico) devido à perda por absorção no volume do filme. Um recurso para eliminar esse problema seria a incidência dos feixes de prova através da camada isolante do dispositivo, de forma que a interface superior seria a interface de interesse, onde ocorre a formação do canal. Para isso, entretanto, seria necessário que as camadas que estivessem sobre o semicondutor (dielétrico, eletrodo de porta e substrato) fossem compostas por materiais transparentes para as faixas de frequência utilizadas no experimento.

Optou-se por realizar os experimentos com o filme de P3HT na parte superior da amostra, com a formação do canal na interface inferior e incidindo os feixes de prova na interface externa, desde que a supressão do sinal no volume do filme não inviabilizasse a obtenção dos espectros.

Foram então preparados filmes de P3HT utilizando diferentes parâmetros, com o propósito de comparar a absorção de filmes com diferentes espessuras. A Tabela 4.1 apresenta os parâmetros de deposição utilizados e a espessura resultante. Todos os filmes foram preparados a partir de soluções em tetralina, sobre filmes de PMMA em substrato de vidro, variando a velocidade de rotação (em 
rotações por minuto) e tempo em rotação (em segundos). A velocidade de rotação foi aumentada gradativamente, executando três passos em sequência e sem intervalo após a aplicação da solução sobre o substrato.

\begin{tabular}{lll}
\hline concentração & parâmetros de spin-casting & espessura \\
\hline $15 \mathrm{mg} / \mathrm{mL}$ & $300 \mathrm{rpm}, 120 \mathrm{~s} ; 1000 \mathrm{rpm}, 150 \mathrm{~s} ; 7000 \mathrm{rpm}, 20 \mathrm{~s}$ & $140 \mathrm{~nm}$ \\
$15 \mathrm{mg} / \mathrm{mL}$ & $400 \mathrm{rpm}, 120 \mathrm{~s} ; 1800 \mathrm{rpm}, 150 \mathrm{~s} ; 7000 \mathrm{rpm}, 20 \mathrm{~s}$ & $130 \mathrm{~nm}$ \\
$15 \mathrm{mg} / \mathrm{mL}$ & $400 \mathrm{rpm}, 120 \mathrm{~s} ; 1000 \mathrm{rpm}, 150 \mathrm{~s} ; 7000 \mathrm{rpm}, 20 \mathrm{~s}$ & $90 \mathrm{~nm}$ \\
$15 \mathrm{mg} / \mathrm{mL}$ & $400 \mathrm{rpm}, 120 \mathrm{~s} ; 2000 \mathrm{rpm}, 150 \mathrm{~s} ; 7000 \mathrm{rpm}, 20 \mathrm{~s}$ & $70 \mathrm{~nm}$ \\
$8 \mathrm{mg} / \mathrm{mL}$ & $500 \mathrm{rpm}, 60 \mathrm{~s} ; 2000 \mathrm{rpm}, 150 \mathrm{~s} ; 7000 \mathrm{rpm}, 20 \mathrm{~s}$ & $40 \mathrm{~nm}$ \\
\hline
\end{tabular}

Tabela 4.1: Varição de parâmetros para obtenção de diferentes espessuras de filme de P3HT.

A Figura 4.2 apresenta as curvas de absorção obtidas dos filmes com espessuras diferentes. Observou-se que os filmes mais finos atenuam apenas cerca de $30 \%$ da radiação no comprimento de onda do sinal SFG. Foram realizados testes SFG e decidiu-de realizar as medidas com filmes de P3HT com cerca de de $50 \mathrm{~nm}$ de espessura, sabendo que os espectros SFG obtidos terão contribuição considerável da interface superior (ar-P3HT).
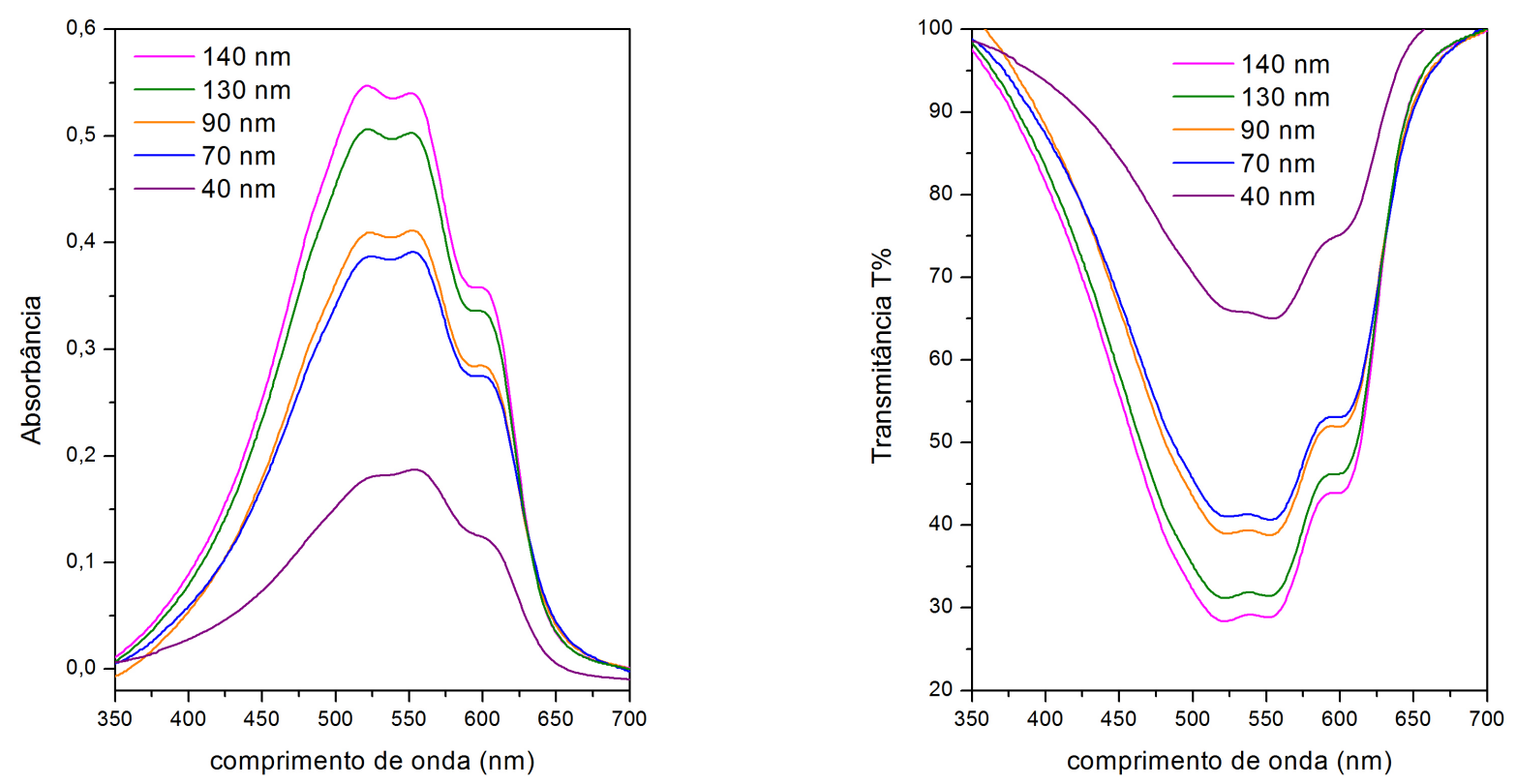

Figura 4.2: Espectros de absorção óptica de filmes de P3HT com espessuras variadas. 


\section{Espectroscopia vibracional}

A Figura 4.3 apresenta o espectro infravermelho do P3HT, juntamente com a nomenclatura dos átomos de carbono do anel tiofênico.

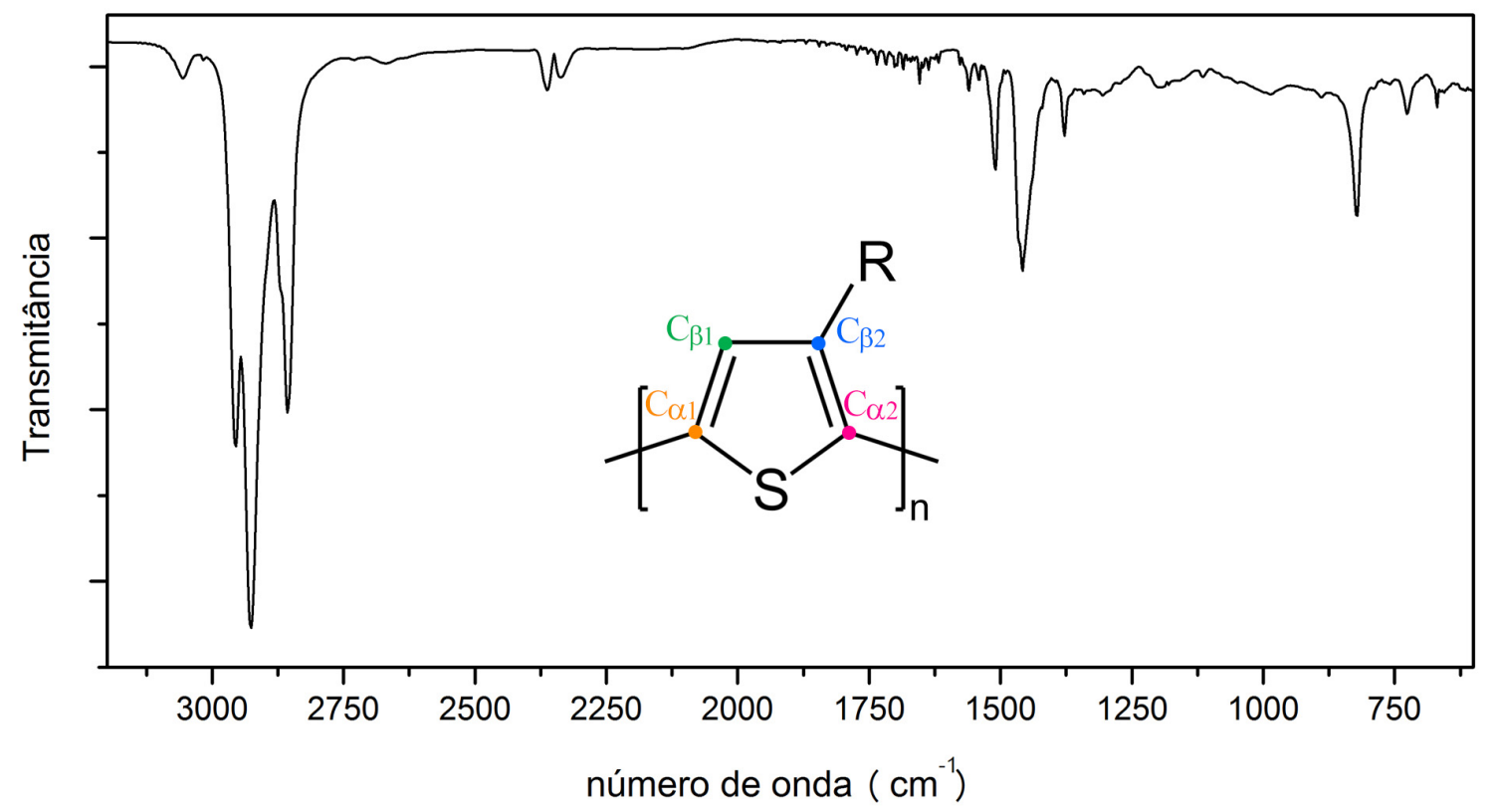

Figura 4.3: Espectro FTIR do P3HT.

As bandas observadas foram caracterizadas de acordo com dados da literatura[47, 48], e os modos vibracionais foram atribuídos como se segue:

$\begin{array}{ll}725 \mathrm{~cm}^{-1} & \text { dobramento } \mathrm{C}-\mathrm{S}-\mathrm{C} \\ 821 \mathrm{~cm}^{-1} & \text { deformação } \mathrm{C}-\mathrm{H} \text { aromático fora do plano } \\ 1220 \mathrm{~cm}^{-1} & \text { estiramento } \mathrm{C}_{\alpha}-\mathrm{C}_{\alpha} \text { entre anéis } \\ 1378 \mathrm{~cm}^{-1} & \text { estiramento } \mathrm{C}_{\beta 1}-\mathrm{C}_{\beta 2} \\ 1457 \mathrm{~cm}^{-1} & \text { estiramento simétrico } \mathrm{C}_{\alpha 1}=\mathrm{C}_{\beta 1} \text { e } \mathrm{C}_{\alpha 2}=\mathrm{C}_{\beta 2} \\ 1457 \mathrm{~cm}^{-1} & \text { estiramento simétrico do anel (breathing) } \\ 1509 \mathrm{~cm}^{-1} & \text { estiramento assimétrico } \mathrm{C}_{\alpha 1}=\mathrm{C}_{\beta 1} \text { e } \mathrm{C}_{\alpha 2}=\mathrm{C}_{\beta 2} \\ 2856 \mathrm{~cm}^{-1} & \text { estiramento simétrico } \mathrm{CH}_{2} \\ 2926 \mathrm{~cm}^{-1} & \text { estiramento simétrico } \mathrm{CH}_{3}\end{array}$




$$
\begin{array}{ll}
2955 \mathrm{~cm}^{-1} & \text { estiramento assimétrico } \mathrm{CH}_{3} \\
3057 \mathrm{~cm}^{-1} & \text { estiramento } \mathrm{C}_{\beta 1}-\mathrm{H}
\end{array}
$$

Foram registrados diversos espectros FTIR da mesma amostra após exposta a luz, atmosfera, temperatura e umidade comuns do laboratório, a fim de avaliar a estabilidade do polímero em condições ambientes. Não foram observadas quaisquer alterações significativas nos espectros após 10 dias de exposição.

\section{Espectroscopia SFG em filmes de P3HT}

Como discutido na apresentação dos resultados de espectroscopia de absorção óptica, para a realização do experimento SFG em filmes de P3HT, foi necessário avaliar o limiar de dano e definir a energia máxima dos feixes incidentes. Essa avaliação foi feita mantendo a amostra exposta a cada um dos feixes individuais por vários minutos e repetindo diversas vezes as medidas para se certificar de que não havia alterações nas características do polímero. A cada adaptação do aparato que alterasse o foco dos feixes em relação à amostra, os limites de energia foram novamente estabelecidos.

Para obter espectros dos filmes fora do dispositivo, pôde-se utilizar feixes focalizados em diâmetros maiores e portanto menos atenuados. As energias típicas dos feixes utilizados para a obtenção dos espectros apresentados nessa seção estão em torno de $9 \mu \mathrm{J}$ para o feixe visível e $200 \mu \mathrm{J}$ para o infravermelho médio. As medidas foram feitas em atmosfera e temperatura ambiente.

Como descrito no Capítulo 3, cada espectro SFG é obtido medindo a intensidade do sinal ao longo da faixa de interesse com um passo de $3 \mathrm{~cm}^{-1}$. A intensidade registrada para cada ponto consiste na média da aquisição de 100 pulsos. Os dados obtidos são normalizados pelas energias de excitação do visível e do infravermelho médio, e o espectro resultante é ainda normalizado pela curva obtida na mesma faixa a partir de uma amostra de referência de sulfeto de zinco $(\mathrm{ZnS})$.

Os espectros SFG foram obtidos na região referente aos modos vibracionais do anel tiofênico, abrangendo a faixa de 1250 a $1550 \mathrm{~cm}^{-1}$. Foram coletadas medidas utilizando três conjuntos de polarização, sendo que a amostra não foi movida entre diferentes medidas, obtendo assim espectros de um mesmo ponto do filme polimérico.

A Figura 4.4 apresenta os espectros SFG de uma amostra de filme de P3HT de espessura em 


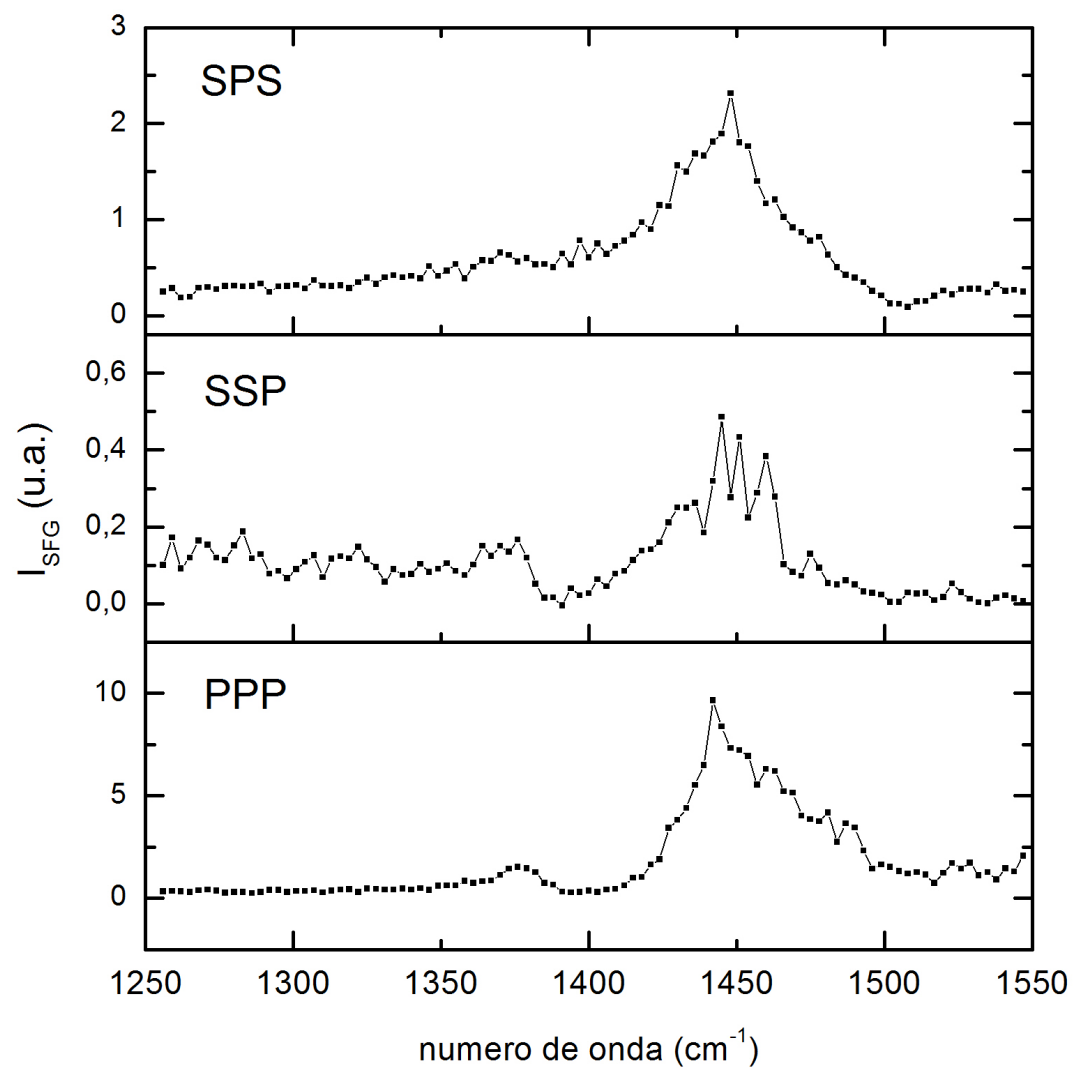

Figura 4.4: Espectros SFG de filme de P3HT sobre PMMA/vidro em três conjuntos de polarização.

torno de $100 \mathrm{~nm}$, depositado sobre filme de PMMA (cerca de $600 \mathrm{~nm}$ ) em substrato de vidro.

Foram preparados filmes de P3HT sobre substrato de silício com cobertura de $90 \mathrm{~nm}$ de $\mathrm{SiO}_{2}$. Os espectros SFG foram obtidos de amostras com tratamento térmico de 15 minutos a $120^{\circ} \mathrm{C}$, e sem tratamento térmico, e estão apresentados nas Figuras 4.5 e 4.6, respectivamente.

A Seção anterior apresentou a atribuição de bandas do espectro FTIR do P3HT. Como mostrado no Capítulo 2, os modos vibracionais visíveis nos espectros SFG devem ser ativos tanto em espectroscpia Raman como em FTIR. As bandas observadas nos espectros obtidos e apresentados nesta seção foram atribuídas de acordo com os dados da literatura [47-50].

A nomenclatura dos átomos de carbono do anel tiofênico é apresentada na Figura 4.3. A banda na região de $1380 \mathrm{~cm}^{-1}$ é atribuída ao estiramento $\mathrm{C}_{\beta 1}-\mathrm{C}_{\beta 2}$. A banda alargada na região de $1450 \mathrm{~cm}^{-1}$ corresponde à sobreposição dos seguintes modos vibracionais, ordenados por ordem crescente de frequência: estiramento simétrico $\mathrm{C}_{\alpha 1}=\mathrm{C}_{\beta 1}$ e $\mathrm{C}_{\alpha 2}=\mathrm{C}_{\beta 2}$, estiramento simétrico do anel, estiramento assimétrico $\mathrm{C}_{\alpha 1}=\mathrm{C}_{\beta 1}$ e $\mathrm{C}_{\alpha 2}=\mathrm{C}_{\beta 2}$. Este último pico interfere com os picos vizinhos e 


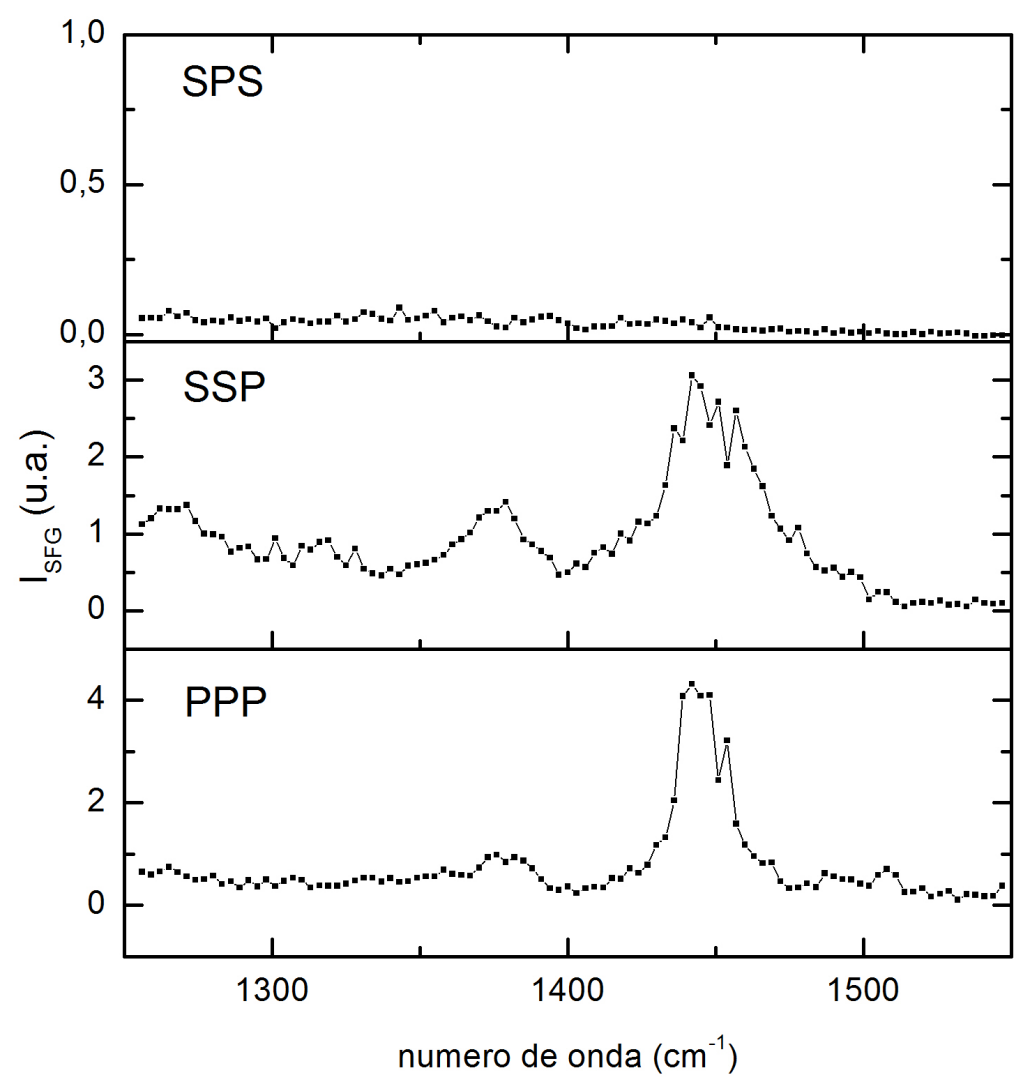

Figura 4.5: Espectros $\mathrm{SFG}$ de filme de $\mathrm{P} 3 \mathrm{HT}$ sobre $\mathrm{SiO}_{2} / \mathrm{Si}$ com tratamento térmico, em três conjuntos de polarização.

com $\chi_{N R}^{(2)}$, apresentando uma forma de linha que pode variar entre pico (como nos espectros $p p p$ nas Figuras 4.5 e 4.6) ou vale (espectro sps na Figra 4.4).

A diferença entre os espectros se deve a mudanças na ordenação e orientação das cadeias. A combinação de polarizações ssp obtém seletivamente os modos vibracionais com dipolos orientados ortogonais ao substrato, pois mede o tensor $\chi_{x x z}^{(2)}$. O conjunto sps, utilizando o feixe infravermelho com polarização $s$, permite obter os modos com os dipolos orientados paralelamente ao substrato, visto que mede $\chi_{x z x}^{(2)}$. Já o conjunto $p p p$ fornece a combinação de todas as contribuições de $\chi_{e f f}^{(2)}$.

$\mathrm{O}$ momento de dipolo do modo simétrico de vibração $\mathrm{C}=\mathrm{C}\left(\mu_{s}\right)$ no monômero de P3HT está no plano do anel. Observa-se na Figura 4.7 que na estrutura regioregular, as unidades se ordenam alternadamente, de forma que os dipolos se cancelariam na direção do eixo $a$. No entanto, os anéis não são paralelos. Com a organização das cadeias em lamelas, os anéis cujos dipolos estão orientados para uma mesma direção estão paralelos entre si. Por outro lado, devido ao ângulo 


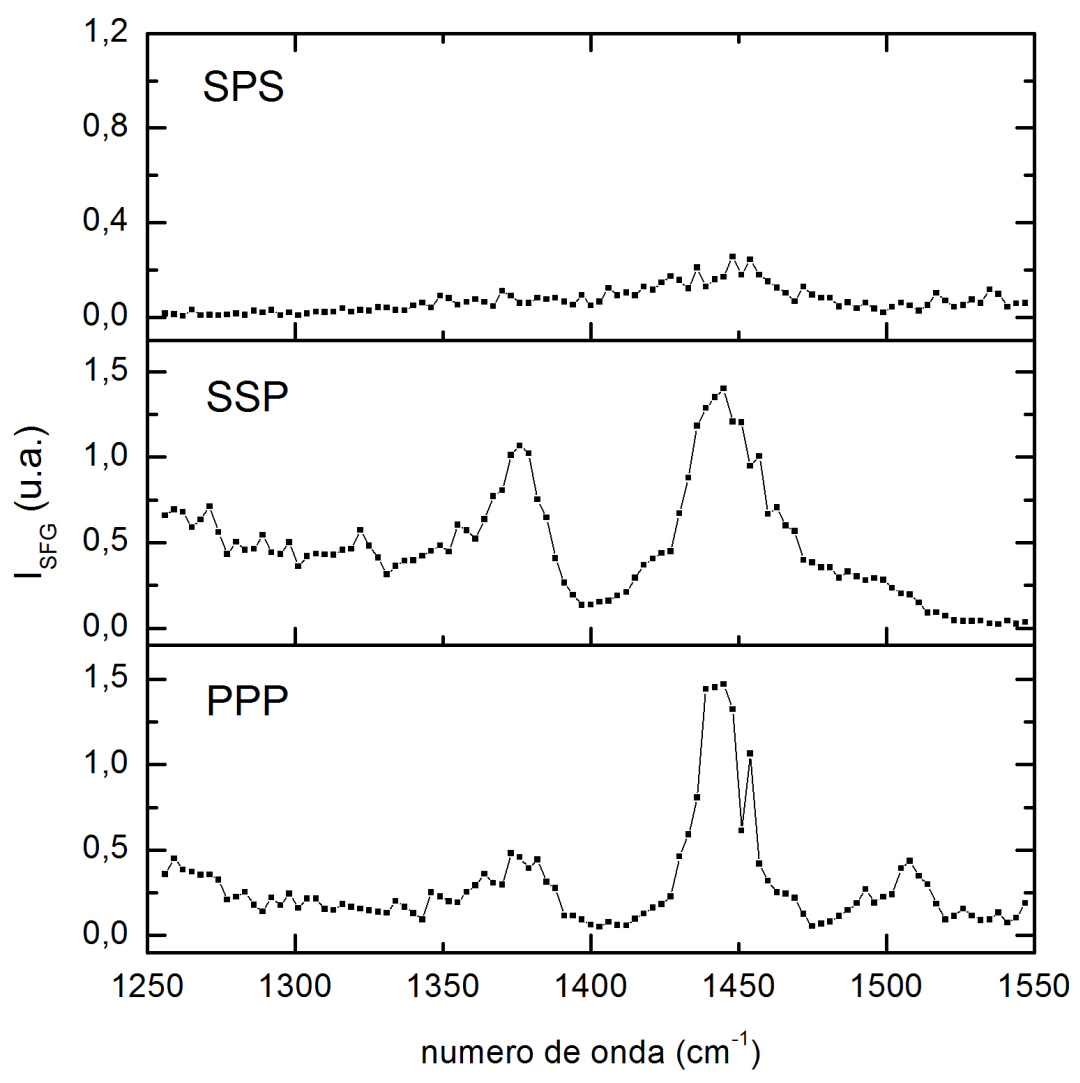

Figura 4.6: Espectros SFG de filme de P3HT sobre $\mathrm{SiO}_{2} / \mathrm{Si}$ sem tratamento térmico, em três conjuntos de polarização.

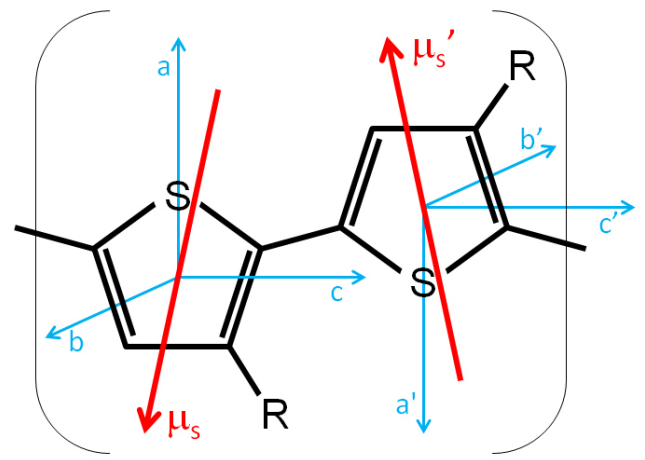

Figura 4.7: Momento de dipolo referente ao modo de estiramento simétrico $\mathrm{C}=\mathrm{C}$ em cada monômero do P3HT regioregular.

de torção diferente de $180^{\circ}$, os anéis de orientação opostas não são antiparalelos. Isto leva a um dipolo resultante aproximadamente ortogonal aos planos dos anéis (Figura 4.8). As diferenças de intensidade deste modo vibracional nos espectros SFG em diferentes polarizações permite analisar 


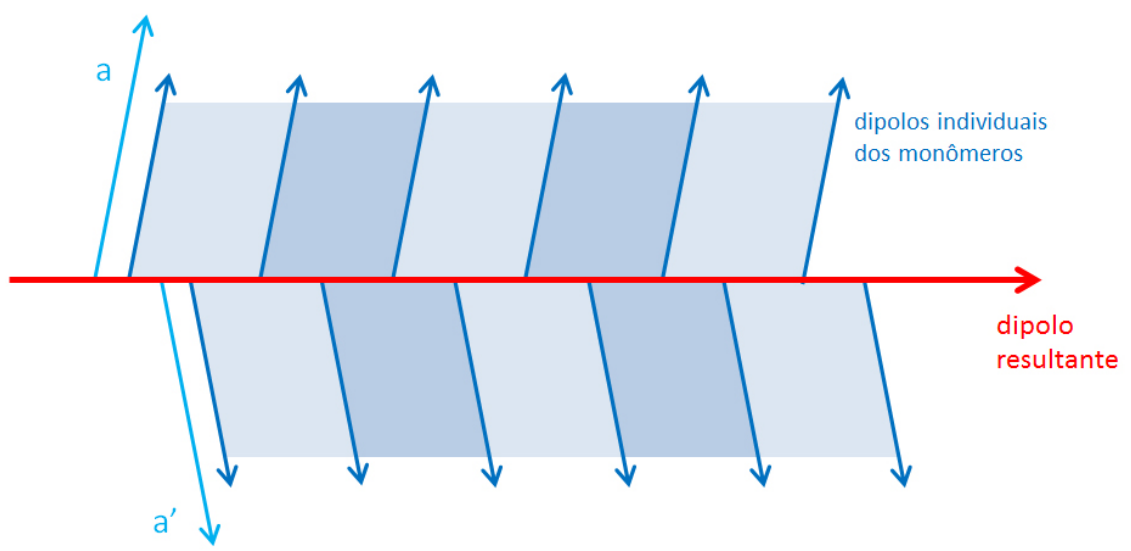

Figura 4.8: Organização das cadeias de P3HT em lamelas, com dipolo resultante aproximadamente perpendicular aos anéis.

a orientação média das cadeias.

Assim como observado por Anglin (2011), o espectro do P3HT sobre $\mathrm{SiO}_{2}$ em polarizações sps tem a intensidade das bandas quase nula, ao contrário do que acontece com filmes de P3HT sobre superfícies de menor energia (mais hidrofóbicas), como o PMMA. Visto que para o modo simétrico em torno de $1450 \mathrm{~cm}^{-1}$ o dipolo $\frac{\partial \vec{\mu}}{\partial Q}$ está praticamente perpendicular aos anéis tiofênicos, pode-se concluir que as cadeias de $\mathrm{P} 3 \mathrm{HT}$ sobre $\mathrm{SiO}_{2}$ são orientadas preferencialmente com os anéis mais paralelos à superfíce do substrato, e nos filmes sobre PMMA apresentam anéis mais inclinados perpendicularmente ao substrato, o que deve favorecer a mobilidade de carga entre cadeias [33]. Maiores detalhes sobre uma análise quali e quantitativa da orientação das cadeias podem ser encontrados no trabalho de Maia [51].

É possível notar ainda a maior intensidade do sinal nos filmes de P3HT sobre $\mathrm{SiO}_{2}$ que foram submetidos a tratamento térmico, em razão do maior ordenamento médio das cadeias. O decréscimo de sinal na polarização sps após o tratamento térmico também indica favorecimento da orientação preferencial com maior organização.

Outro tipo de filme de P3HT que foi estudado são os filmes Langmuir-Schaefer. Esse método de preparação resulta em filmes altamente ordenados, o que resulta em alta intensidade de sinal SFG.

A Figura 4.9 apresenta a comparação de espectros obtidos a partir de diferentes amostras com filmes de P3HT, sendo uma delas preparadas com filme Langmuir-Schaefer (P3HT-LS) e a outra pelo procedimento spin-casting, ambas sem tratamento térmico. Pode-se observar claramente a diferença de intensidade entre os filmes preparados pelos diferentes métodos. 


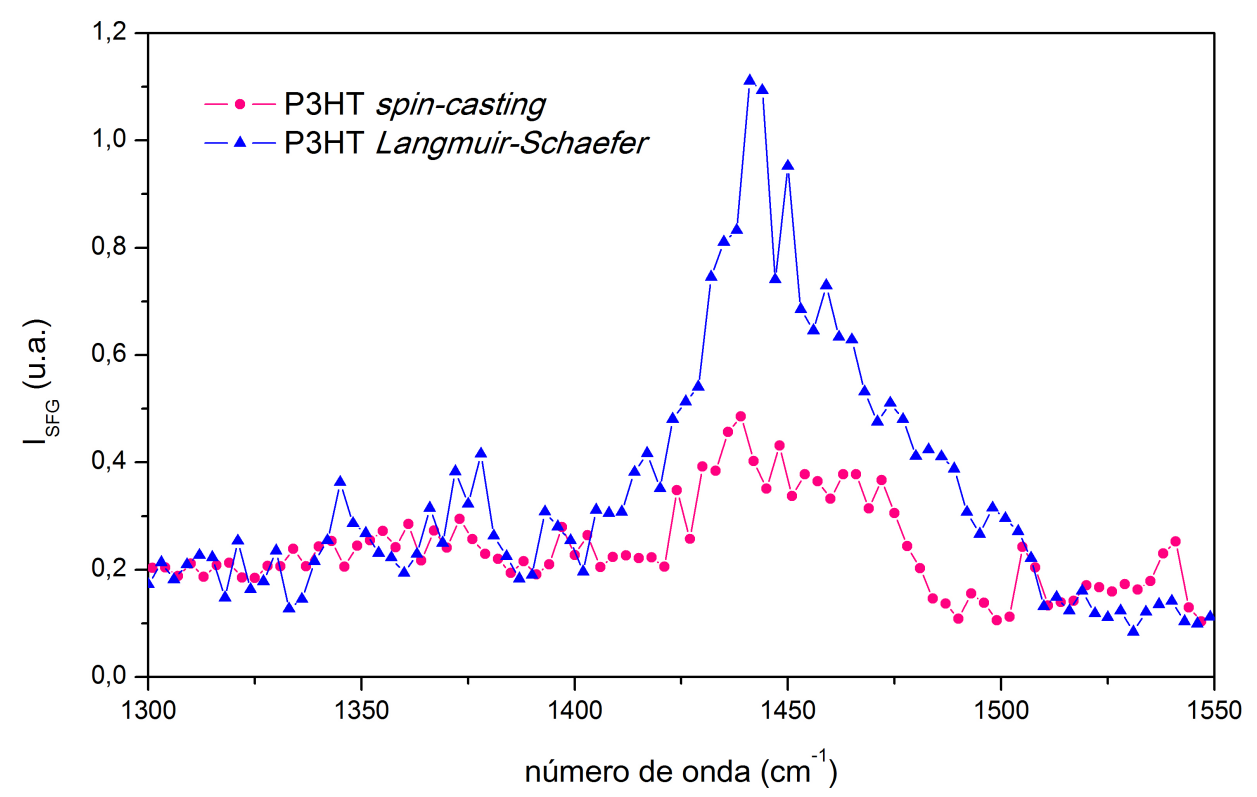

Figura 4.9: Espectros SFG de filmes de P3HT sobre $\mathrm{SiO}_{2} / \mathrm{Si}$ depositados pelos métodos de spincasting e Langmuir-Schaefer, em polarização ppp.

Devido aos obstáculos encontrados na realização do experimento SFG visando obter espectros na pequena região do canal de OFETs, as amostras preparadas com filmes Langmuir-Schaefer foram as que apresentaram melhores resultados, devido à maior relação sinal/ruído.

\subsection{OFETs vidro/PMMA/P3HT}

Os dispositivos em substrato de vidro, utilizando alumínio como eletrodo de porta e PMMA como dielétrico, foram preparados como descrito no Capítulo 3 e apresentaram bom funcionamento. Medidas de perfilometria determinaram a espessura dos filme como sendo cerca de $600 \mathrm{~nm}$ de PMMA e $100 \mathrm{~nm}$ de P3HT.

Devido a sombras na evaporação dos eletrodos, alguns dispositivos de canal mais estreito muitas vezes apresentaram curto-circuito. São apresentadas as curvas de saída de alguns OFETs preparados (Figuras 4.10 a 4.14).

A Figura 4.15 apresenta as curvas de transferência sobrepostas dos diferentes dispositivos normalizadas pela razão de dimensões W/L dos canais de cada OFET. É possivel notar grande semelhança entre as curvas, o que demonstra boa reprodutibilidade na fabricação dos dispositivos. 


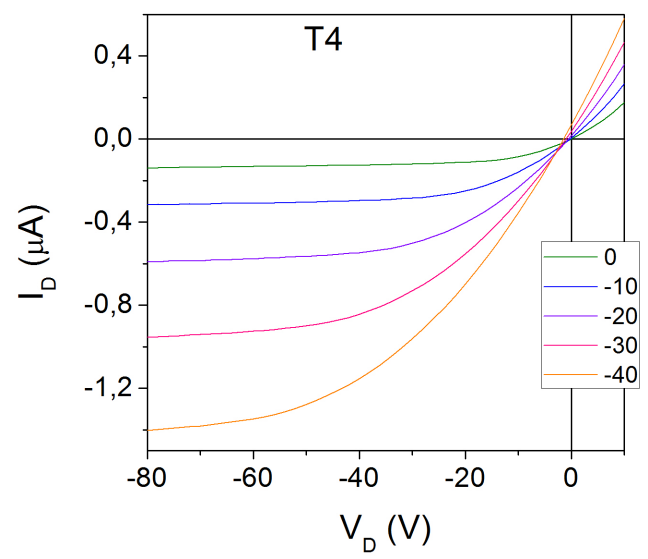

Figura 4.10: Curvas de saída de um OFET vidro $/ \mathrm{PMMA} / \mathrm{P} 3 \mathrm{HT} \mathrm{L}=75 \mu \mathrm{m} \mathrm{W}=1 \mathrm{~mm}$

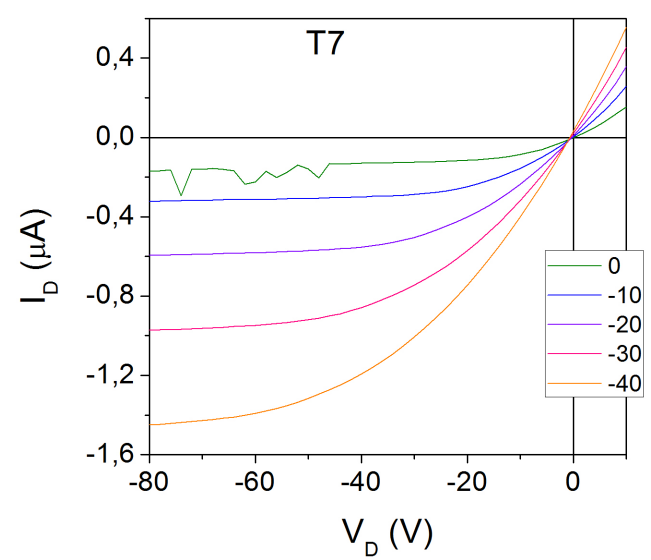

Figura 4.12: Curvas de saída de um OFET vidro $/ \mathrm{PMMA} / \mathrm{P} 3 \mathrm{HT} \mathrm{L}=150 \mu \mathrm{m} \mathrm{W}=2 \mathrm{~mm}$

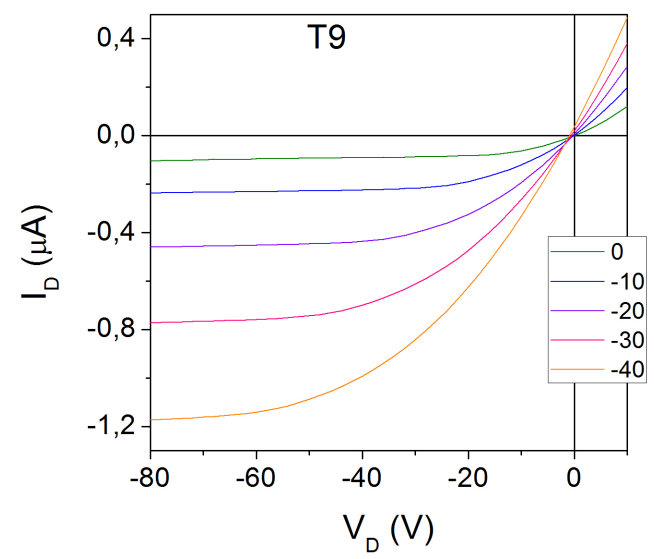

Figura 4.14: Curvas de saída de um OFET vi$\mathrm{dro} / \mathrm{PMMA} / \mathrm{P} 3 \mathrm{HT} \mathrm{L}=200 \mu \mathrm{m} \mathrm{W}=2,66 \mathrm{~mm}$

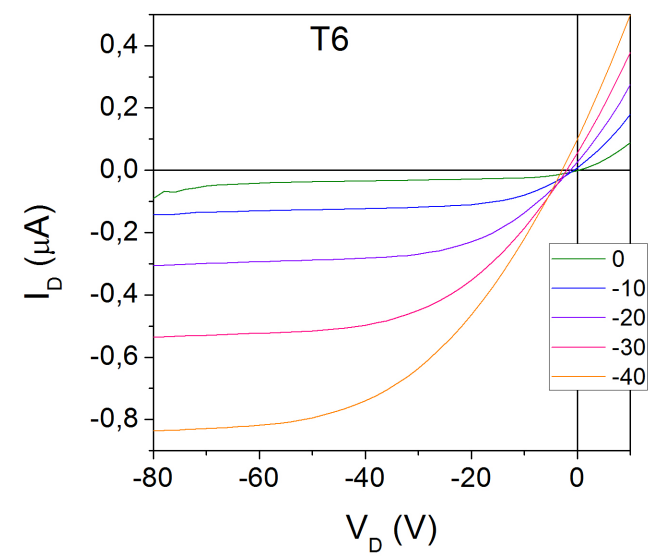

Figura 4.11: Curvas de saída de um OFET vidro/PMMA/P3HT L $=125 \mu \mathrm{m} \mathrm{W}=1,66 \mathrm{~mm}$

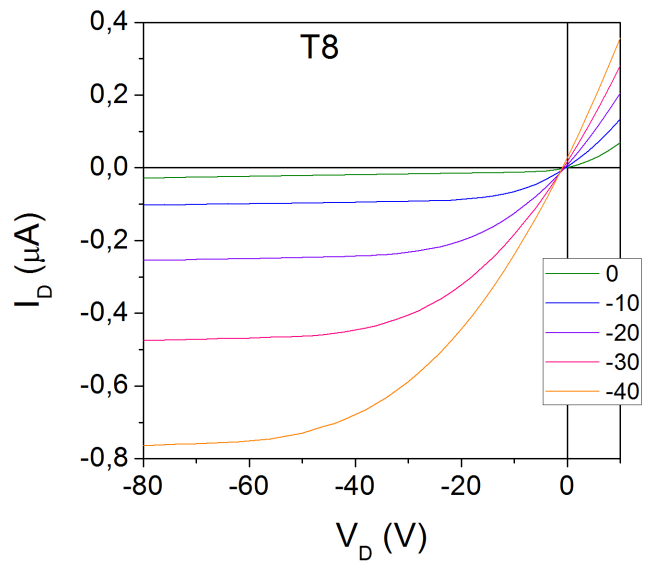

Figura 4.13: Curvas de saída de um OFET vidro $/$ PMMA $/ \mathrm{P} 3 \mathrm{HT} \mathrm{L}=175 \mu \mathrm{m} \mathrm{W}=2,33 \mathrm{~mm}$

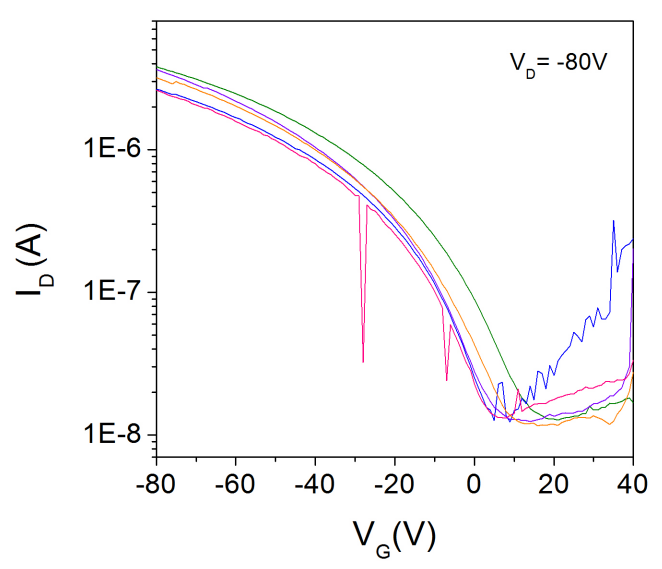

Figura 4.15: Curvas de transferência normalizadas conforme $\mathrm{W} / \mathrm{L}$ 
Os dispositivos aqui apresentados foram utilizados como amostra para medidas SHG após a caracterização elétrica. Foram coletadas medidas da intensidade do sinal SHG (em unidades arbitrárias) em função do tempo, conforme a aplicação de diferentes condições de potencial.

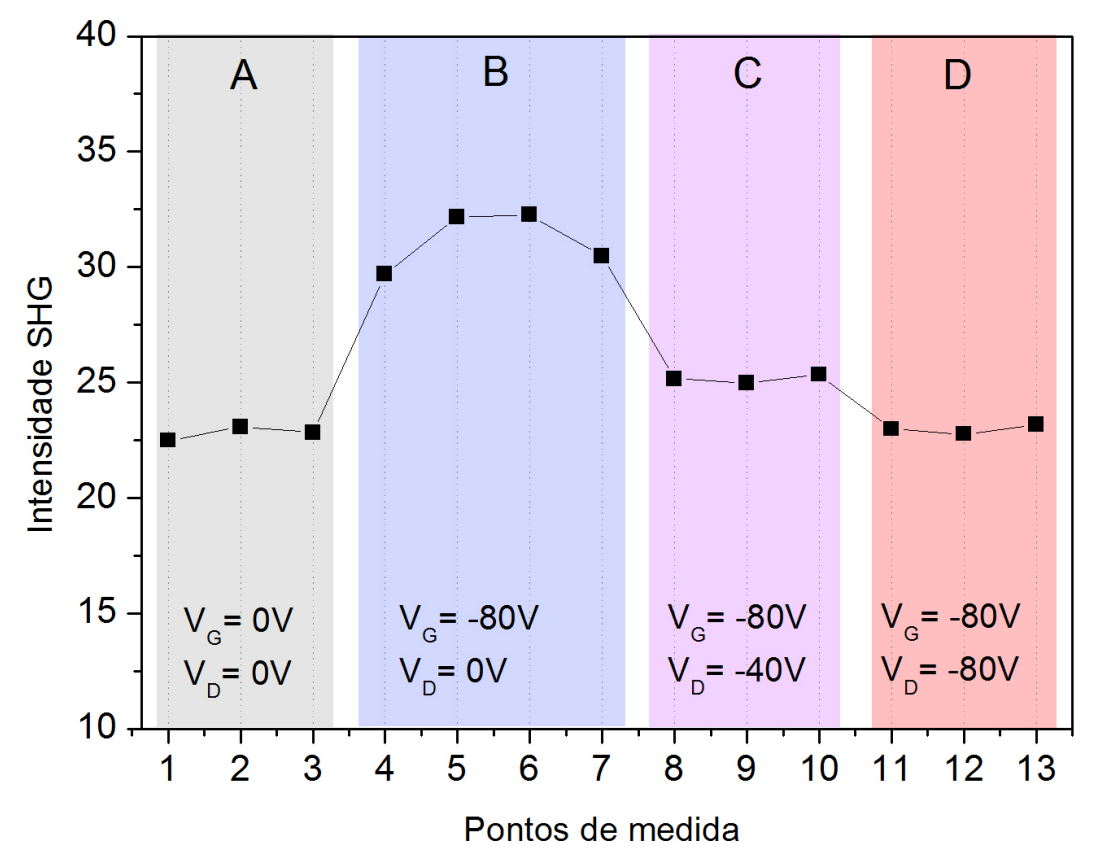

Figura 4.16: Medidas de intensidade SHG em um canal de OFET vidro/PMMA/P3HT em polarização $p p$.

Como é possível observar claramente na Figura 4.16, o sinal tem um aumento substancial de intensidade ao ser aplicado o potencial de porta (região B) em relação às medidas obtidas do OFET sem aplicação de potencial (região A). Ao aplicar um potencial intermediário entre dreno e fonte simultaneamente ao potencial de porta, a intensidade do sinal cai (região C), voltando ao mesmo valor original da região $\mathrm{A}$ quando $V_{D}$ atinge o valor da região de saturação (região $\mathrm{D}$ ). A intensificação do sinal SHG se deve o efeito EFISHG (descrito no Capítulo 2) em função do campo elétrico DC perpendicular ao canal com aplicação de $V_{G}$. A formação do canal e injeção de portadores com a aplicação de $V_{D}$ altera a distribuição de campo elétrico ao longo do canal, concentrando o acúmulo de cargas na região próxima ao eletrodo de fonte e diminuindo a área do canal responsável pelo aumento do sinal SHG.

Esses dados estão de acordo com os resultados relatados na literatura. No trabalho de Manaka $[26,29]$ foi analisado o efeito EFISHG no canal de transistores de pentaceno. Também foi utilizado 
o conjunto de polarizações $p p$, porém com ângulo de incidência próximo ao eixo normal $\left(10^{\circ}\right)$, de forma que a componente do campo DC analisada foi na direção paralela ao substrato. Assim, observou-se o efeito do campo elétrico paralelo ao canal, com o aumento de intensidade SHG com a aplicação de $V_{D}$, e a supressão do sinal com a aplicação simultânea de $V_{G}$. Já no caso deste trabalho, utilizando o feixe infravermelho com polarização $p$ e ângulo de incidência de $60^{\circ}$, o efeito majoritário observado é do campo elétrico perpendicular ao substrato.

O experimento SFG demonstrou-se inviável para esse tipo de amostra, uma vez que a incidência dos feixes laser causou danos muito acentuados na região do canal do dispositivo, mesmo com a energia profundamente atenuada. Esse efeito foi atribuído à alta refletividade do filme de alumínio na parte inferior do dispositivo, somado a fenômenos de interferência entre as reflexões das interfaces inferior e superior da camada de PMMA, cuja espessura é bastante próxima do comprimento de onda do feixe visível.

\subsection{OFETs $\mathrm{Si} / \mathrm{SiO}_{2} / \mathrm{P} 3 \mathrm{HT}$}

Os dispositivos preparados em substrato de silício nos quais a camada isolante consistia unicamente de $\mathrm{SiO}_{2}$ apresentaram corrente de fuga muito alta. Isso se deve em grande parte às dimensões dos eletrodos de ouro depositados por evaporação, que apresentam uma ampla superfície separada do silício condutor por uma camada muito fina de isolante. Em muitas das amostras a corrente de canal não era suficiente para superar a corrente de fuga, e o dispositivo não apresentou o comportamento esperado. Outro fator que contribuiu para o aumento da corrente de fuga é a temperatura dos substratos durante evaporação dos contatos metálicos, que pode atingir valores suficientes para a difusão do ouro através da camada de óxido.

Utilizando substratos com $90 \mathrm{~nm}$ de espessura na camada de $\mathrm{SiO}_{2}$ a otimização do processo de fabricação permitiu a obtenção de dispositivos funcionais. Para isso as amostras foram preparadas em arquitetura top-contacts, e foram criados bloqueios na máscara de evaporação para diminuir a superfície do eletrodo criado. As curvas de saída de alguns exemplos de OFETs preparado por meio deste processo são apresentados na Figura 4.17.

Apesar de ainda apresentarem altas correntes de fuga em relção a baixas correntes de canal, e características elétricas divergentes do que se espera de um OFET de boa performance, esses dispositivos apresentam o comportamento característico desejado, efeito de campo e saturação das 

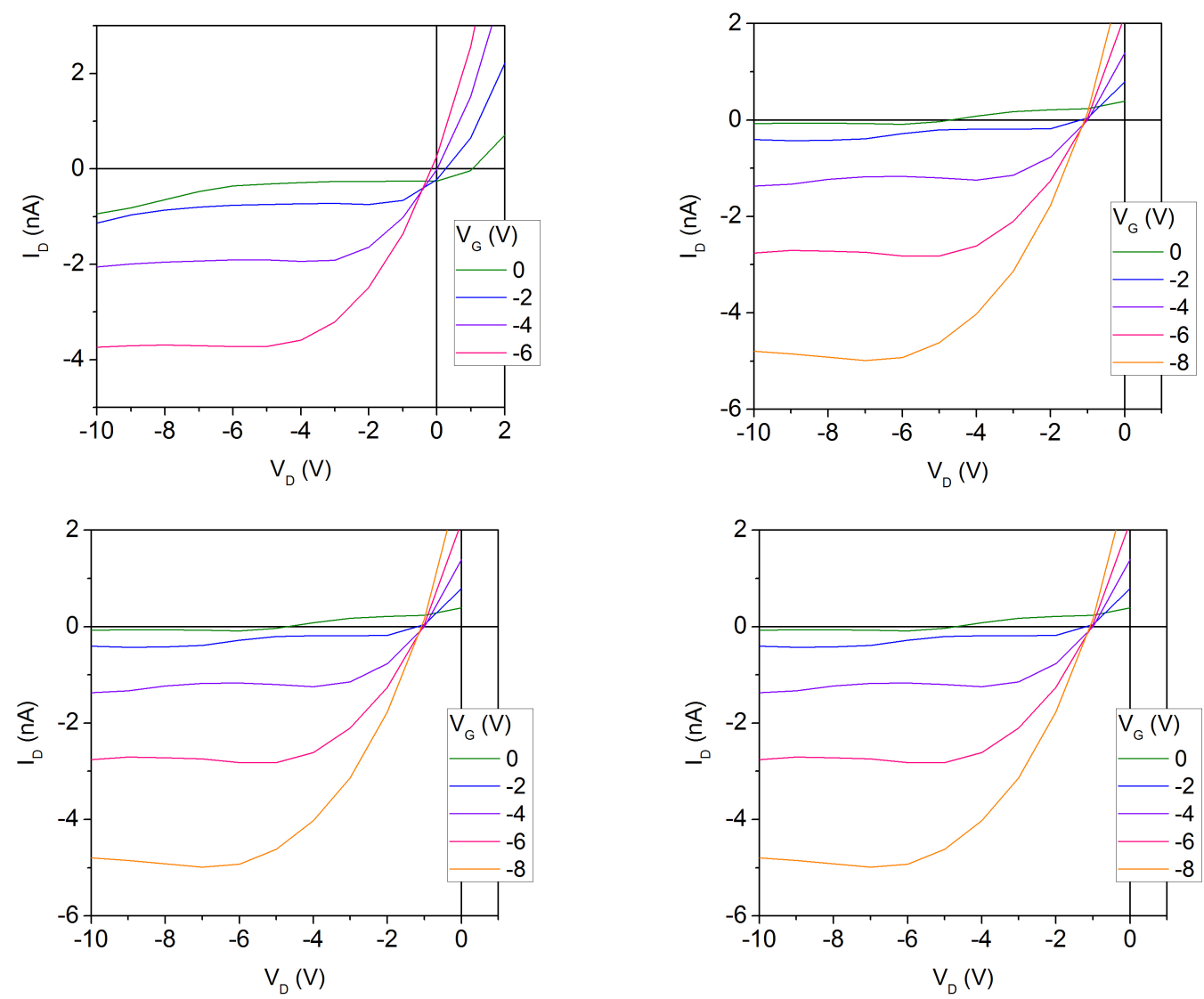

Figura 4.17: Curvas de saída de alguns OFETs $\mathrm{Si} / \mathrm{SiO}_{2} / \mathrm{P} 3 \mathrm{HT}$ de dimensões $\mathrm{L}=80 \mu \mathrm{m}$ e $\mathrm{W}=2$ $\mathrm{mm}$.

curvas, sendo suficientes para os estudos pretendidos.

Por outro lado, esses fatores limitam a utilidade das amostras, uma vez que operam com baixas tensões e correntes, que podem não ser suficientes para observar efeitos substanciais nas medidas SFG e os potenciais aplicados causam danos na camada dielétrica, causando um aumento na corrente de fuga e perda de performance ao longo de um curto tempo de operação. Essas amostras não apresentaram resultados conclusivos em relação ao experimento SFG, porém foram utilizadas para melhorar o aparato a fim de obter melhores espectros da região do canal.

Foram utilizados também substratos de silício com cobertura de $300 \mathrm{~nm}$ de $\mathrm{SiO}_{2}$, a fim de alcançar menores correntes de fuga e melhor performance elétrica nos OFETs. A Figura 4.18 apresenta a caracterização elétrica de um dispositivo $\mathrm{Si} / \mathrm{SiO}_{2} / \mathrm{P} 3 \mathrm{HT}$-LS (no qual o filme de P3HT foi preparado pelo processo de Langmuir-Schaefer como descrito no Capítulo 3), e que foi utilizado na realização de medidas SFG.

Este dispositivo foi submetido a análise com espectroscopia SFG, obtendo-se espectros da região 


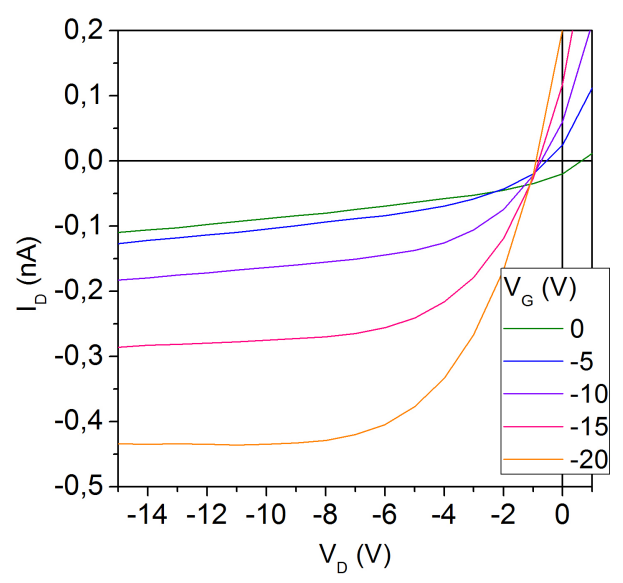

(a)
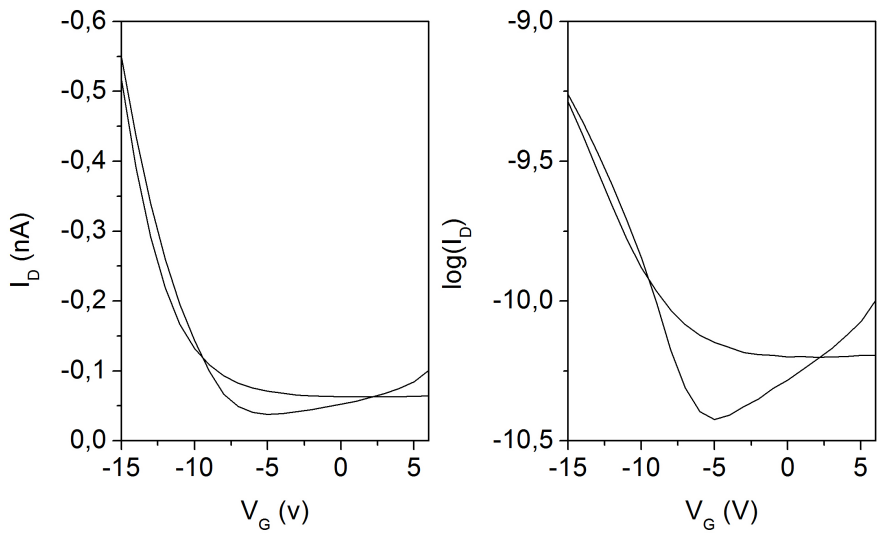

(b)

Figura 4.18: (a) Curvas de saída de um OFET Si/SiO $/$ P3HT-LS com $300 \mathrm{~nm}$ de espessura de óxido e dimensões $\mathrm{L}=100 \mu \mathrm{m}$ e $\mathrm{W}=2 \mathrm{~mm}$. (b) Curvas de transferência (com $V_{D}=-10 \mathrm{~V}$ ) em escala linear e escala semi-logarítmica.

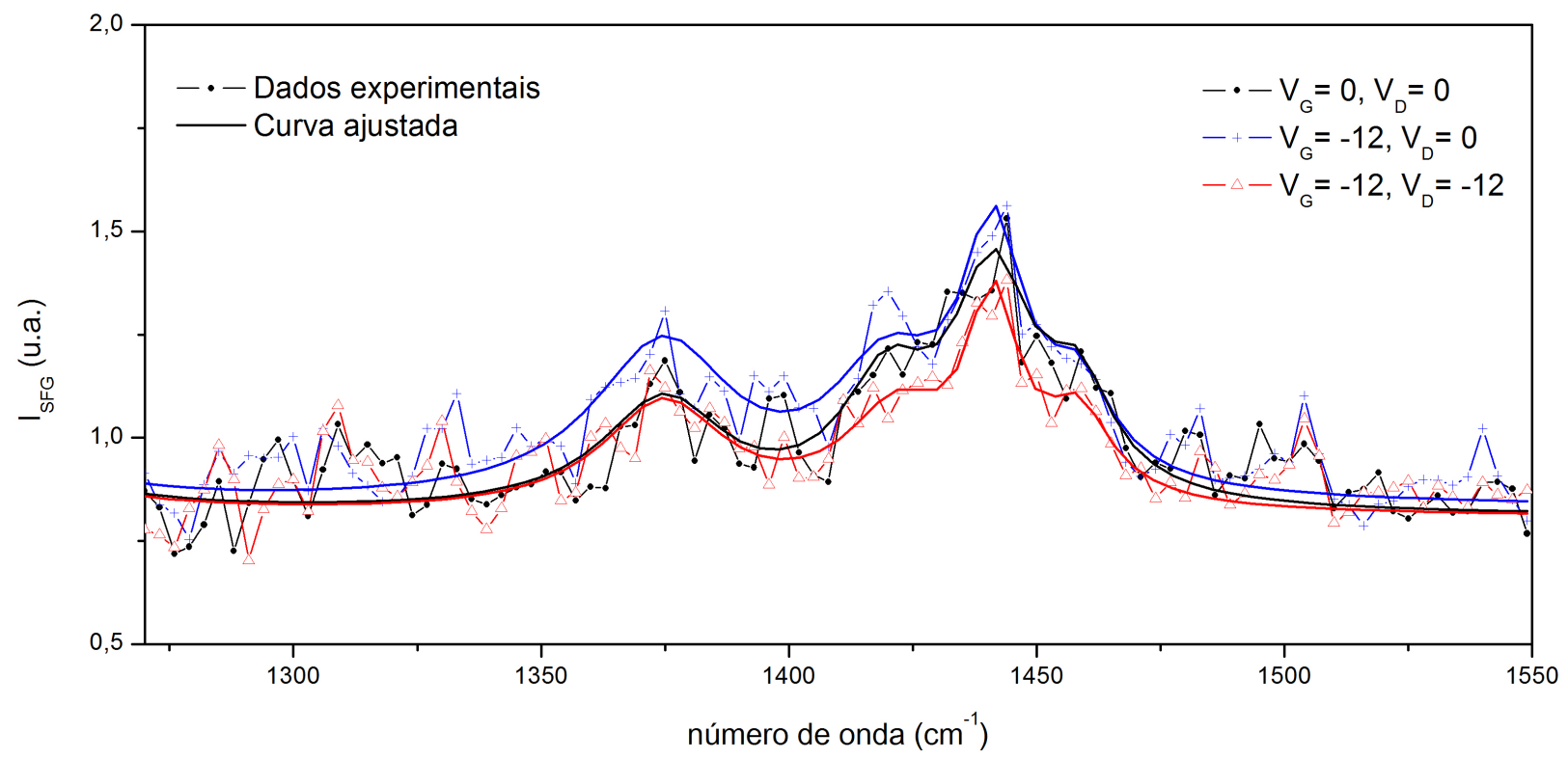

Figura 4.19: Espectros SFG obtidos no canal do OFET Si/SiO $2 / \mathrm{P} 3 \mathrm{HT}-\mathrm{LS}$ referente às curvas da Figura 4.18.

de modos vibracionais das ligações $\mathrm{C}-\mathrm{C}$ das cadeias conjugadas. Foram obtidas medidas de intensidade SFG na faixa de 1250 a $1550 \mathrm{~cm}^{-1}$ atenuando os feixes de excitação de forma com que não causassem danos ao polímero ou aos eletrodos metálicos. Foram adquiridos espectros nas condições de $V_{G}$ e $V_{D}$ nulos, com aplicação de apenas $V_{G}$ e com aplicação de $V_{G}$ e $V_{D}$ simultaneamente, ou 
seja, no estado ligado do dispositivo, com passagem de corrente no canal. Foram feitas as médias a partir de três espectros normalizados obtidos em cada condição. Estes dados e as respectivas curvas ajustadas de acordo com a equação de intensidade de sinal SFG (Equação 2.13) são apresentados na Figura 4.19.

O espectro referente ao P3HT com aplicação de potencial de porta exibe um aparente aumento de intensidade. Esta observação concorda com os resultados das medidas SHG apresentadas na Seção 4.2, onde é observado o efeito EFISHG que causa um aumento no $\chi^{(2)}$ efetivo devido à presença do campo elétrico DC. Ao aplicar também $V_{D}$, o dispositivo passa ao estado ligado, com passagem de corrente entre dreno e fonte. O espectro do P3HT nessa condição demonstra queda de intensidade na sobreposição de bandas na região de $1450 \mathrm{~cm}^{-1}$. Mudanças na forma de linha nessa faixa do espectro podem estar relacionadas a alterações na estrutura eletrônica e na conjugação das cadeias com a injeção e acúmulo de cargas positivas no canal.

Embora as observações apresentadas sejam obtidas a partir de médias de diversas medidas, a razão sinal/ruído não é alta o suficiente para obter conclusões mais detalhadas.

\subsection{OFETs $\mathrm{Si} / \mathrm{SiO}_{2} / \mathrm{PMMA} / \mathrm{P} 3 \mathrm{HT}$}

Em decorrência da alta corrente de fuga apresentada pelos dispositivos em substrato de silício recobertos com $\mathrm{SiO}_{2}$, foram preparadas amostras com filme de PMMA depositado sobre o óxido, de forma a aumentar a capacidade isolante do dielétrico. A Figura 4.20 apresenta as curvas de saída de alguns dispositivos preparados com P3HT depositado sobre um filme de PMMA com cerca de $600 \mathrm{~nm}$ de espessura sobre uma camada de $90 \mathrm{~nm}$ de $\mathrm{SiO}_{2}$.

Os dispositivos com filmes de P3HT preparados por spin-casting não forneceram resultados conclusivos devido à baixa intensidade do sinal SFG, portanto foram preparados dispositivos com filmes de P3HT depositados sobre o PMMA pelo método Langmuir-Schaefer (P3HT-LS, conforme descrito no Capítulo 3).

A Figura 4.21 apresenta a caracterização elétrica de um dispositivo preparado por meio deste processo e que foi submetido ao experimento SFG. A amostra em questão foi preparada com um filme de $700 \mathrm{~nm}$ de PMMA sobre substrato de silício recoberto apenas com $\mathrm{SiO}_{2}$ formado por oxidação química (cerca de $2 \mathrm{~nm}$ ). O OFET utilizado para as medidas espectroscópicas foi um $\mathrm{T} 6(\mathrm{~L}=100 \mu \mathrm{m}$ e $\mathrm{W}=2 \mathrm{~mm})$ com o intuito de aproveitar a maior largura do canal para obter 


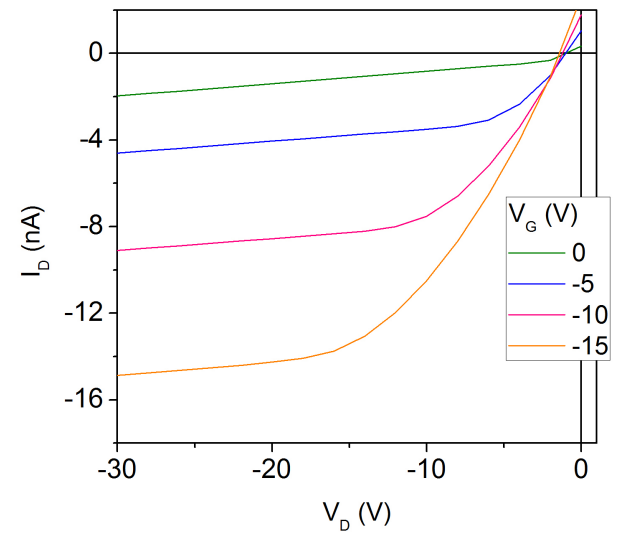

(a)

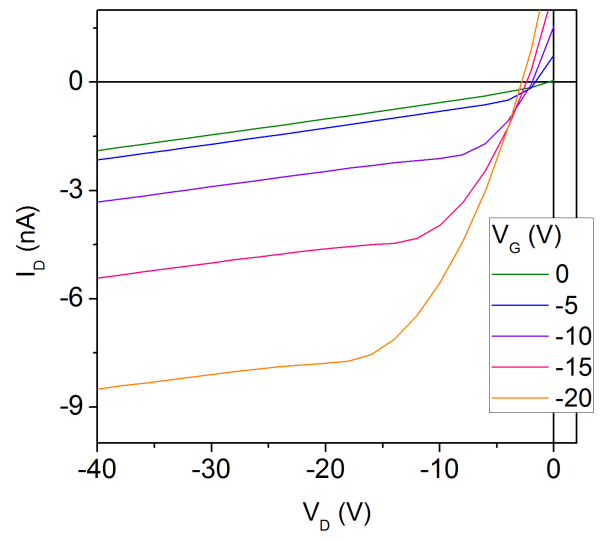

(b)

Figura 4.20: Curvas de saída de alguns OFETs $\mathrm{Si} / \mathrm{SiO}_{2} / \mathrm{PMMA} / \mathrm{P} 3 \mathrm{HT}$ com L $=100 \mu \mathrm{m}$ e W $=2$ $\mathrm{mm}$.

melhores espectros.

Foram obtidos espectros SFG do canal do transistor na faixa de frequência dos modos vibracionais $\mathrm{C}-\mathrm{C}$ e $\mathrm{C}=\mathrm{C}$ do $\mathrm{P} 3 \mathrm{HT}$. Os espectros foram obtidos sem aplicação de potencial, com aplicação de potencial de porta, e também com aplicação de potenciais de porta e dreno. Os conjuntos de dados experimentais traçados na Figura 4.22 consistem em médias de três aquisições na mesma condição de potenciais, e são apresentados juntamente com as curvas ajustadas de acordo com a equação de intensidade de sinal SFG (Equação 2.13).

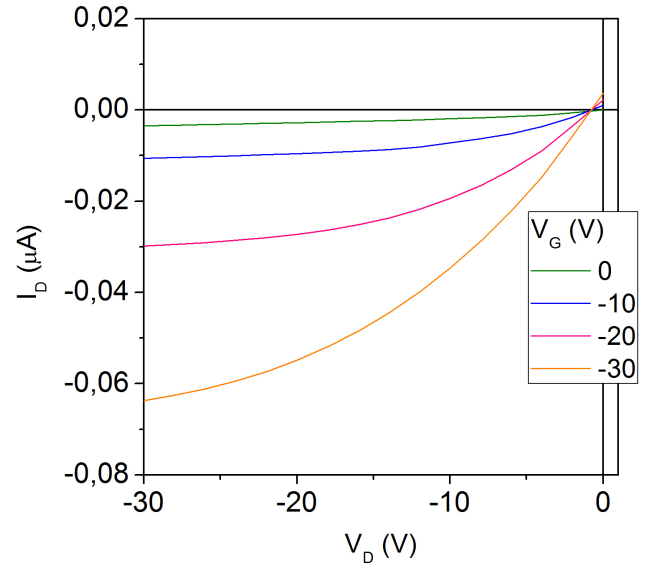

(a)
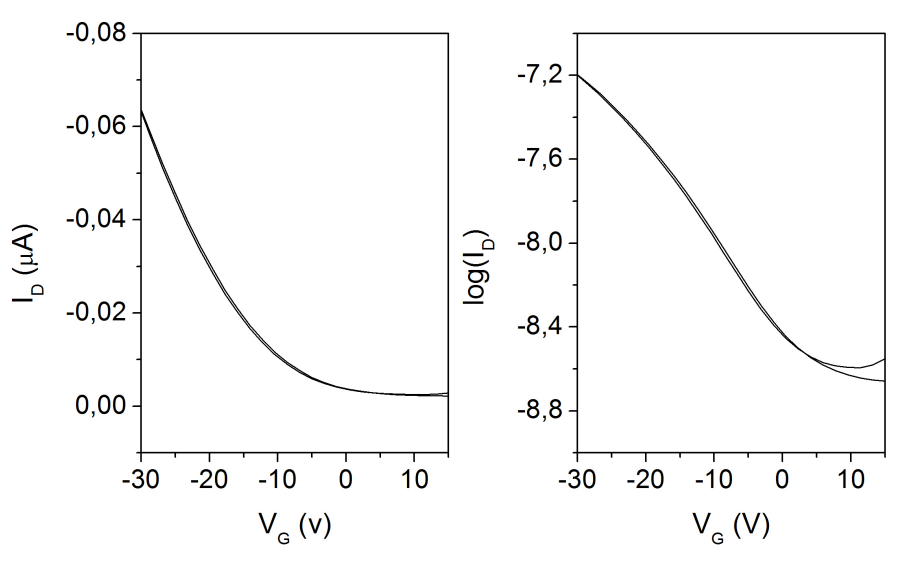

(b)

Figura 4.21: (a) Curva de saída de um OFET Si/SiO $/$ PMMA/P3HT-LS (de dimensões L = 100 $\mu \mathrm{m}$ e $\mathrm{W}=2 \mathrm{~mm}$ ) utilizado no estudo SFG. (b) Curvas de transferência (com $V_{D}=-30 \mathrm{~V}$ ) em escala linear e escala semi-logarítmica. 


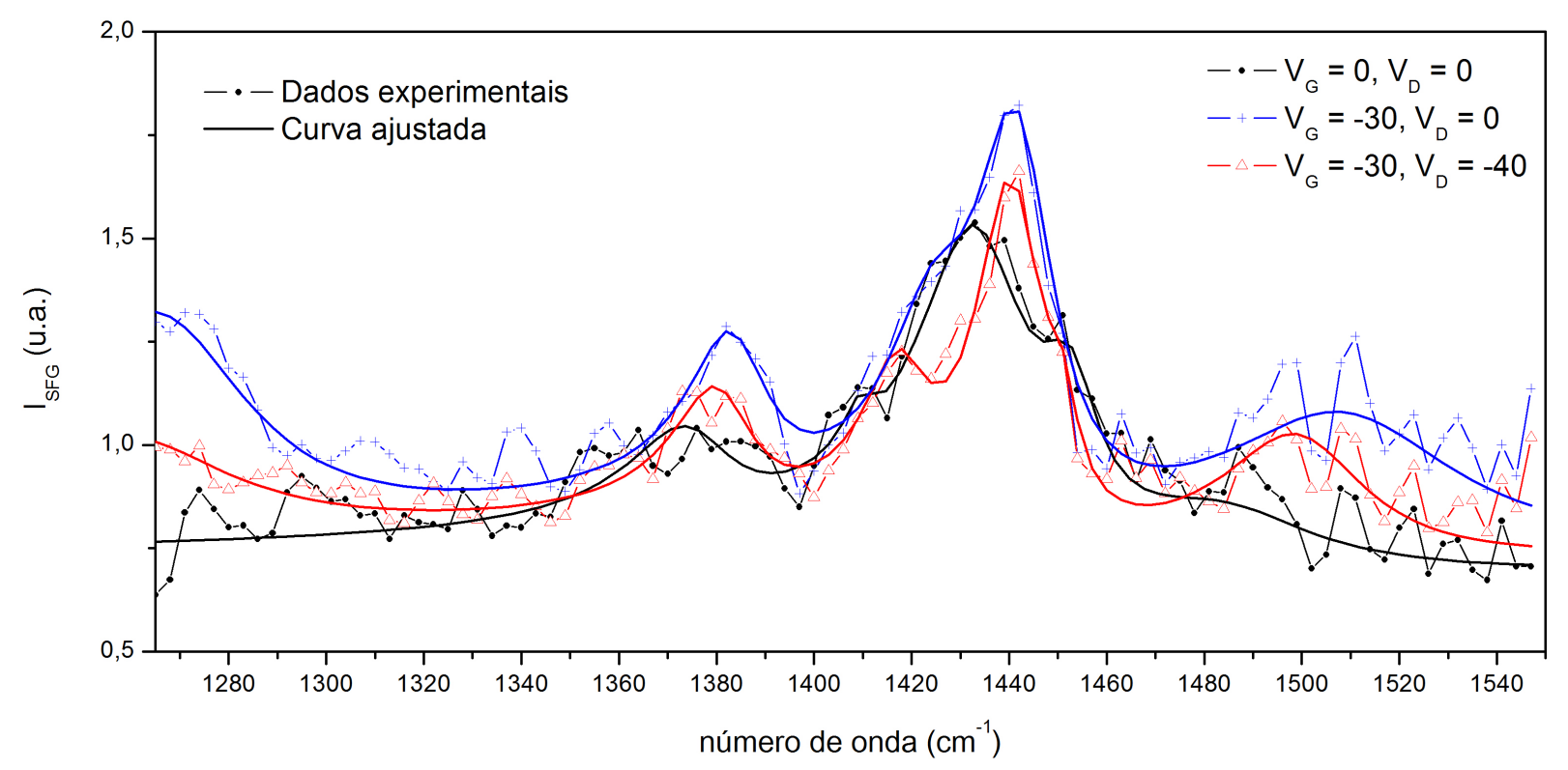

Figura 4.22: Espectros SFG em polarização ppp obtidos do canal do OFET Si/SiO $2 / \mathrm{PMMA} / \mathrm{P} 3 \mathrm{HT}$ LS referente às curvas da Figura 4.21.

De forma similar aos dados obtidos dos dispositivos OFET Si/SiO $/$ P3HT apresentados na seção anterior, é possível observar na sobreposição dos espectros da Figura 4.22 uma certa amplificação de intensidade com aplicação de potencial de porta, além de uma aparente alteração do formato da sobreposição de bandas na região de $1440 \mathrm{~cm}^{-1}$, que passa a ficar evidente nesses espectros de melhor qualidade. Como discutido anteriormente, a amplificação de sinal SFG com aplicação de $V_{G}$ está em conformidade com a observação do efeito EFISHG nas medidas SHG, e a deformação do espectro com aplicação de $V_{G}$ e $V_{D}$ pode ser consequência da alteração da estrutura conjugada das cadeias com a presença de buracos.

Um novo aspecto notório nos espectros é o surgimento de uma banda próxima a $1240 \mathrm{~cm}^{-1}$ ao ser aplicado $V_{G}$, cuja intensidade também é reduzida com aplicação de $V_{D}$. Essa banda foi investigada varrendo a faixa de 1150 a $1350 \mathrm{~cm}^{-1}$ e aplicando diferentes valores de $V_{G}$. Os dados obtidos são apresentados na Figura 4.23, juntamente com as curvas ajustadas. Embora a relação sinal/ruído nessa faixa de frequência seja baixa, é possível observar claramente o aumento de intensidade da banda conforme o aumento de tensão aplicada.

Outra amostra preparada com filme de PMMA sobre o óxido de silício foi submetida a espectroscopia SFG para estudar o aparecimento dessas novas bandas com mais detalhes. A amostra 


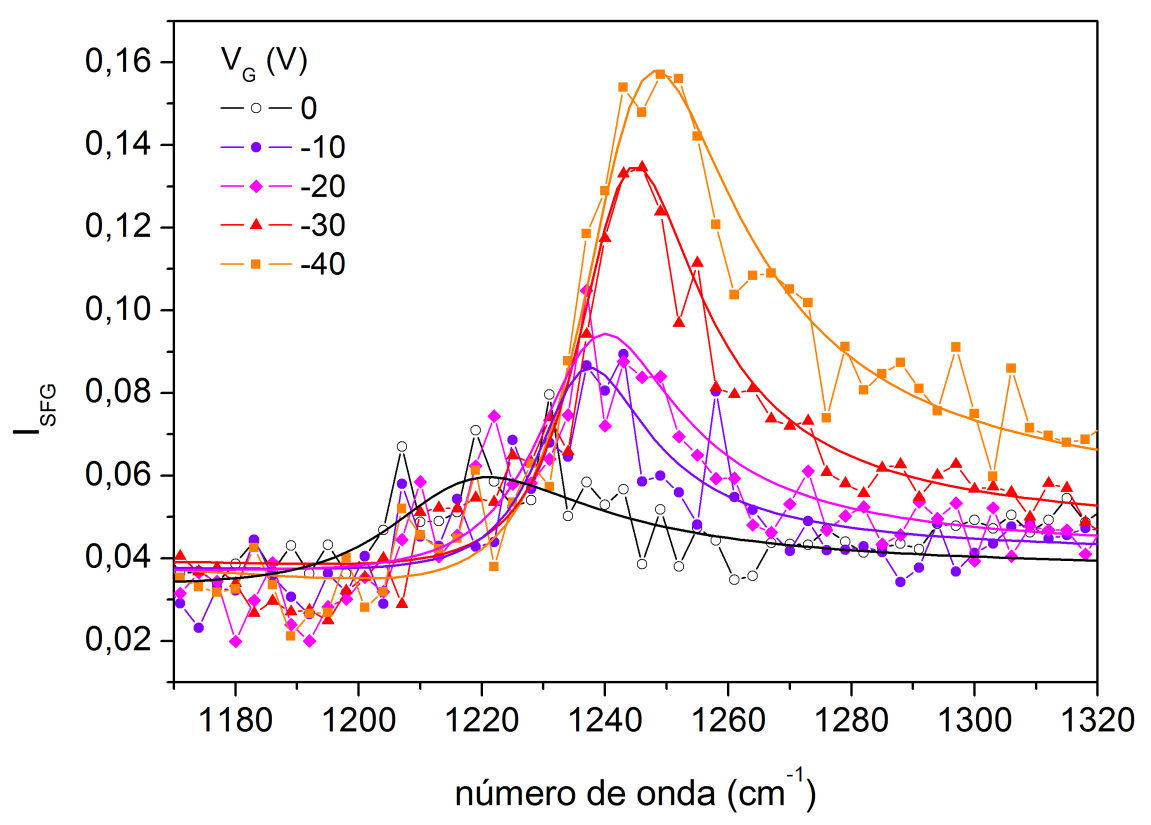

Figura 4.23: Manifestação da banda em $1240 \mathrm{~cm}^{-1}$ no OFET $\mathrm{Si} / \mathrm{SiO}_{2} / \mathrm{PMMA} / \mathrm{P} 3 \mathrm{HT}$ conforme aplicação de $V_{G}$ (dados sem normalização com referência de ZnS, espectros obtidos com polarização ppp).

cuja caracterização elétrica é apresentada na Figura 4.24 foi preparada com cerca de $800 \mathrm{~nm}$ de espessura do filme de PMMA, e o filme de P3HT foi depositado por spin-casting.

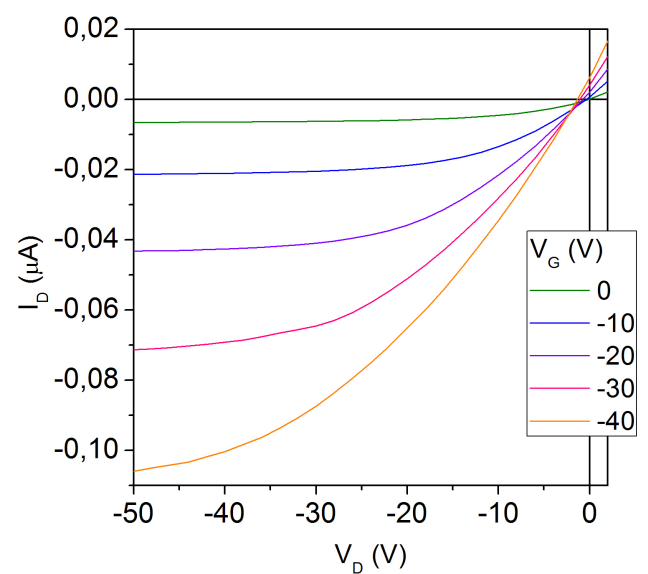

(a)
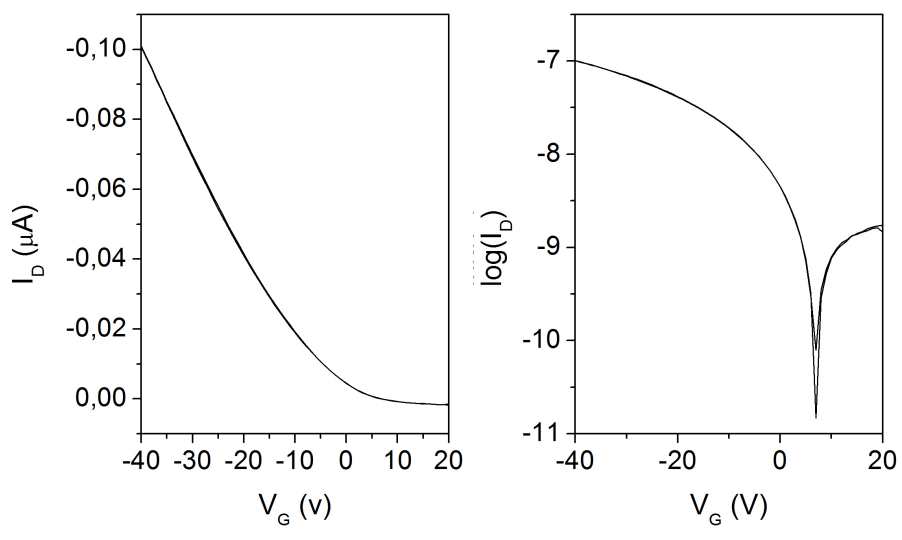

(b)

Figura 4.24: (a) Curva de saída de um OFET Si/SiO $/$ PMMA/P3HT (de dimensões $\mathrm{L}=100 \mu \mathrm{m}$ e W $=2 \mathrm{~mm}$ ) utilizado no estudo SFG. (b) Curvas de transferência (com $V_{D}=-40 \mathrm{~V}$ ) em escala linear e escala semi-logarítmica.

O mesmo fenômeno foi constatado na região de $1240 \mathrm{~cm}^{-1}$, e também encontrou-se uma nova 
banda na região característica de modos vibracionais de grupos carbonila (cerca de $1720 \mathrm{~cm}^{-1}$ ) e que, da mesma forma, se torna visível apenas com aplicação do potencial de porta, e tem sua intensidade aumentada com maiores valores de potencial aplicado, como mostra a Figura 4.25.

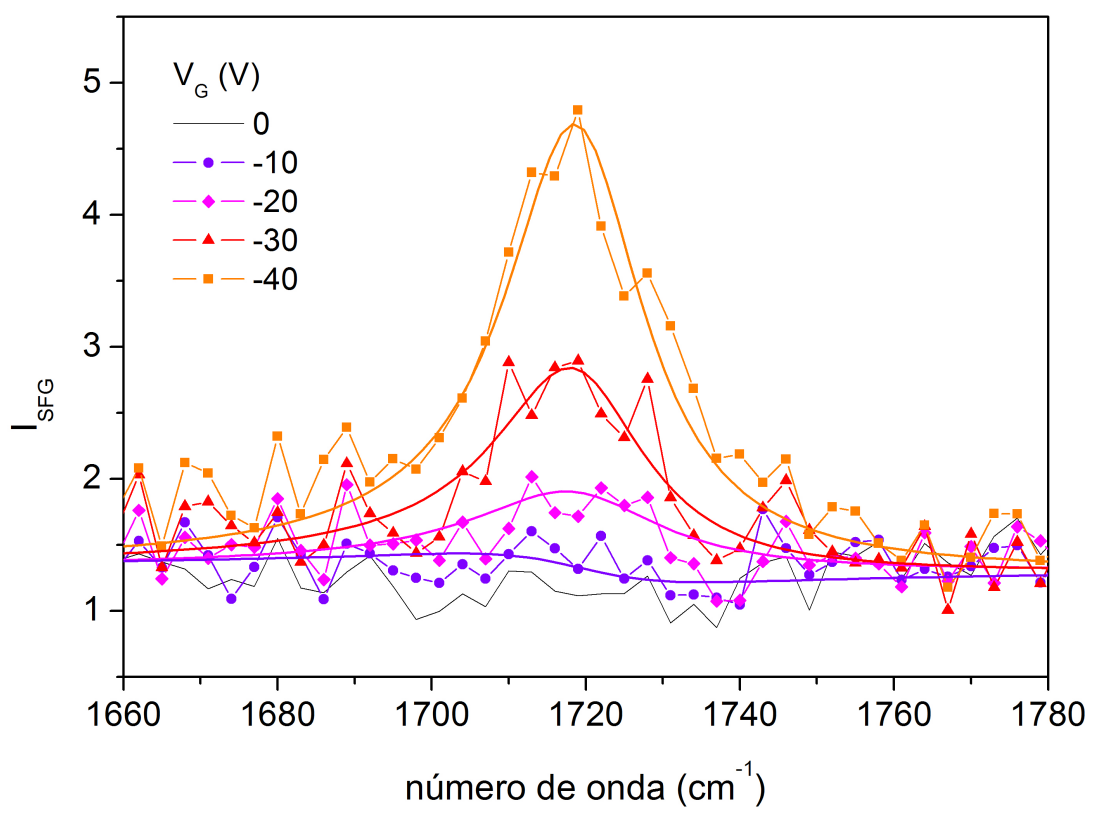

Figura 4.25: Manifestação da banda em $1720 \mathrm{~cm}^{-1}$ no OFET Si/SiO $2 / \mathrm{PMMA} / \mathrm{P} 3 \mathrm{HT}$ conforme aplicação de $V_{G}$ (dados normalizados, espectros obtidos com polarização $\left.p p p\right)$ )

Esta banda também tem a intensidade reduzida quando simultaneamente a $V_{G}$ aplica-se $V_{D}$, como mostra a Figura 4.26. Este fenômeno está de acordo com os resultados apresentados na Seção 4.2, onde foi apresentado a modulação do sinal SHG pela aplicação de potenciais, e a diminuição de intensidade do sinal devido à alteração na distribuição do campo elétrico ao longo do canal. As frequências dessas novas bandas, bem como o comportamento observado, são consistentes com os modos vibracionais das ligações $\mathrm{C}-\mathrm{O}$ e $\mathrm{C}=\mathrm{O}$ do $\mathrm{PMMA}$.

Foram realizadas medidas nas amostras preparadas em substrato de silício sem PMMA nas regiões de 1240 e $1720 \mathrm{~cm}^{-1}$ com diversas variações de potencial de porta a fim de certificar a ausência dessas bandas, indicando então o filme de PMMA como a origem das bandas. Ademais, os filmes de P3HT preparados por spin-casting na amostra em estudo manifestam baixa intensidade de sinal nas bandas características do polímero. As bandas observadas com aplicação de $V_{G}$ em 1240 e $1720 \mathrm{~cm}^{-1}$ apresentam alta intensidade, sugerindo que têm origem na orientação de dipolos em todo o volume do filme de PMMA em função do campo elétrico. Medidas SFG realizadas em filmes 


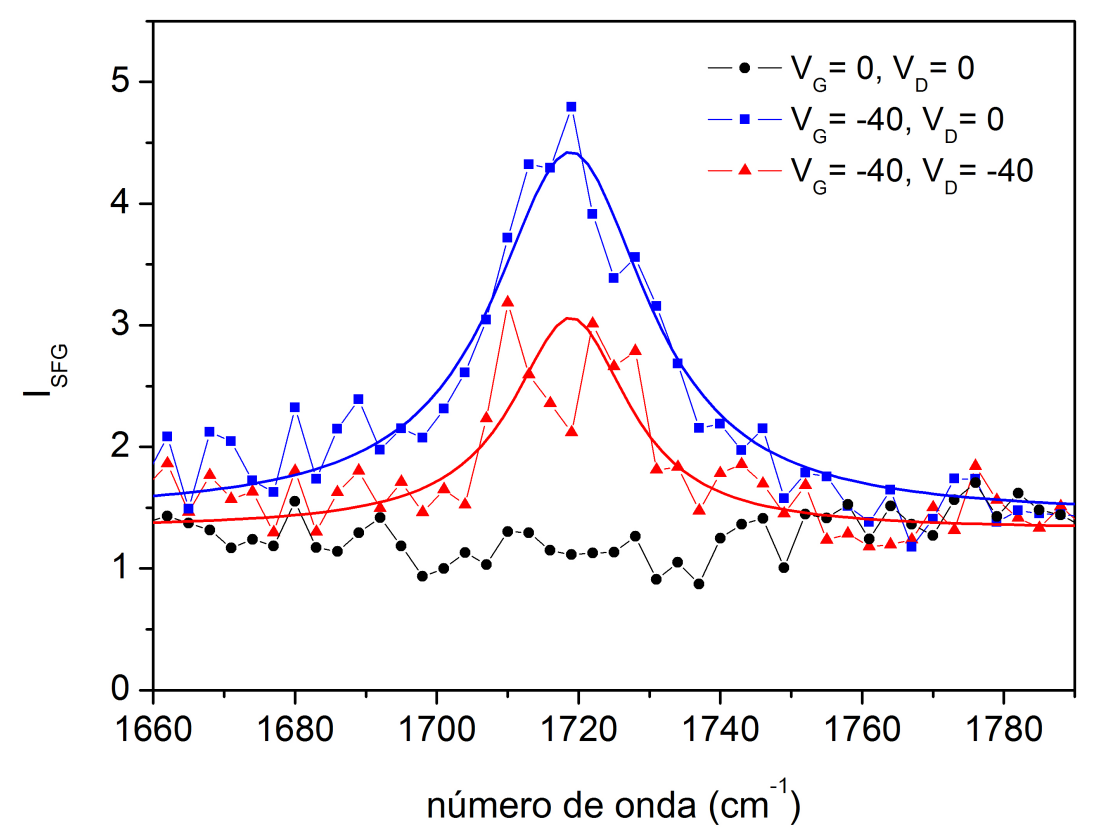

Figura 4.26: Manifestação da banda em $1720 \mathrm{~cm}^{-1}$ no OFET Si/SiO $/$ PMMA/P3HT conforme aplicação de $V_{G}$ e $V_{D}$ (dados normalizados, espectros obtidos com polarização $\left.p p p\right)$ )

de PMMA sobre vidro e sobre substratos de silício atestaram que as bandas deste polímero não são visíveis nos espectros utilizando as energias dos feixes de prova empregadas nos experimentos, uma vez que não há intensificação do sinal por ressonância eletrônica.

Avaliou-se também a intensificação das bandas em 1240 e $1720 \mathrm{~cm}^{-1}$ com aplicação de valores positivos de $V_{G}$. O que pode ser notado na Figura 4.27 é uma aparente mudança na forma de linha dos picos. Isso ocorre devido à interferência entre $\chi_{N R}^{(2)}$ e $\chi_{R}^{(2)}$. Este último tem a fase alterada em razão das orientações opostas dos dipolos em cada caso. É importante ressaltar que os dados traçados contém uma parte do sinal referente ao $\chi_{N R}^{(2)}$ da superfície dos eletrodos de ouro, portanto não é possível quantizar o sinal e comparar os valores ajustados de intensidade.

Para melhor considerar os dados apresentados foi também preparada uma amostra com filme de PMMA sobre o substrato de silício e depositados os eletrodos metálicos sem a deposição de P3HT. Constatou-se como era de se esperar que as bandas em 1240 e $1720 \mathrm{~cm}^{-1}$ não se manifestam com aplicação de $V_{G}$ sem a presença do filme de P3HT, uma vez que o campo elétrico através do filme de PMMA se forma unicamente na parte coberta pelos eletrodos e portanto inacessível aos feixes de prova. No caso do dispositivo funcional, a manifestação dessas bandas é uma consequência do 


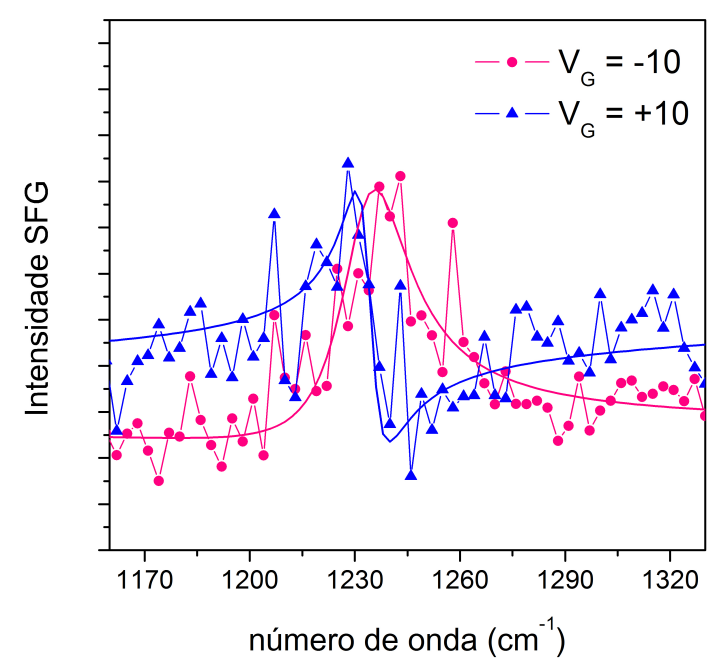

(a)

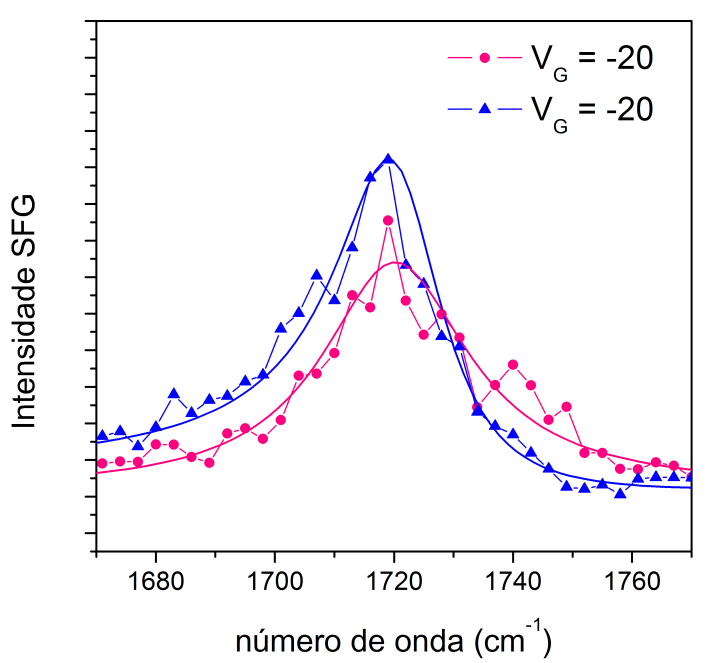

(b)

Figura 4.27: Manifestação das bandas em (a) $1240 \mathrm{~cm}^{-1}$ e (b) $1720 \mathrm{~cm}^{-1}$ em OFETs $\mathrm{Si} / \mathrm{SiO}_{2} / \mathrm{PMMA} / \mathrm{P} 3 \mathrm{HT}$ conforme aplicação de valores positivos e negativos de $V_{G}$. Espectros obtidos com polarização $p p p$ )

campo elétrico gerado pelas cargas acumuladas no filme de P3HT na região do canal. Dessa forma, é possível admitir que a intensidade do sinal SFG nessas frequências de ressonância do polímero isolante é uma medida indireta do acúmulo de portadores de carga no semicondutor orgânico.

\subsection{Degradação}

Análises por espectroscopia FTIR não demonstraram sinais consideráveis de degradação química em filmes de P3HT expostos a condições ambientes por vários dias. Procurou-se investigar se a operação elétrica dos dispositivos acelerariam o processo de degradação, e se isso levaria a alterações perceptíveis nos espectros SFG.

Uma vez que o funcionamento dos OFETs apresenta tempo de vida consideravelmente alto na ausência de oxigênio atmosférico e luz ambiente, os dispositivos foram submetidos a um determinado período de operação expostos ao ar e com iluminação intensa. Os resultados a seguir são referentes ao dispositivo $\mathrm{Si} / \mathrm{SiO}_{2} / \mathrm{P} 3 \mathrm{HT}-\mathrm{LS}$ cuja caracterização elétrica foi apresentada na Figura 4.18, e exemplificam o comportamento observado em outras amostras.

A Figura 4.28 ilustra as alterações no comportamento elétrico do OFET exposto ao ar atmosférico e luz branca durante cinco horas de operação contínua. A amostra foi mantida na mesma 


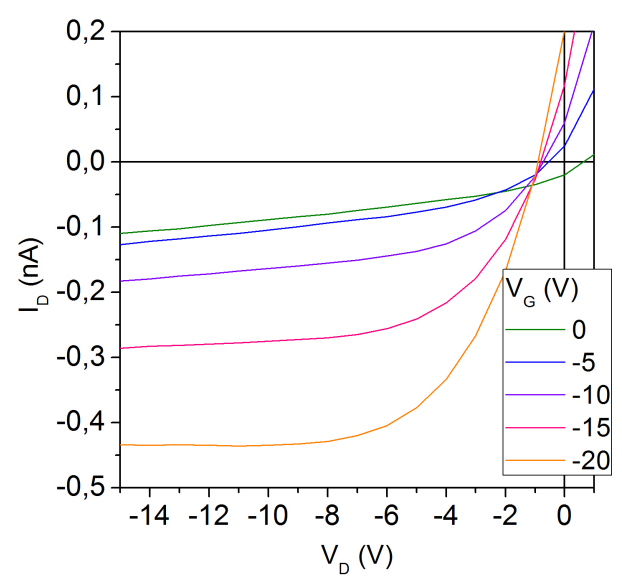

(a)

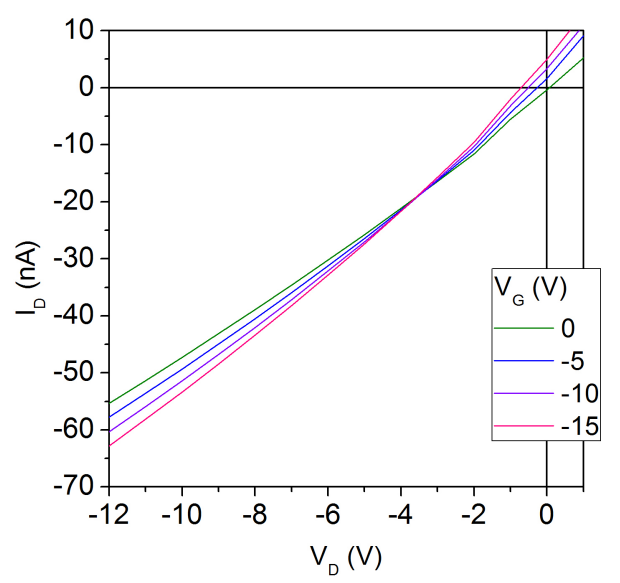

(b)

Figura 4.28: Curvas de saída de um OFET Si/SiO $/$ P3HT-LS (a) antes e (b) depois de cinco horas em operação e exposição a atmosfera e luz.

posição a fim de manter o alinhamento da estação de medida SFG durante o período de desgaste elétrico. O porta-amostra foi deixado aberto ao ar atmosférico, com aplicação contínua de $V_{G}=$ $-12 \mathrm{~V}$ e $V_{D}=-12 \mathrm{~V}$ e a iluminação foi feita utilizando uma lanterna de LED de alta intensidade com foco regulável.

Além da diminuição do efeito de campo e ausência de saturação, a corrente do canal tem um aumento de duas ordens de grandeza. Esse efeito é consequência da dopagem do P3HT pelo oxigênio atmosférico que penetra o filme polimérico.

A Figura 4.29 apresenta o espectro SFG obtido do P3HT no canal do OFET após o período de desgaste, correspondente à curva elétrica da Figura 4.28.b. É possível observar uma queda de intensidade em algumas bandas e uma deformação na região que corresponde aos modos vibracionais do anel conjugado (em torno de $1440 \mathrm{~cm}^{-1}$ ). Essas alterações aparentemente diferem das que foram observadas nos espectros do dispositivo em operação, nos quais o polímero possuía cargas injetadas e acumuladas em função dos potenciais elétricos aplicados. Aparentemente, a maior queda de intensidade ocorreu na região de maior frequência da sobreposição de bandas, porém a baixa relação sinal/ruído não permite uma análise mais detalhada.

As medidas SFG na faixa de frequências referentes a grupos carbonila não apresentaram nenhum sinal de aparecimento de bandas. É importante ressaltar que o dispositivo em análise não possui PMMA, portanto as observações nos espectros SFG provém unicamente do P3HT, e o aparecimento de bandas de grupos carbonila seriam oriundas de processos de degradação. Caso haja degradação 


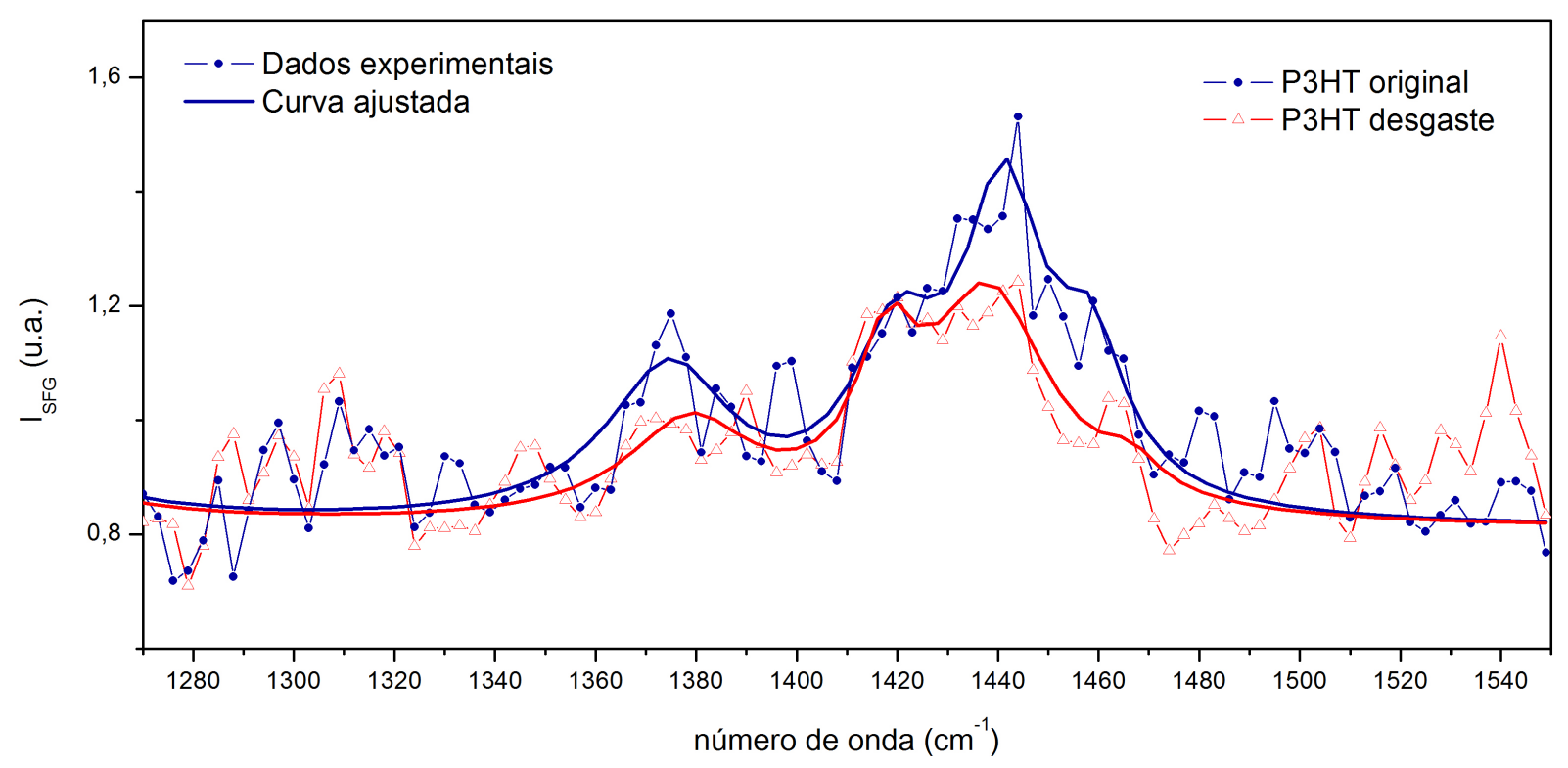

Figura 4.29: Espectros SFG do P3HT no canal do OFET no OFET Si/SiO $/ 2$ PMMA/P3HT cujas curvas elétricas são apresentadas na Figura 4.28, antes e depois do tempo de operação exposto a luz e oxigênio.

química do P3HT na região do canal dos OFETs analisados, o experimento não possuiu sensibilidade suficiente para detectar nenhum surgimento de novos modos vibracionais. Assim sendo, é possível inferir que a alteração causada no material seja devido à exposição prolongada ao oxigênio. Para avaliar a reversibilidade da degradação do polímero, a amostra foi mantida em vácuo a fim de retirar o oxigênio difundido no filme de P3HT.

A Figura 4.30 apresenta as curvas de saída do mesmo OFET representado na Figura 4.28 após 12 e 30 horas na câmara ligada a uma bomba de vácuo, com pressão mantida em cerca de $10^{-6}$ mbar. Houve um aumento da corrente de fuga provavelmente em razão dos danos ao $\mathrm{SiO}_{2}$ causados pelas tensões a que a camada dielétrica foi submetida por diversas horas. Observa-se também diferenças no formato das curvas e maior ruído elétrico. Ainda assim, nota-se que a corrente de canal foi recuperada para valores próximos aos originais e as curvas voltaram a apresentar as características de efeito de campo e saturação.

Ao atestar a reversibilidade do desgaste causado no dispositivo, pode ser afirmado que as mudanças no comportamento elétrico são majoritariamente atribuídas à presença de oxigênio no filme polimérico [52]. A dopagem leva a uma diminuição da resistência entre os contatos de ouro com o 


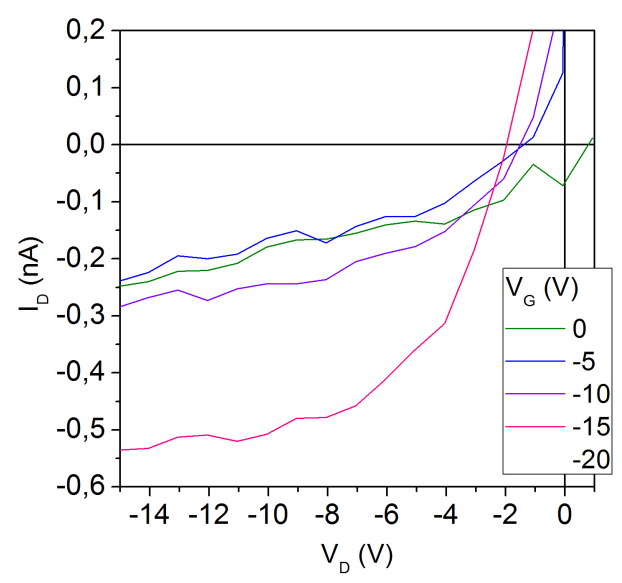

(a)

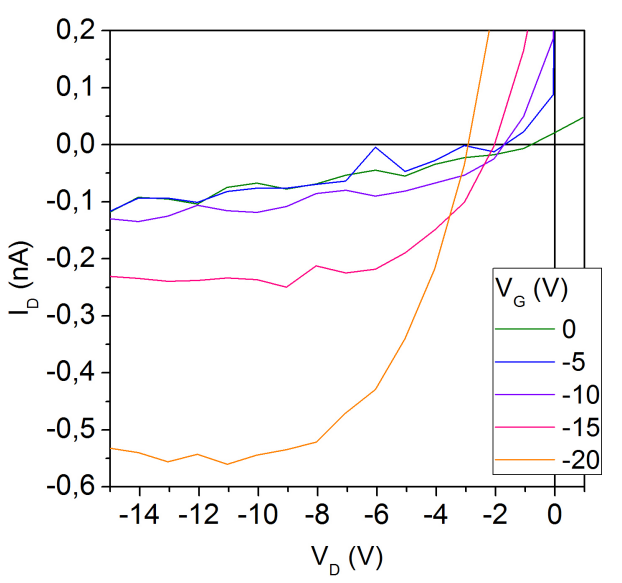

(b)

Figura 4.30: Curvas de saída do OFET Si $/ \mathrm{SiO}_{2} / \mathrm{P} 3 \mathrm{HT}$ da Figura 4.28 (a) após 12 horas em vácuo e (b) após 30h em vácuo.

polímero [53] e o oxigênio atmosférico forma um complexo de transferência de carga com o P3HT[46], aumentando a presença de portadores de carga, o que causa aumento da condutividade e diminuição da mobilidade de efeito de campo [54].

Até o presente momento não foi possível realizar estudos de degradação a mais longo prazo, ou avaliar o desgaste em condições mais severas (por exemplo, em atmosfera saturada de oxigênio e incidência de luz ultravioleta). 


\section{Conclusões}

Vários objetivos iniciais do trabalho foram alcançados. Por exemplo, os dispositivos foram preparados com êxito. Após as etapas de otimização e realização de ensaios variando métodos de preparação, foi possível obter OFETs funcionais nas três construções abordadas: vidro/PMMA/P3HT, $\mathrm{Si} / \mathrm{SiO}_{2} / \mathrm{P} 3 \mathrm{HT}$ e $\mathrm{Si} / \mathrm{SiO}_{2} / \mathrm{PMMA} / \mathrm{P} 3 \mathrm{HT}$. Ainda que parte dos OFETs demonstram características elétricas impróprias para dispositivos de alta performance, como alta corrente de fuga ou baixa razão ON/OFF, o comportamento apresentado foi satisfatório para o estudo dos fenômenos que ocorrem nos polímeros durante a operação dos dispositivos.

O aparato óptico para espectroscopia SFG foi adaptado para possibilitar a realização das medidas pretendidas, contornando dificuldades técnicas com as dimensões do canal, espalhamento de sinal, ruído e limiar de dano. Os espectros SFG obtidos in-situ do P3HT no canal dos OFETs em operação apresentaram alterações na faixa de frequências referentes aos modos vibracionais do anel tiofênico, o que indica alterações na estrutura eletrônica da conjugação. Não foi possível, no entanto, identificar com detalhes as modificações ocorridas.

Duas bandas referentes ao modos vibracionais de $\mathrm{C}-\mathrm{O}$ e $\mathrm{C}=\mathrm{O}$ provenientes da camada isolante de PMMA se tornaram visíveis, e com alta intensidade, com a aplicação de potencial de porta. Isto é uma consequência da reorientação dos dipolos elétricos no volume do filme em resposta às cargas acumuladas na camada superior de P3HT. Foi também constatado que a intensidade absoluta dessas bandas é reduzida ao aplicar também potencial entre dreno e fonte, devido à alteração na distribuição de cargas no canal e consequentemente do campo elétrico atuando sobre o filme de PMMA. Isto pode ser considerado uma nova ferramenta para estudar a distribuição de portadores de carga e de campo elétrico no canal de OFETs.

A operação contínua dos OFETs expostos a luz e oxigênio resulta em perda das características de curvas de transistor, com um aumento da corrente e perda de efeito de campo e da saturação. Os 
espectros SFG do polímero obtidos da região do canal, em comparação com os espectros originais da amostra em vácuo, demonstram pequenas alterações na faixa de frequências referentes aos modos vibracionais do anel conjugado. Essas alterações observadas nos espectros do polímero dopado por contato prolongado com oxigênio diferem das deformações nos espectros obtidos a partir dos dispositivos em operação, onde ocorre dopagem por aplicação de potenciais elétricos.

Com a atual sensibilidade do aparato experimental não foram observados sinais de degradação irreversível nos filmes de P3HT em um período relativamente curto de tempo. As alterações no comportamento elétrico observadas foram atribuídas a dopagem pelo oxigênio absorvido no filme, e são reversíveis ao remover o oxigênio da atmosfera. Seria interessante comparar esses resultados com o de experimentos onde a degradação do polímero é mais significativa e controlada, como, por exemplo, por exposição à luz ultravioleta ou plasma. Esses experimentos serão realizados futuramente. 


\section{Bibliografia}

[1] ITO, T., SHIRAKAWA, H. e IKEDA, S. (1974). "Simultaneous polymerization and formation of polyacetylene film on the surface of concentrated soluble Ziegler-type catalyst solution". Journal of Polymer Science: Polymer Chemistry Edition, 12, 1, pp. 11-20.

[2] CHIANG, C. K. et al. (1977). "Electrical Conductivity in Doped Polyacetylene". Physical Review Letters, 39, 17, pp. 1098-1101.

[3] FACCHETTI, A. (2010). " $\pi$-Conjugated Polymers for Organic Electronics and Photovoltaic Cell Applications". Chemistry of Materials, 23, 3, pp. 733-758.

[4] FORREST, S. R. (2004). "The path to ubiquitous and low-cost organic electronic appliances on plastic". Nature, 428, 6986, pp. 911-918.

[5] HOROWITZ, G. (1998). "Organic Field-Effect Transistors". Advanced Materials, 10, 5, pp. 365-377.

[6] MACIEL, A. D. C. Fabricação e estudo das propriedades de transporte de transistores de filmes finos orgânicos. Tese. Universidade de São Paulo, 2012.

[7] LOO, Y.-L. e MCCUlLOCH, I. (2008). "Progress and Challenges in Commercialization of Organic Electronics". MRS Bulletin, 33, 07, pp. 653-662.

[8] SIRRINGHAUS, H. et al. (1999). "Two-dimensional charge transport in self-organized, highmobility conjugated polymers". Nature, 401, 6754, pp. 685-688.

[9] WANG, G. et al. (2003). "Increased mobility from regioregular poly(3-hexylthiophene) fieldeffect transistors". Journal of Applied Physics, 93, 10, pp. 6137-6141.

[10] MALIK, S. e NANDI, A. K. (2002). "Crystallization mechanism of regioregular poly(3-alkyl thiophene)s". Journal of Polymer Science Part B: Polymer Physics, 40, 18, pp. 20732085 . 
[11] HUANG, T.-S., SU, Y.-K. e WANG, P.-C. (2007). "Study of organic thin film transistor with polymethylmethacrylate as a dielectric layer". Applied Physics Letters, 91, 9, pp. 9211392116.

[12] MANCEAU, M. et al. (2009). "The mechanism of photo- and thermooxidation of poly(3hexylthiophene) (P3HT) reconsidered". Polymer Degradation and Stability, 94, 6, pp. 898907.

[13] HOLDCROFT, S. (1991). "A photochemical study of poly(3-hexylthiophene)". Macromolecules, 24, 17, pp. 4834-4838.

[14] ABDOU, M. S. A. e HOLDCROFT, S. (1993). "Mechanisms of photodegradation of poly(3alkylthiophenes) in solution". Macromolecules, 26, 11, pp. 2954-2962.

[15] ABDOU, M. S. A. e HOLDCROFT, S. (1995). "Solid-state photochemistry of $\pi$-conjugated poly(3-alkylthiophenes)". Canadian Journal of Chemistry, 73, 11, pp. 1893-1901.

[16] HINTZ, H. et al. (2010). "Photo-oxidation and ozonization of poly(3-hexylthiophene) thin films as studied by UV/VIS and photoelectron spectroscopy". Polymer Degradation and Stability, 95, 5, pp. 818-825.

[17] LJUNGQVIST, N. e HJERTBERG, T. (1995). "Oxidative Degradation of Poly(3-octylthiophene)". Macromolecules, 28, 18, pp. 5993-5999.

[18] LAZZARONI, R. et al. (1994). "The chemical and electronic structure of the interface between aluminum and conjugated polymers". Electrochimica Acta, 39, 2, pp. 235-244.

[19] GIRO, R. e CALDAS, M. J. (2008). "Atomistic molecular dynamics study of interface formation: Al on poly(p-phenylene vinylene)". Physical Review B, 78, 15, p. 155312.

[20] SAX, S. et al. (2010). "Efficient Blue-Light-Emitting Polymer Heterostructure Devices: The Fabrication of Multilayer Structures from Orthogonal Solvents". Advanced Materials, 22, 18, pp. 2087-2091.

[21] TRAN, V. H. et al. (1993). "Interactions in metal-polymer-metal interfaces". Polymer, 34, 15, pp. 3179-3183.

[22] PARENTE, V. et al. (1998). "The Vibrational Signature of the Aluminum/Polythiophene Interface". Advanced Materials, 10, 4, pp. 319-324. 
[23] XUE, G., LU, Y. e SHI, G. (1994). "Surface-enhanced Raman scattering used as an in situ analytical method for studies of polymer-metal interface". Polymer, 35, 12, pp. 2488-2494.

[24] SHEN, Y. R. (1994). "Surfaces probed by nonlinear optics". Surface Science, 299?300, pp. 551-562.

[25] SHEN, Y. R. The Principles of Nonlinear Optics. New York: Wiley-Interscience, 1984, p. 575.

[26] MANAKA, T. et al. (2005). "Modulation in optical second harmonic generation signal from channel of pentacene field effect transistors during device operation". Applied Physics Letters, 87,22 , p. 222107.

[27] IWAmOTO, M. e MANAKA, T. (2010). "Probing and modeling of carrier motion in organic devices by optical second harmonic generation". Thin Solid Films, 519, 3, pp. 961-963.

[28] MANAKA, T. et al. (2006). "Probing of the electric field distribution in organic field effect transistor channel by microscopic second-harmonic generation". Applied Physics Letters, 89,7, p. 72113.

[29] MANAKA, T. et al. (2009). "Studying Transient Carrier Behaviors in Pentacene Field Effect Transistors Using Visualized Electric Field Migration". The Journal of Physical Chemistry C, 113, 23, pp. 10279-10284.

[30] YE, H. et al. (2006). "Probing organic field effect transistors in situ during operation using SFG." Journal of the American Chemical Society, 128, 20, pp. 6528-6529.

[31] YE, H. et al. (2007). "Correlations between SFG Spectra and Electrical Properties of Organic Field Effect Transistors". Journal of Physical Chemistry B, 111, 35, pp. 13250-13255.

[32] ANGLin, T. C., O?BRIEN, D. B. e MASSARI, A. M. (2010). "Monitoring the Charge Accumulation Process in Polymeric Field-Effect Transistors via in Situ Sum Frequency Generation". The Journal of Physical Chemistry C, 114, 41, pp. 17629-17637.

[33] Anglin, T. C., SPEROS, J. C. e MASSARI, A. M. (2011). "Interfacial Ring Orientation in Polythiophene Field-Effect Transistors on Functionalized Dielectrics". The Journal of Physical Chemistry C, 115, 32, pp. 16027-16036. 
[34] ANGLin, T. C., SOHRABPOUR, Z. e MASSARI, A. M. (2011). "Nonlinear Spectroscopic Markers of Structural Change during Charge Accumulation in Organic Field-Effect Transistors". The Journal of Physical Chemistry C, 115, 41, pp. 20258-20266.

[35] WALteR, S. R. et al. (2012). "In-Situ Probe of Gate Dielectric-Semiconductor Interfacial Order in Organic Transistors: Origin and Control of Large Performance Sensitivities". Journal of the American Chemical Society, 134, 28, pp. 11726-11733.

[36] NAKAI, I. F. et al. (2009). "Molecular structure and carrier distributions at semiconductor/dielectric interfaces in organic field-effect transistors studied with sum frequency generation microscopy". Applied Physics Letters, 95, 24, p. 243304.

[37] CONWELL, E. M. (1956). "Impurity Band Conduction in Germanium and Silicon". Phys. Rev. 103, 1, pp. 51-61.

[38] ZIEMELIS, K. E. et al. (1991). "Optical spectroscopy of field-induced charge in poly(3-hexyl thienylene) metal-insulator-semiconductor structures: Evidence for polarons". Phys. Rev. Lett. 66, 17, pp. 2231-2234.

[39] SZE, S. M. Physics of semiconductor devices. $2^{\mathrm{a}}$ ed. Wiley, 1981.

[40] SHOCKLEY, W. (1952). "A Unipolar "Field-Effect"Transistor". Proceedings of the IRE, 40, 11, pp. 1365-1376.

[41] GILLES HOROWITZ, RIADH HAJLAOUI e PHILIPPE DELANNOY. (1995). "Temperature Dependence of the Field-Effect Mobility of Sexithiophene. Determination of the Density of Traps". J. Phys. III France, 5, 4, pp. 355-371.

[42] VISSENBERG, M. e MATTERS, M. (1998). "Theory of the field-effect mobility in amorphous organic transistors". Physical Review B, 57, pp. 12964-12967.

[43] BOYD, R. W. Nonlinear Optics. San Diego: Academic Press Inc., 1992, p. 439.

[44] LAmBERT, A. G., DAVIES, P. B. e NEIVAndT, D. J. (2005). "Implementing the Theory of Sum Frequency Generation Vibrational Spectroscopy: A Tutorial Review". Applied Spectroscopy Reviews, 40, 2, pp. 103-145. 
[45] MAZZARA, C. et al. (1999). "Hydrogen-terminated $\mathrm{Si}(111)$ and $\mathrm{Si}(100)$ by wet chemical treatment: linear and non-linear infrared spectroscopy". Surface Science, 427?428, pp. 208213.

[46] ABDOU, M. S. A. et al. (1997). "Interaction of Oxygen with Conjugated Polymers: Charge Transfer Complex Formation with Poly(3-alkylthiophenes)". Journal of the American Chemical Society, 119, 19, pp. 4518-4524.

[47] LOUARN, G. et al. (1993). "Comparison of the vibrational properties of polythiophene and polyalkylthiophenes". Synthetic Metals, 55, 1, pp. 587-592.

[48] AKIMOTO, M. et al. (1986). "Correlation between vibrational spectra and electrical conductivity of polythiophene". Synthetic Metals, 15, 4, pp. 353-360.

[49] BAIBARAC, M. et al. (1998). "SERS spectra of poly(3-hexylthiophene) in oxidized and unoxidized states". Journal of Raman Spectroscopy, 29, 9, pp. 825-832.

[50] LOUARN, G. et al. (1996). "Raman Spectroscopic Studies of Regioregular Poly(3-alkylthiophenes)". The Journal of Physical Chemistry, 100, 30, pp. 12532-12539.

[51] MAIA, F. C. B. Estudo da interação interfacial entre polímeros semicondutores e metais ou surfactantes. Tese. Universidade de São Paulo, 2011.

[52] TAYLOR, D. M. et al. (1991). "Effect of oxygen on the electrical characteristics of field effect transistors formed from electrochemically deposited films of poly(3-methylthiophene)". Journal of Physics D: Applied Physics, 24, 11, p. 2032.

[53] REP, D. B. A., MORPURGO, A. F. e KLAPWIJK, T. M. (2003). "Doping-dependent charge injection into regioregular poly(3-hexylthiophene)". Organic Electronics, 4, 4, pp. 201-207.

[54] ABDOU, M. S. A. et al. (1995). "Nature of Impurities in .pi.-Conjugated Polymers Prepared by Ferric Chloride and Their Effect on the Electrical Properties of Metal-Insulator-Semiconductor Structures". Chemistry of Materials, 7, 4, pp. 631-641. 